\title{
Desenvolvimento de um Núcleo Multi-Usuário para um Sistema de Gerenciamento de Base de Dados Orientada a Objetos
}

\author{
Nivaldi Calônego Jr.
}

\section{Orientação:}

Prof. Dr. Caetano Traina Jr.

Dissertação apresentada ao Instituto de Ciências Matemáticas de São Carlos USP como parte dos requisitos para obtenção do título de Mestre em Ciências de Computação e Matemática Computacional

USP - São Carlos

Julho de 1991 
Aos meus pais, Nivaldi e Godiva.

Aos meus irmãos, Cássia, Elisabete e Cesar. Aos meus sobrinhos André e Camila. À Reni. 


\section{$\underline{\text { Agradecimentos }}$}

Ao amigo e orientador Prof. Dr. Caetano Traina Júnior pela presteza e paciência dispensadas para que este trabalho se realizasse.

A todos os amigos que, direta ou indiretamente, contribuiram com o seu apoio e auxílio. Às secretárias, do Departamento de Ciências de Computação e Estatística, Angela e Sueli pela dedicação e eficiência nos serviços prestados e, especialmente, à secretária Luisa e ao técnico do Laboratório Didático e Científico de Computação Luciano pelo trabalho de edição e formatação do texto dessa dissertação.

Ao CNPq, CAPES e FAPESP pelo apoio financeiro dado para o desenvolvimento do projeto. E ao Instituto de Ciências Matemáticas de São Carlos pela oportunidade de aprimoramento técnico e científico que me foi oferecida. 


\section{RESUMO}

O GEO (GErenciador de Objetos) é um Sistema de Gerenciamento de Base de Dados, originalmente mono-usuário, implementado para suportar elementos modelados utilizando-se o MRO (Modelo de Representação de Objetos).

Neste trabalho apresenta-se um novo núcleo para o sistema GEO, cujos principais objetivos são: assegurar a atomicidade e a consistência das transações; permitir acesso multi-usuário a base; incorporar mecanismos de comunicação entre processos para que se possa efetuar acessos concorrentes na base.

O protótipo desenvolvido para a versão multi-usuário do núcleo do GEO, que implementa controle de concorrência, no nível de registros lógicos da base, é descrito. Este tratamento de concorrência é necessário para evitar que usuários não autorizados modifiquem objetos, inadvertidamente, como resultado da execução de operações intrínsecas da base. Os testes efetuados indicam que o controle de concorrência, nesse sistema, não necessita ser implementado no nível de registro lógico do arquivo da base, mas, podem ser controlados num nível semântico mais alto. 


\begin{abstract}
GEO (GErenciador de Objetos) is a Data Base Management System which suports entities modeled using the Object Representition Model - MRO (Modelo de Representação de Objetos).

This work presents a new kernel for the GEO system, whose main goals are: to ensure atomic and consistent transactions; to suport multi-user access to the Data Base; and to implement mechanisms for interprocess commmunication, so that concurrent accesses are allowed.

A prototype for GEO's new multi-user kernel was developed and is reported here. It implements concurrency control at the logical registers access level in the database. This treatment for concurrency control is required to avoid inadverted, non autorized, access to the database objects, which may result from the execution of intrinsec data base operations. Tests indicate, however, that concurrency control in the system can be dealt more efficiently not in the level of logical registers, but at a highest semantic level.
\end{abstract}




\section{Conteúdo}

1 Introdução 1

1.1 Motivação . . . . . . . . . . . . . . . . . . 2

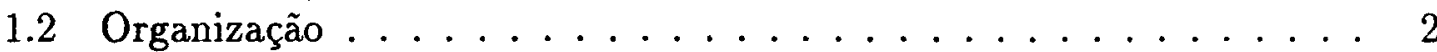

2 Revisão Bibliográfica 4

2.1 Conceitos de Sistemas Operacionais . . . . . . . . . . . . . . 4

2.1.1 Sistema de Gerenciamento de Processos . . . . . . . . . . . . . 6

2.1.2 Mecanismos de Comunicação entre Processos . . . . . . . . . . 8

2.1.3 Sistemas de Gerenciamento de Arquivos . . . . . . . . . . . . 14

2.2 Bases de Dados . . . . . . . . . . . . . . . . . 15

2.2.1 Conceito de Base de Dados . . . . . . . . . . . . . 15

2.2.2 Necessidade e Objetivo de um Sistema de Gerenciamento de

Base de Dados . . . . . . . . . . . . . . . . . 17

2.2.3 Níveis de Abstração em uma Base de Dados . . . . . . . . . . 19

2.2.4 Modelos de Representação de Dados . . . . . . . . . . . . 19

2.2.5 Consistência em Bases de Dados . . . . . . . . . . . . . 30

2.2.6 Integridade em Bases de Dados . . . . . . . . . . . 30

2.2 .7 Versões ..................... . . 31

2.3 Conclusão ........................... 31

3 Transações $\quad 32$

3.1 Definição de Transação . . . . . . . . . . . . . . . . . . 32

3.2 Atomicidade de Transação . . . . . . . . . . . . . . . 33

3.3 Transações Seriais e Entrelaçadas . . . . . . . . . . . . . . 34

3.4 Domínio de Consistência de Transações . . . . . . . . . . . . . . . . . . . . 34

3.5 Estados de uma Transação. . . . . . . . . . . . . . . . 35

3.6 Considerações sobre Granularidade em Sistemas Orientados a Transações . . . . . . . . . . . . . . . . . 38

3.7 Considerações . . . . . . . . . . . . . . . . 39 
4 Controle de Concorrência em Sistemas Orientados a Transações 40

4.1 Algoritmos de Controle de Concorrência . . . . . . . . . . 40

4.1.1 Algoritmo Baseado em Ordenação por Tempo de Chegada . . 41

4.1 .2 Algoritmo Otimista . . . . . . . . . . . . . . . 42

4.1.3 Algoritmo Baseado em Bloqueio . . . . . . . . . . . . . 43

4.2 Deteç̧ão e Eliminação de Impasses em Bases de Dados . . . . . . . 46

4.3 Um Sistema de Controle de Concorrência Orientado a Transações . . 48

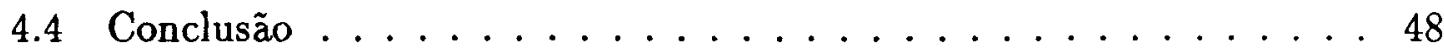

5 Modelo de Representação de Objetos 50

5.1 Apresentação do modelo . . . . . . . . . . . . . . 50

5.2 Abrangência dos Identificadores de Objetos . . . . . . . . . . 51

5.3 Meta-base de Dados . . . . . . . . . . . . . . 51

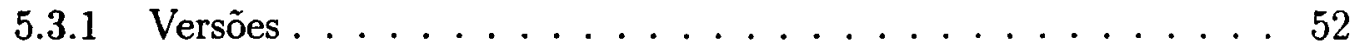

5.4 Conclusão $\ldots \ldots \ldots \ldots \ldots \ldots \ldots \ldots \ldots \ldots \ldots \ldots$

6 Projeto de uma Versão Multiprogramada do GEO 56

6.1 Estrutura Lógica do Sistema GEO . . . . . . . . . . . . . . 61

6.2 Modificações Efetuadas Sobre a Versão Mono-usuário . . . . . . . 66

6.2.1 O Sistema de Gerenciamento de Memória do GEO . . . . . . 66

6.2.2 O Sistema de Gerenciamento de Transações do GEO . . . . . 72

6.2.3 Sistema de Comunicação Servidor/Cliente . . . . . . . . 83

6.3 O Sistema de Escalonamento de Transações do GEO . . . . . . . 89

7 Conclusões e Propostas $\quad 95$

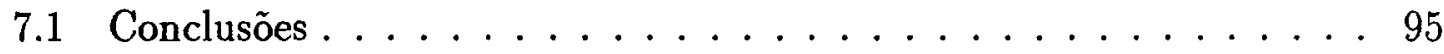

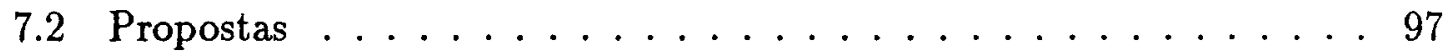




\section{Lista de Figuras}

2.1 Representação das Máquinas Virtuais . . . . . . . . . . . . 5

2.2 Estados de um Processo . . . . . . . . . . . . . . . . . . 7

2.3 Estrutura Lógica de um Sistema de Gerenciamento de Base de Dados 18

2.4 Niveis de Abstração numa Base de Dados . . . . . . . . . . . . 20

2.5 Relação de Dados . . . . . . . . . . . . . . . . . . 23

2.6 Relação de Dados Normalizados . . . . . . . . . . . . . . . 24

2.7 Representação no ME-R da figura $2.6 \ldots \ldots \ldots$. . . . . . . . . . . . . . . . . 26

2.8 Representação no ME-R . . . . . . . . . . . . . . . . 26

2.9 Representação no Modelo de Rede da Figura 2.6 . . . . . . . . . . . 27

2.10 Representação no Modelo de Rede de um Relacionamento de Cardinalidade M:N . . . . . . . . . . . . . . . . . 28

2.11 Representação no Modelo Hierárquico de um Relacionamento de Cardinalidade $1: \mathrm{N} \ldots \ldots \ldots \ldots \ldots . \ldots \ldots$

2.12 Representação no Modelo Hierárquico de um Relacionamento de Cardinalidade $\mathrm{M}: \mathrm{N} \ldots \ldots \ldots \ldots$. . . . . . . . . . . 29

3.1 Estados de uma transação . . . . . . . . . . . . . . . . 37

4.1 Função de Compatibilidade de Operações . . . . . . . . . . . . . . . . 43

4.2 Fases de uma Transação em Função do Tempo . . . . . . . . . . . . . . 44

4.3 Grafo de Espera . . . . . . . . . . . . . . . . . . . 47

4.4 Grafo de Espera Apresentando um Impasse . . . . . . . . . . . . . 47

5.1 DRO da figura $2.6 \ldots \ldots \ldots \ldots \ldots$

5.2 DRI da figura $2.6 \ldots \ldots \ldots \ldots \ldots \ldots \ldots \ldots \ldots \ldots$

5.3 Meta-Esquema do MRO ................. 54

6.1 Módulos Lógicos do GEO . . . . . . . . . . . . . . . 57

6.2 Módulos Lógicos do GEO Multi-usuário . . . . . . . . . . . . . . . 57

6.3 Representação do Sistema de Comunicação do GEO . . . . . . . . . . 59

6.4 Diagrama de Fluxo de Dados do Sistema . . . . . . . . . . . . . . . . 62

6.5 Diagrama de Fluxo de Dados das Ferramentas do ABD . . . . . . . . 64

6.6 Controle do Tipo de Operação Efetuada sobre a Página . . . . . . . . 67 
6.7 Diagrama Hierárquico do SGM versão mono-usuário . . . . . . . . 68

6.8 Diagrama Hierárquico do SGM versão multi-usuário . . . . . . . . . 69

6.9 Estrutura de Controle de Transação . . . . . . . . . . . . . . . 70

6.10 Estrutura Servidor/Cliente Mono-programado . . . . . . . . . 74

6.11 Diagrama de Fluxo de Dados do Núcleo GEO . . . . . . . . . 76

6.12 Explosão do Módulo "Gerenciar Transações" . . . . . . . . . . . . . 78

6.13 Estrutura de Controle de Transações Local . . . . . . . . . . . . . 81

6.14 Estrutura Lógica do Sistema de Comunicação . . . . . . . . . . 84

6.15 Mecanismo de Comunicação entre Clientes/Servidores . . . . . . . 87

6.16 Diagrama Hierárquico do Módulo Gerenciador . . . . . . . . . . . 91

6.17 Diagrama Hierárquico do Módulo SGT_Executa . . . . . . . . 92 


\section{Capítulo 1}

\section{Introdução}

Os Sistemas de Gerenciamento de Bases de Dados (SGBD) surgiram na década de 60 devido a necessidade de se manipular grandes volumes de dados, estruturalmente semelhantes, relacionados a um empreendimento. Esses SGBDs, ditos convencionais, demonstraram ser ineficientes em ambientes de desenvolvimento de projetos de engenharia.

Nos últimos anos desenvolveu-se muita pesquisa em Sistemas de Gerenciamento de Base de Dados para aplicação em Engenharia (SGDE) como exemplos têm-se: suporte a aplicações para CAD/CAM, processamento de imagens, gerenciamento de conhecimento e outras. Estes SGDEs são assim chamados por manipularem dados que podem não possuir semelhança estrutural e, normalmente, o volume de dados a ser manipulado é relativamente pequeno em relação aos SGBDs convencionais. Estas diferentes aplicações para SGDEs, além de imporem novos requisitos para os Sistemas de Gerenciamento de Base de Dados (SGBD), fazem com que novos modelos de representação de dados sejam propostos.

Diversos SGBDs foram implementados para dar suporte a esses modelos de dados. Para a implementação de tais sistemas de gerenciamento de base de dados depara-se com diversos problemas, como por exemplo: deve-se garantir consistência $e$ integridade da base, especialmente em ambientes onde se tem multi- programação. $O$ objetivo desse trabalho é implementar o núcleo para um sistema de gerenciamento de base de dados orientada a objetos, que dê suporte a aplicações em ambientes de desenvolvimento de projetos de engenharia. A fim de se atingir o objetivo do trabalho, são apresentados conceitos de sistemas operacionais e de sistemas de gerenciamento de bases de dados. Utilizando-se desses conhecimentos especifica-se uma proposta de implementação de um núcleo para um SGDE multi-programado. 


\subsection{Motivação}

Foi proposto um novo modelo para representação de dados que dá suporte a aplicaçôes em engenharia, o qual é denominado Modelo de Representação de Objetos [Traina Jr.86]. Apoiado por este modelo, foi implementado o Gerenciador de Objetos (GEO), que é um Sistema de Gerenciamento de Base de Dados (SGBD) implementado em microcomputadores compatíveis com a linha IBM-PC, utilizando-se de um sistema operacional monoprogramado.

Neste trabalho propõe-se a especificação de uma interface entre o Sistema Operacional (SO) e o GEO a fim de torná-lo um SGBD Multiprogramado. Com esse objetivo, são estudadas teorias sobre bases de dados e mostradas algumas peculiaridades do MRO que se destinam a auxiliar a construção desta interface.

\subsection{Organização}

Para o desenvolvimento deste trabalho, apresenta-se uma visão macroscópica de publicações em revistas de renome, captando-se conceitos de cada um dos trabalhos a fim de aplicá-los a este novo SGBD.

Este trabalho possui a seguinte organização lógica:

- capítulo 1: São apresentadas as idéias que motivaram o seu desenvolvimento, bem como sua organização.

- capítulo 2: Apresentam-se conceitos de Sistemas Operacionais e de Bases de Dados.

- capítulo 3: É dada uma definição de transação e são detalhados aspectos de atomicidade, entrelaçamento, domínio de consistência e quais os possíveis estados a que uma transação pode estar associada. É feita também uma breve consideração a respeito de granularidade em Sistemas de Base de Dados orientados a transações.

- capítulo 4: Trata dos aspectos de concorrência sobre os dados em ambientes multiprogramados, apresentando três formas básicas de desenvolvimento para algorítmos de controle de concorrência.

- capítulo 5: É feita uma apresentação detalhada do MRO, introduzindo os conceitos de Meta-base, para modelagem do Sistema Gerenciador de Objetos (GEO). São especialmente consideradas características que possibilitam um sistema de proteção sobre ítens de dados intrínsecos do modelo. 
- capítulo 6: Baseando-se nas noções gerais apresentadas nos capítulos 1 a 4, juntamente com a visão direcionada pelo capítulo 5 , é apresentado um projeto lógico para a implementação de um núcleo, para o GEO, que suporta acessos concorrentes. 


\section{Capítulo 2}

\section{Revisão Bibliográfica}

Neste capítulo serão introduzidos conceitos de Sistemas Operacionais e Sistemas de Gerenciamento de Bases de Dados, que são importantes para o desenvolvimento deste trabalho.

\subsection{Conceitos de Sistemas Operacionais}

Desde os primórdios da ciência da computação até a atualidade, profundas modificações conceituais têm acontecido associadas à utilização de computadores. Inicialmente, as máquinas eram pouco flexíveis e os usuários deveriam conhecer sua arquitetura para que pudessem construir seus programas. Devido às dificuldades impostas pela interação direta homem/máquina concebeu-se o conceito de Sistema Operacional.

Pode-se, grosseiramente, dividir os programas em dois grandes grupos: os programas de aplicação (escritos por usuários a fim de resolver os seus problemas) e os programas do sistema (que são programas que fazem com que o computador controle a si mesmo). O mais fundamental dos programas do sistema é o que se conhece por Sistema Operacional (SO). Este programa tem por finalidade controlar todos os recursos do sistema e fornecer uma base sobre a qual programas de aplicação podem ser escritos [Tanenbaum87].

Este conceito também pode ser compreendido a partir da construção de máquinas virtuais sobre um sistema eletrônico ("Hardware") o qual é denominado Computador. Máquinas virtuais são programas que buscam facilitar e flexibilizar a utilização do computador pelo homem. A figura 2.1 mostra um computador sobre o qual são construídas máquinas virtuais.

No nivel de dispositivo físico tem-se os componentes eletrônicos com suas 


\begin{tabular}{|c|c|c|c|c|}
\hline \multicolumn{2}{|c|}{ Aplicativos } & $\begin{array}{l}\text { Sistemas } \\
\text { Bancários }\end{array}$ & Jogos & $\begin{array}{c}\text { Programas de } \\
\text { Aplicacão }\end{array}$ \\
\hline Compiladores & SGBDs & Editores & $\begin{array}{l}\text { Interpretador de } \\
\text { Comandos do SO }\end{array}$ & $\begin{array}{l}\text { Programas } \\
\text { do }\end{array}$ \\
\hline \multicolumn{4}{|c|}{ Sistema Operacional } & \\
\hline \multicolumn{4}{|c|}{ Linguagem de Máquina } & \multirow{3}{*}{ Computador } \\
\hline \multicolumn{4}{|c|}{ Microprogramação } & \\
\hline \multicolumn{4}{|c|}{ Dispositivo Físico } & \\
\hline
\end{tabular}

Figura 2.1: Representação das Máquinas Virtuais 
ligações, fontes de alimentação de energia do sistema, impressoras e outros. A microprogramação é um nível de programa armazenado em memória, não volátil, que serve de interface entre o nível da Linguagem de Máquina e o Dispositivo Físico. Entende-se por Linguagem de Máquina o conjunto de instruções pré-definida pelo fabricante do computador que pode ser interpretado pelo nível de microprogramação.

Neste contexto, o SO surge como uma máquina virtual construída sobre o computador. $\mathrm{E}$ a interface entre o $\mathrm{SO}$ e os programas dos usuários se faz através de um conjunto de funções básicas (ou primitivas) do sistema.

Com estas primitivas, o SO consegue "esconder" do usuário as máquinas virtuais que estão abaixo dele, tornando o sistema mais flexível. Ou seja, usuários podem imaginar que estão utilizando máquinas diferentes dependendo dos programas do sistema de que se utilizem.

Pode-se supor que um SO possui quatro grandes componentes, que são: 0 Gerenciador de Processos, Gerenciador de Memória, Gerenciador de Entrada/Saída e o Sistema de Gerenciamento de Arquivos, dos quais serão apresentados neste capítulo apenas os conceitos relativos aos sistemas de gerenciamento de processos e arquivos, por ser de interesse para o desenvolvimento deste trabalho [Tanenbaum87].

\subsubsection{Sistema de Gerenciamento de Processos}

A compreensão dos conceitos que envolvem um Gerenciador de Processos exige que se compreenda, a priori, o conceito de Processo. Para o propósito deste trabalho um processo é um programa em execução, ou seja, um código executável juntamente com suas estruturas de dados e registradores da Unidade Central de Processamento.

Os computadores modernos possuem mecanismos que permitem ao SO executar diversos programas num derterminado intervalo de tempo, causando aos usuários a impressão de que existe um computador alocado para cada um deles. Estes sistemas operacionais são ditos multiprogramados e seus escalonadores são baseados na técnica de utilização da Unidade Central de Processamento (UCP) em tempo compartilhado ("Time-Sharing"). Nesta técnica de compartilhamento de tempo de UCP, embora os processos sejam diferentes entre si (podendo possuir o mesmo código mas, com diferentes estados), um processo pode gerar saídas que serão entradas de outros. E isto, obviamente, introduz alguns problemas, tais como: sincronismo, concorrência por recursos e impasses ("Dead lock") entre processos.

Note-se que a execução de um processo pode ser temporariamente suspensa em dois casos:

- o processo necessita de dados, os quais devem ser enviados por um outro processo, 


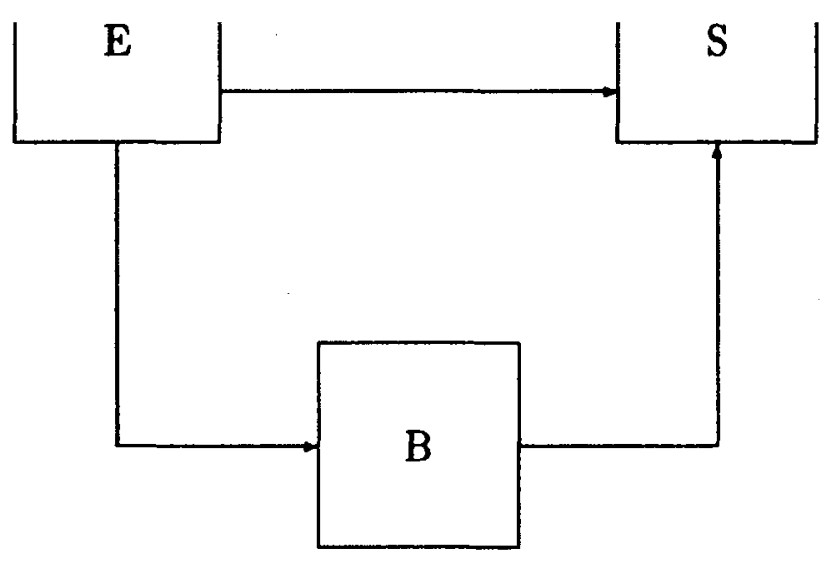

Figura 2.2: Estados de um Processo

- o sistema operacional elegeu um outro processo para executar por algum tempo;

com isto, pode-se assumir que um processo pode estar em um destes três estados: "Executando" (E), "Suspenso" (S), "Bloqueado" (B), conforme mostra a figura 2.2 Entenda-se por:

- E - a UCP está sendo ocupada por algum processo,

- S - o processo está temporariamente parado a espera da UCP. Normalmente, isso ocorre para que outro processo entre em execução,

- B - o processo está desabilitado para execução até que ocorra algum evento externo.

As técnicas para se conseguir sincronismo de processos, controle dos recursos do sistema e a prevenção e eliminação de impasses, já são bastante difundidas [Tanenbaum87].

A plataforma Sun modelo Sparc-I, juntamente com o sistema operacional SunOS, oferece as características desejadas para o desenvolvimento deste trabalho. $O$ SunOS é um sistema operacional compatível com o sistema operacional UNIX versão Berkeley 4.3 [SunOS]. Isto significa que, dentre outras coisas, o sistema operacional possui um sub-sistema de escalonamento de processos ("scheduler") preemptivo, 
que utiliza a técnica de compartilhamento de tempo da unidade central de processamento ("Time Sharing") e que oferece ao usuário um conjunto de primitivas que permitem a comunicação entre processos.

\subsubsection{Mecanismos de Comunicação entre Processos}

O mecanismo de comunicação entre processos "IPC" ("Inter Process Comunication") do sistema UNIX ("Sistem V") permite que processos arbitrários troquem dados e sincronizem sua execução. Este mecanismo foi incorporado ao sistema operacional SunOS e permite que processos enviem cadeias de dados formatadas para quaisquer processos.

Através do compartilhamento de seu espaço de endereçamento virtual, e utilizando-se de primitivas de controle de acesso à região crítica (semafóros), o sistema UNIX permite a comunicação entre processos. O sistema SunOS diminui o trabalho do programador e implementa as primitivas de troca de mensagens através do conceito de "units", que fazem com que os processos tenham propriedades comuns, que são:

1. Cada "unit" contêm uma tabela que descreve todas as instâncias dos meios de comunicação do mesmo.

2. Cada fila (entrada da tabela) possui uma chave numérica ("key"), a qual possui um nome escolhido pelo usuário.

3. Cada mecanismo de comunicação possui uma primitiva do sistema operacional ("msgget") cujo valor de retorno corresponde a uma nova entrada ("fila") ou a alguma entrada já existente; e os parâmetros para chamadas que são: uma chave e um "flag". O núcleo do sistema operacional ("kernel") procura a tabela apropriada para uma entrada nomeada pela chave. Assim, para assegurar o retorno de uma entrada não utilizada, os processos podem executar um "msgget" com com valor de chave igual a "IPC_PRIVATE", isto assegura o retorno de uma entrada não utilizada. Colocando em "flag" o valor "IPC_CREAT" permite criar uma nova entrada caso a chave dada não exista.

Existem quatro primitivas do sistema operacional para manipulação de mensagens, que são:

1. msgget: retorna um descritor de mensagem que designa uma fila de mensagens para o uso em outras chamadas do sistema.

Sintaxe : identificador_de_fila = msgget (key, flag)

onde, identificador_de_fila é o descritor retornado pela função. 


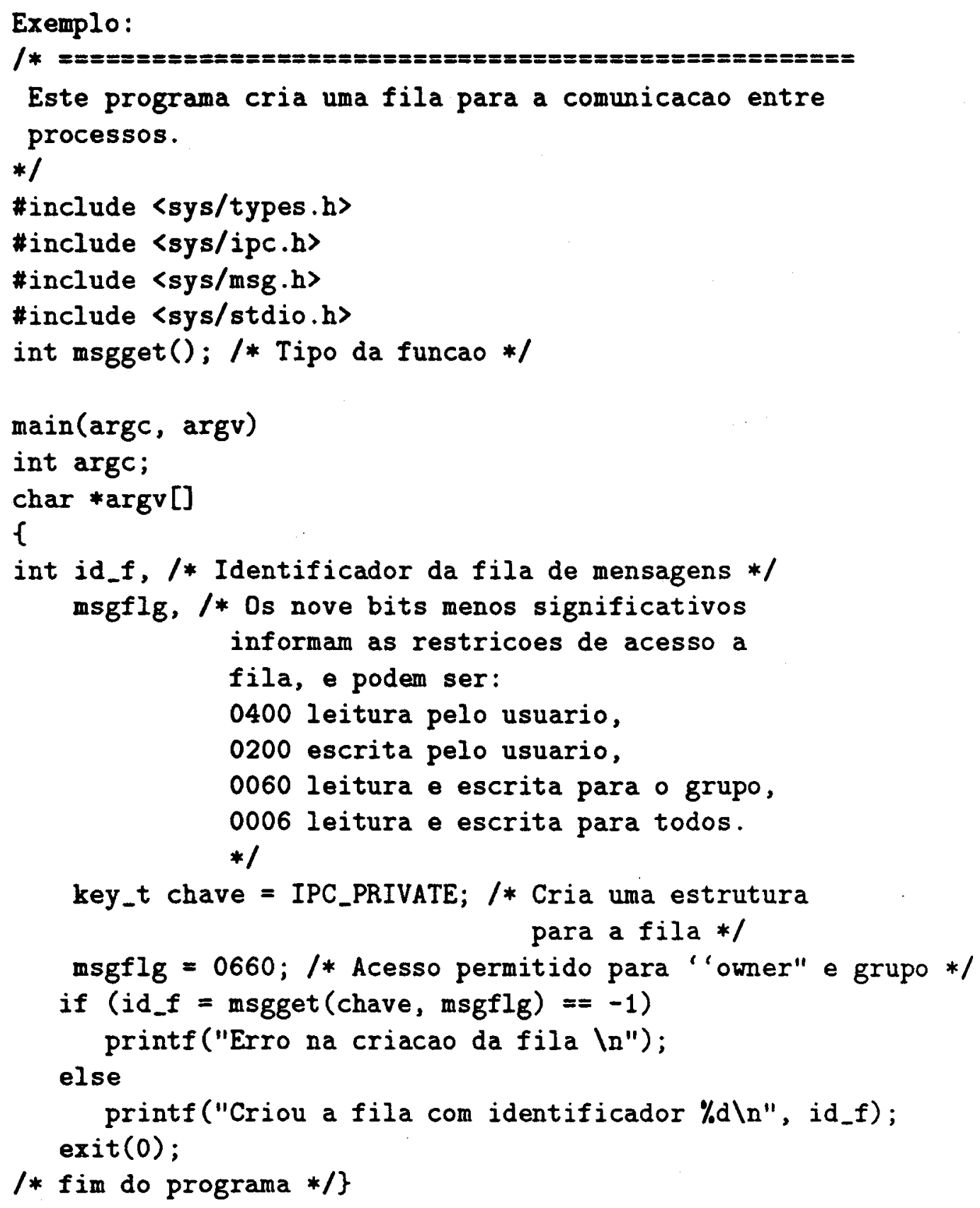

2. msgctl: oferece opções para modificar e/ou retornar parâmetros associados a um descritor. Esta função também permite a eliminação de uma fila do sistema. Mas, apenas o "owner" (elemento que possui o atributo de ser o criador da fila) ou o "super usuário" do sistema operacional é que podem eliminar uma fila do sistema.

Sintáxe: msgctl(id_f, cmd, buf)

Exemplo: 


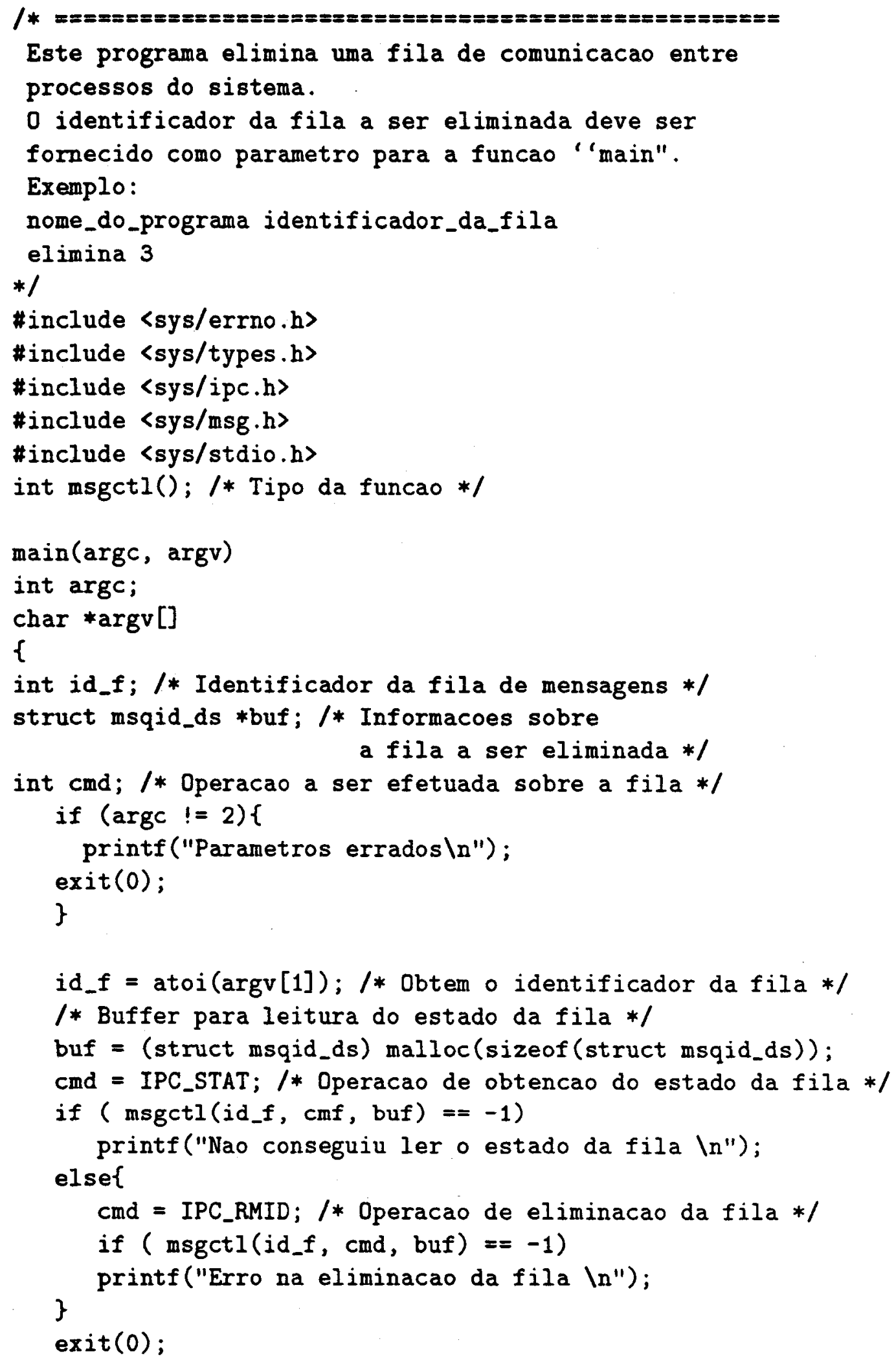




\section{/* Fim do programa */\}}

3. msgsnd: coloca uma cadeia formatada na fila especificada pela chave.

Sintáxe: msgsnd(id f, msg, msgsz, flag)

Exemplo:

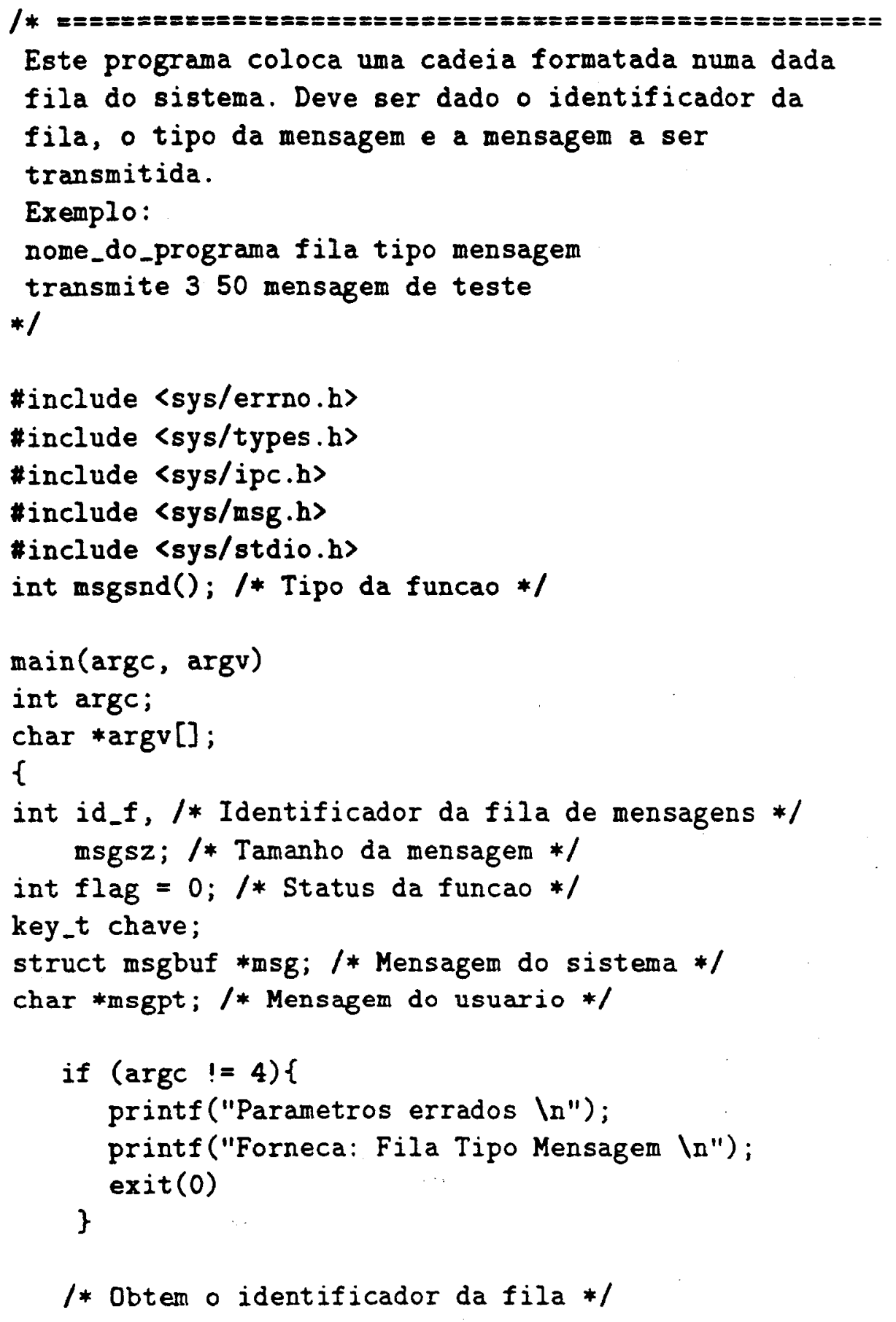


id_f = atoi (argv[1]);

/* Aloca espaco para a estrutura da mensagem do sistema *f

msg $=($ struct msgbuf $*)$ malloc(sizeof (struct msgbuf));

/* Obtem o tipo da mensagem */

msg->mtype $=$ (long) atoi (argv[2]);

/* Obtem mensagem *1

strcpy (msgpt, argv[3]);

/* Otem tamanho da mensagem a ser transmitida */

msgsz $=\operatorname{strlen}(m s g P t)$;

/* Copia a mensagem para a estrutura da mensagem do sistema $* 1$

strcpy (msg->mtext, msgpt);

/* Transmite a mensagem */

if (msgsnd (id_f, msg, msgsz, flag) $==-1$ ) printf("Erro de transmissao ln");

else

printf("Transmitiu correntamente $(n ")$;

$\operatorname{exit}(0)$;

/* Fim do Programa */\}

4. msgrcv: obtem uma cadeia formatada de uma determinada fila. Caso o tipo da mensagem seja 0 (zero) então a primeira mensagem da fila sera lida. Se o tipo é negativo, então é lida a mensagem anterior ao módulo do tipo dado.

Sintáxe: msgrcv(jd_f, msg, msgsz, msgtype, flag)

Exemplo:

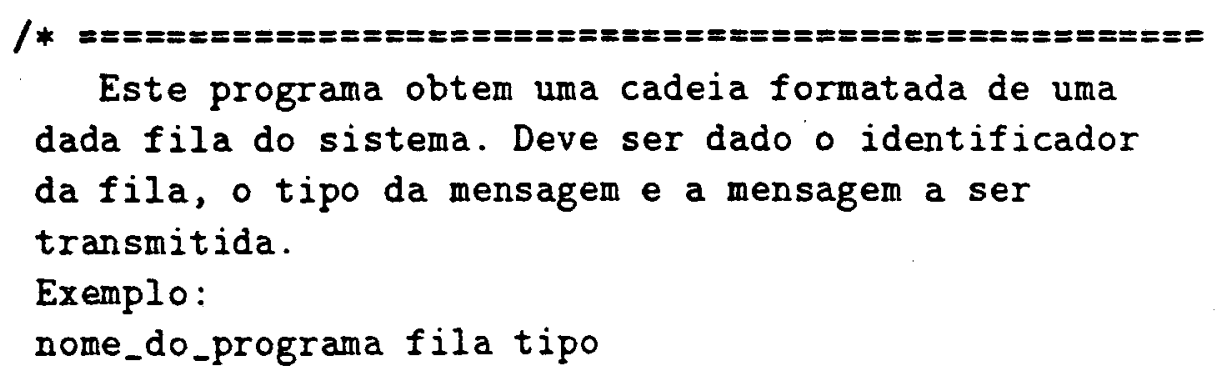




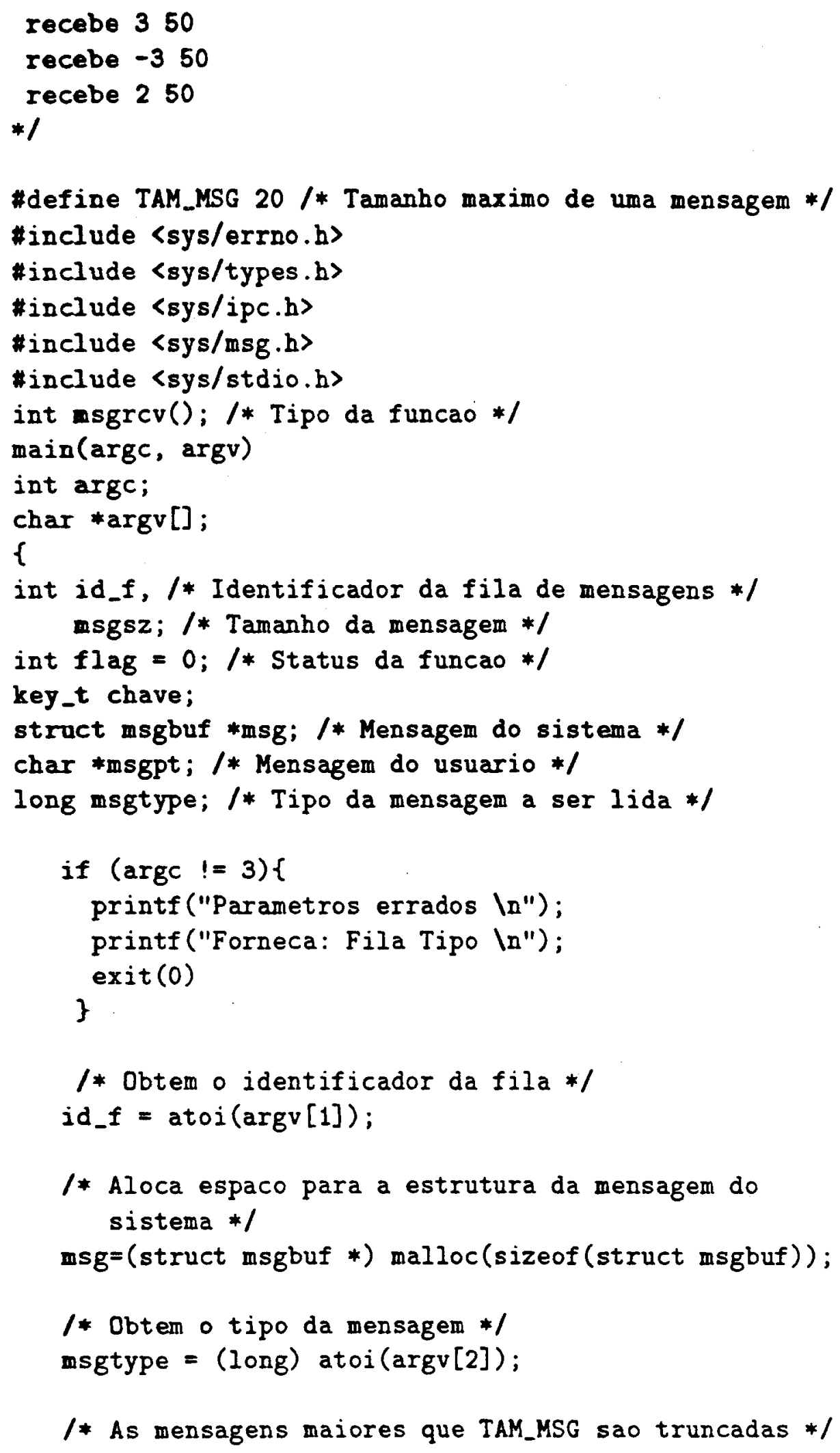




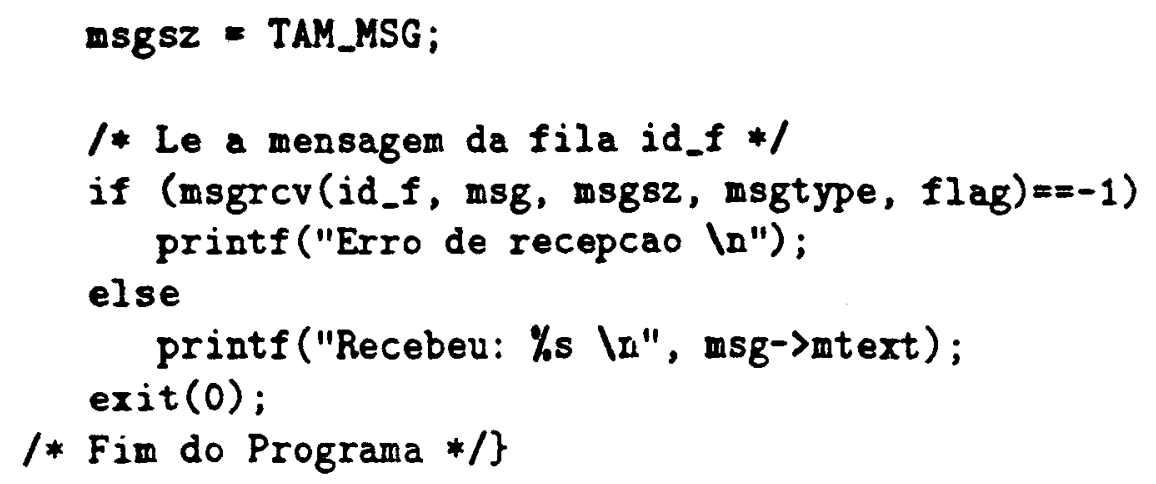

Estas primitivas do Sistema Operacional permitirão a comunicação "Aplicativo/Gerenciador" e sincronizarão as atividades do Sistema de Gerenciamento de Base de Dados, conforme será apresentado no capitulo 6.

\subsubsection{Sistemas de Gerenciamento de Arquivos}

Os programas de aplicação que aparecem na máquina virtual da figura 2.1 , manipulam dados que são lidos ou escritos em dispositivos de armazenamento de massa, por exemplo: discos e fitas magnéticas, ou outros. Nesse sentido, o aspecto mais importante de um Sistema de Gerenciamento de Arquivos (SGA) é a forma como este se apresenta para o usuário. Ou seja, de que se constitue um arquivo e quais operações são possíveis sobre os mesmos.

O conceito de arquivo está relacionado ao conceito de registro. Entende-se por registro qualquer tipo estruturado de dado. Assim, diz-se que um arquivo é uma coleção de registros.

$\mathrm{Na}$ década de 60 , um usuário que desejasse escrever um programa COBOL, teria que descrever um registro lógico que seria muito semelhante a sua forma de armazenamento em memória secundária. Esta maneira de se tratar os dados produzia inconvenientes, tais como: os programas nâo eram portáveis facilmente e os espaços livres dos dispositivos de armazenamento de massa eram mal distribuídos. Para eliminar tais problemas, criou-se o Sistema de Gerenciamento de Arquivos (SGA). O SGA é constituído por um conjunto de funções básicas que permitem aos usuários o acesso aos dados dos arquivos, sem que se preocupem com a forma de armazenamento e acesso aos mesmos. Para isto, um conjunto de registros lógicos, associados aos usuários, é criado em memória principal. Cabe ao SO estabelecer o mapeamento entre registros lógicos e respectivos registros físicos, ler e escrever os registros físicos no dispositivo de armazenamento de massa, bem como gerenciar os espaços disponiveis para os usuários. 


\subsection{Bases de Dados}

Utilizando-se um sistema operacional com as caracteristicas abordadas acima, tanto para o Gerenciador de Processos quanto para o Gerenciador de Arquivos, pode-se supor um processo especialmente incorporado aos programas do sistema, denominado Sistema de Gerenciamento de Base de Dados (SGBD). O qual será apresentado a seguir.

Os primeiros trabalhos de relevância, com o objetivo de se criar Sistemas de Gerenciamento de Bases de Dados, surgiram na década de 60, tendo despertado maior interesse no final dos anos 70. Desde então, não apenas o objetivo de suporte de bases de dados cresceu, mas também novas áreas de pesquisa em bases de dados têm se desenvolvido. Atualmente, entre as áreas de grande interesse de pesquisa, pode-se citar: Máquinas de Bases de Dados, Linguagens de Bases de Dados, Otimizadores de consultas, Bases de Dados Orientadas a Objetos, Sistemas de Bases de Dados Distribuídos, Modelos de Bases de Dados Semânticos, Bases de Dados para Sistemas Especialistas e outros.

Neste capítulo, serão definidos termos e introduzidos conceitos básicos de SGBDs que serão utilizados no desenvolvimento deste trabalho. Serão também apresentadas ferramentas conceituais para modelagem de dados, abstraçôes, visões e descrição de elementos que compõe um sistema de gerenciamento de base de dados.

\subsubsection{Conceito de Base de Dados}

A palavra dado será utilizada neste trabalho para referir-se a algum valor armazenado na base. Quando um programa de aplicação manipula um dado, ou seja, associa um significado ao mesmo, isto referenciar-se-á a uma informação ao invés de um dado.

O termo objeto será utilizado para representar agregações de dados com significado sem que se preocupe com a sua implementação em termos de registros, tuplas, arquivos ou outras formas de representação [Katz86].

Para apresentar os conceitos utilizar-se-á o exemplo de uma empresa que mantém as seguintes informações de seus funcionários: - Nome, R.G., Endereço, código do funcionário, cargo que ocupa e salário.

Pode-se imaginar vários programas de aplicação que manipulam arquivos de dados, com as informações citadas acima. Assim, cada programa de aplicação é responsável por definir e manipular as estruturas de dados, devendo o programador conhecer o formato dos registros dos arquivos que seu aplicativo manipula.

Com o passar do tempo as necessidades da empresa podem se modificar e 
novos programas de aplicação podem ser construidos, e mesmo novos arquivos de dados podem ser criados. Este é um ambiente tipicamente conhecido como Sistema de Processamento de Arquivo, suportado por sistemas operacionais convencionais. Nesse ambiente, diversos programas de aplicação manipulam diferentes arquivos, acessando registros armazenados em algum tipo de dispositivo de armazenamento de massa [Korth86]. Diversas desvantagens podem ser encontradas quando aplicativos que utilizam vários arquivos são construidos utilizando-se sistemas de processamento de arquivo, como por exemplo:

- Redundância de Dados: devido a existência de inúmeras aplicações manipulando os mesmos dados, é muito provável que informaçôes sejam replicadas. Por exemplo, o código do funcionário deverá aparecer em todos os arquivos onde a pesquisa a respeito do funcionário é efetuada através de seu código.

- Inconsistência de Dados: a redundância de dados pode fazer com que um determinado aplicativo que modifique um dado num arquivo, não o faça sobre o mesmo dado que esteja noutro arquivo. Isto faz com que os dados do sistema sejam incoerentes. Suponha que houvesse necessidade de mudar o código do funcionário; caso não sejam atualizados todos os arquivos, poderia ocorrer que funcionários diferentes possuissem o mesmo código; isto é dito inconsistência de dados.

- Dificuldade de acesso aos dados: imagine arquivos com diferentes formatos. Caso fosse necessário uma listagem contendo o nome do usuário e sua função, o programador responsável pela implementação deste aplicativo teria necessariamente que conhecer os formatos de todos os arquivos.

- Isolamento de dados: uma vez que os dados estão espalhados em diversos arquivos, torna-se cada vez mais difícil escrever um programa de aplicação que manipule todos os arquivo e novos tipos de dados.

- Segurança: nem todo aplicativo deveria ter acesso a todas as informaçòes dos arquivos. Por exemplo, um usuário poderá ter acesso à informação do cargo de um funcionário, sem que possa ter acesso ao valor de seu salário.

Os Sistemas de Gerenciamento de Bases de Dados (SGBD) surgiram da necessidade de melhorar os sistemas de processamento de dados existentes no início dos $\operatorname{anos} 60$. 


\subsubsection{Necessidade e Objetivo de um Sistema de Gerencia- mento de Base de Dados}

Caracteriza-se um Sistema de Gerenciamento de Base de Dados como uma coleção de arquivos de dados inter-relacionados de um empreendimento, juntamente com suas primitivas de manipulação, as quais permitem ao usuário ter acesso aos dados, sem que o mesmo tenha conhecimento das estruturas de dados envolvidas.

Pode-se dizer que um Sistema de Gerenciamento de Base de Dados é um sistema dinâmico que surgiu com o objetivo de oferecer ao usuário:

- representação sucinta e compreensível, do estado do sistema a qualquer instante,

- acesso eficiente e de alto nível aos dados,

- atualizações simples e consistentes.

Identifica-se, em um SGBD, quatro grupos distintos de usuários, a saber: usuários simples (que utilizam programas de aplicação); programadores de aplicação; usuários ocasionais (que fazem alguma consulta ocasionalmente) e $o$ administrador da base. A interface entre a base e os usuários é feita através de módulos funcionais, conforme se pode verificar na figura 2.3

Note-se que cada usuário deve ter uma idéia limitada da base, isto é, o sistema tem que esconder certos detalhes de armazenamento, estrutura dos dados da base ou ainda, impedir que usuários não autorizados tenham acesso aos dados que não lhes dizem respeito. Com isso, estabelece-se o conceito de niveis de abstração em Bases de Dados.

Cabe observar que os quatro grupos de usuários mencionados acima podem ser reagrupados em dois conjuntos, que são: Administrador da Base de Dados (ABD) e Projetistas: onde, entendese por projetistas os usuários ocasionais, programadores de aplicação e usuários que utilizam os programas de aplicação. 


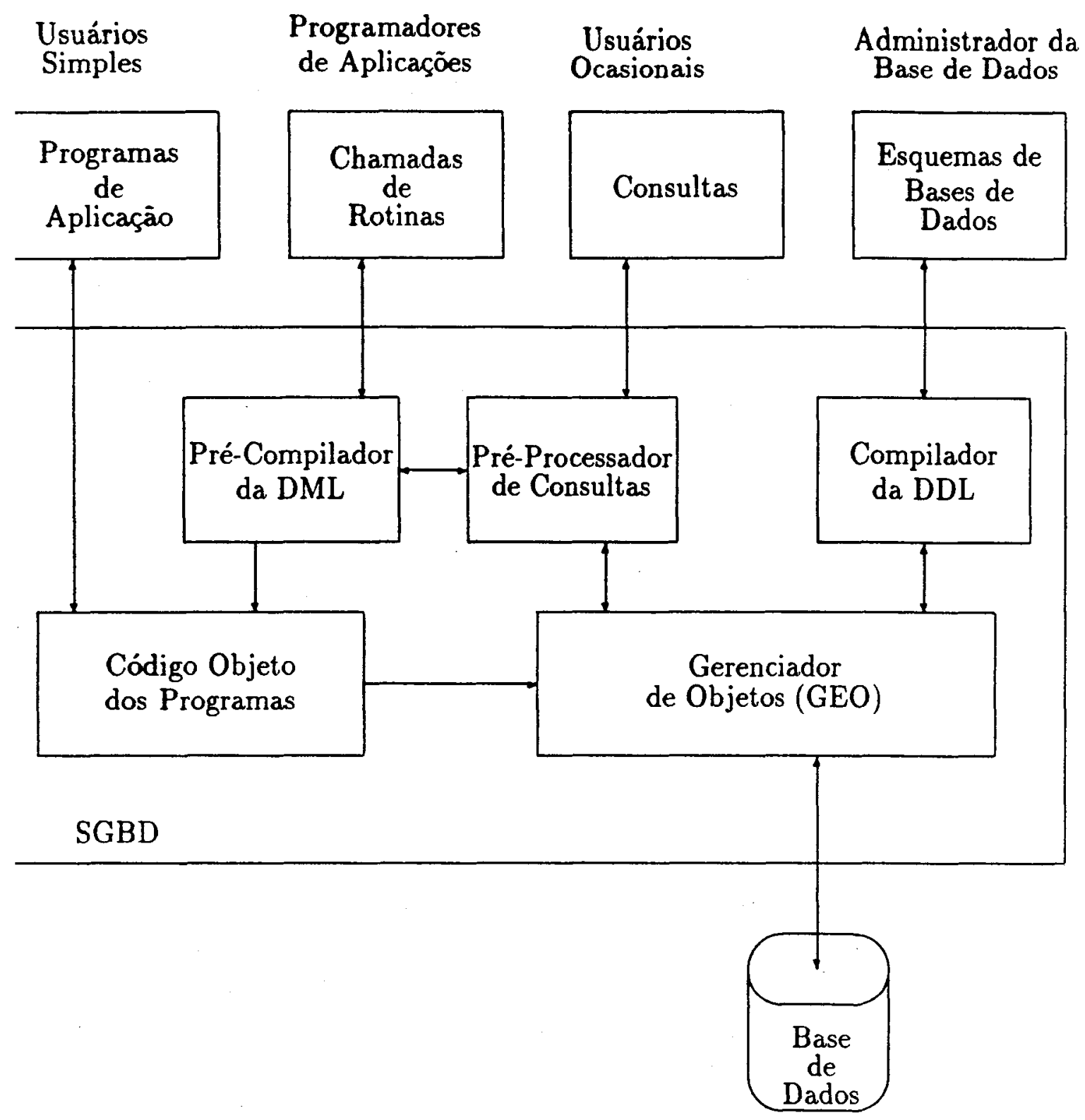

Figura 2.3: Estrutura Lógica de um Sistema de Gerenciamento de Base de Dados 


\subsubsection{Niveis de Abstração em uma Base de Dados}

Uma Abstração de algum ente é um modelo do mesmo sobre o qual alguns detalhes são deliberadamente omitidos. A escolha desses detalhes é feita considerandose a aplicação, bem como o interesse de seus usuários. $\mathrm{O}$ objetivo é permitir que o usuário preste atenção apenas em aspectos que sejam relevantes, ignorando os demais detalhes.

Um SGDB, segundo a padronização CODASYL, apresenta três níveis distintos de abstração sobre os dados. Neste padrão, cada nível utiliza um esquema de representação de dados que indica qual é a idéia que um usuário qualquer tem da base e qual é a forma como determinados usuários (administrador da base de dados "ABD" e/ou projetistas) imaginam os dados [CODASYL71]. Estes níveis são:

- Nível de Visão: Este é o nível mais alto de abstração. Pode-se dizer que é o conjunto de esquemas dos vários programas de aplicação, caracterizando como cada programa "visualiza" os dados armazenados na base. É definido este nivel devido à quantidade muito grande de dados armazenados e tem por objetivo estabelecer a abrangência da visão de cada usuário, de acordo com sua necessidade de acesso às informações da base. Assim, o sistema pode dar ao usuário, através de várias visões, diferentes idéias da representação lógica dos dados.

- Nível Conceitual: descreve quais dados são realmente armazenados na base e quais são associações entre objetos. Caracterizando como os dados são vistos como um todo, de forma lógica, pelo indivíduo que atua como gerente da base de dados. Este nível, embora seja muitas vezes de implementação complexa, estabelece um conjunto relativamente simples de estruturas, com as quais se descrevem os dados e suas associações. A expressão "njvel conceitual" é também empregada para denominar o conjunto de todos os dados [Date86]. O nível conceitual seria, segundo Date, "uma visão do conteúdo total da base de dados, e o esquema conceitual é uma aplicação dessa visão".

- Nível físico: caracteriza a forma com que a base armazena os dados. Este nível é responsável por oferecer, ao sistema, flexibilidade de controle e acesso aos dados armazenados na base.

A figura 2.4 ilustra estes três niveis de abstração. [Date86].

\subsubsection{Modelos de Representação de Dados}

Modelos de representação de dados são ferramentas lógicas que permitem ao Administrador da Base de Dados descrever, de forma lógica, dados que serão arma- 


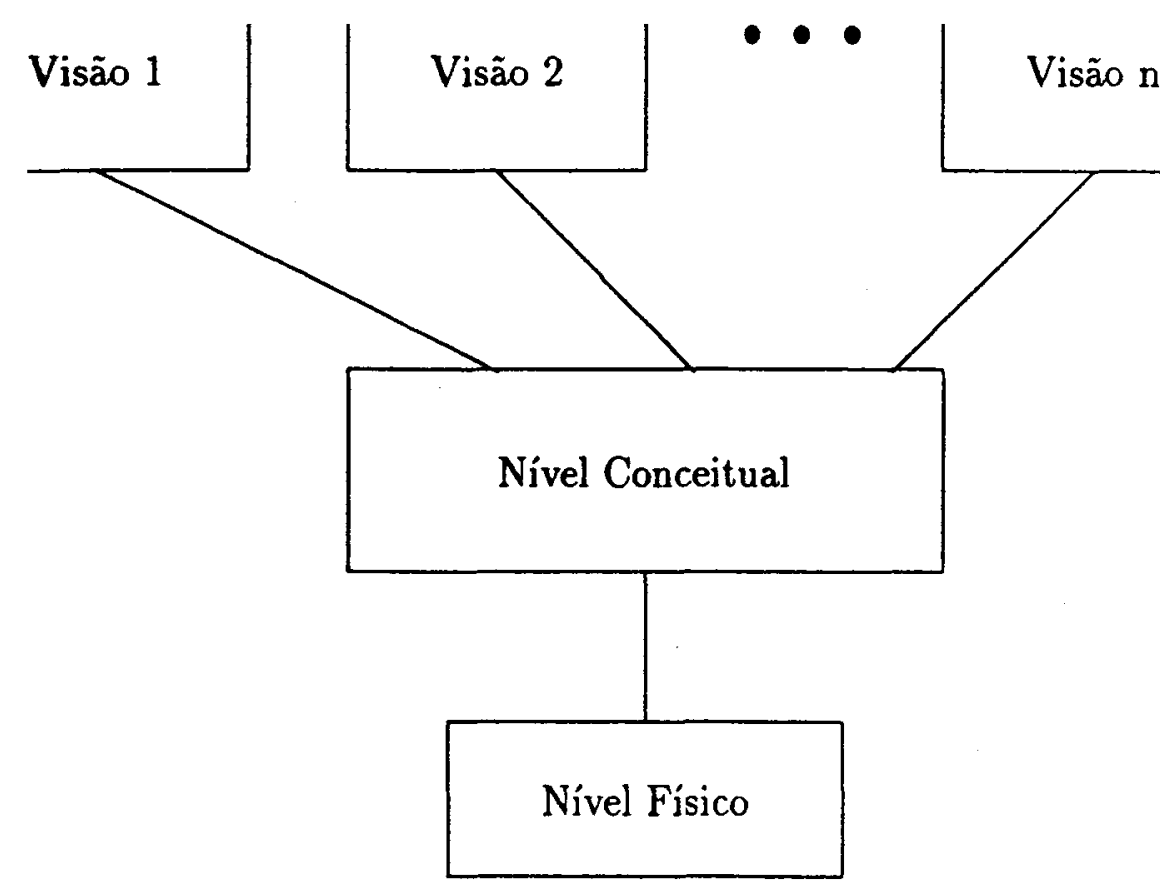

Figura 2.4: Niveis de Abstração numa Base de Dados 
zenados na base. É importante diferenciar o modelo da base, que é uma maneira estritamente lógica de se pensar nos dados, de uma instância da base, que é um valor que a base assume num dado instante (lembrando-se sempre que a base é um sistema dinámico). Para ilustrar melhor o conceito, pode-se estabelecer uma analogia entre o esquema de uma base de dados e a criação de um tipo de variável numa linguagem procedural de programação, tal como a linguagem "C" ou a linguagem PASCAL. Neste caso, uma instância da base seria análoga ao valor da variável num dado instante.

Os modelos podem ser classificados em três grupos distintos [Korth86].

- Modelos Baseados em Objetos: são aqueles que permitem uma descrição das informaçôes nos níveis de visão e conceitual. As ferramentas utilizadas são caracterizadas por embutirem muita flexibilidade, capacidade de estruturação de dados e, normalmente, possuirem capacidade de expressar multiplas restriçôes de dados. Como exemplo, tem-se o Modelo Entidade-Relacionamento e - Modelo de Representação de Objetos (MRO) [Traina Jr.86], que serão apresentados neste capítulo por serem necessários na introdução e compreensão de alguns conceitos. Inclui-se neste item, também os modelos de dados semânticos [Chen76].

- Modelos Baseados em Registros: assim como os modelos baseados em objetos, os modelos baseados em registros também são utilizados na descrição dos niveis conceitual e de visão. Contudo, não possuem a caracteristica de oferecer restrição de dados. Como exemplo tem-se o Modelo Relacional [Codd70], - Modelo de Rede, o modelo Hierárquico, e outros.

- Modelos de Dados Físicos: em contraste com ambos os modelos citados anteriormente, estes são usados para descrever a estrutura física de armazenamento de dados na base, sendo uma característica intrínseca da implementação, e não serão apresentados por estarem fora do propósito deste trabalho.

Exitem autores que classificam os modelos de dados separando os modelos orientados a objetos dos modelos semânticos [Hull87]. Contudo, a classificação dada acima é suficiente para o propósito deste trabalho [Korth86].

\section{Modelo Relacional}

O Modelo Relacional, é baseado na álgebra de relações entre conjuntos [Codd70]. Para ilustrar o modelo, considere-se o exemplo: 
Uma empresa deseja manter as seguintes informações a respeito de seus fornecedores:

- Nome do Fornecedor (NF), CGC, Número do Produto (NP), Data de Entrega (DE), Quantidade (Q).

Pode-se supor que todas essas informaçôes estejam armazenadas em uma tabela, como mostrado na figura 2.5 .

Pode-se notar que existem cinco conjuntos distintos na tabela acima denotados por: "NF", "CGC", "NP", "DE" $\mathrm{e}$ " $\mathrm{Q}$ " os quais possuem os seguintes elementos: $\mathrm{NF}$ $=\{$ Lord S.A.; Tavares LTDA; MiniMax S.A. $\}, C G C=\{002312 ; 081273 ; 199981\}$, $\mathrm{DE}=\{21 / 05 / 89 ; 31 / 01 / 90 ; 15 / 02 / 90\}$ e $\mathrm{E}=\{88 ; 30 ; 90\}$.

Matematicamente, uma relação é um subconjunto do produto cartesiano entre conjuntos que definem o dominio desta relação. Pode-se estabelecer uma analogia entre o conceito matemático de relação e a tabela da figura 2.5 , onde identifica-se no quadro o subconjunto do produto cartesiano entre os conjunto Nome do Fornecedor, CGC, Número de Cadastro, Número do Produto, Data de Entrega e Quantidade. Cada linha da tabela corresponde a uma n-upla deste produto cartesiano. $\mathrm{Na}$ terminologia do modelo relacinal, cada linha da tabela é chamada de "tupla" e não é permitido que existam linhas idênticas na tabela, o que garante a propriedade do produto cartesiano, fazendo com que cada tupla seja única.

Utilizando-se a formalidade do modelo relacional, diz-se que uma tupla é constituída de atributos e para cada atributo há um conjunto de valores permitidos, que são chamados domínio do atributo. Sejam então, D1, D2,..., Dn atributos de uma n_tupla (denomina-se n_tupla a uma tupla que seja um elemento do resultado do produto cartesiano de n conjuntos). Sejam v1, v2, .., vn domínios de D1, D2,.., Dn respectivamente. Desta forma, qualquer subconjunto do conjunto abaixo corresponderá ao conjunto de todas as tuplas existentes no sistema.

n

$X \mathrm{Di}$; onde:

$\mathrm{i}=1$

- X é o produto cartesiano

- n é definido como o grau da relação

A unicidade de uma tupla torna possível que um determinado subconjunto de atributos identifique unicamente uma tupla. Este subconjunto de atributos denomina-se Super-chave. O menor subconjunto de atributos que possa identificar uma tupla é definido como chave candidata. Note-se que mais de que um subconjunto pode ser usado como chave candidata. Assim sendo, cabe ao ABD es. 


\begin{tabular}{|c|c|c|c|c|}
\hline NF & CGC & NP & DE & Q \\
\hline \hline Lord S.A. & 002312 & 152 & $21 / 05 / 89$ & 88 \\
\hline Tavares LTDA & 081273 & 022 & $31 / 01 / 90$ & 30 \\
\hline MiniMax S.A. & 199981 & 003 & $15 / 02 / 90$ & 90 \\
\hline Lord S.A. & 002312 & 131 & $22 / 12 / 89$ & 16 \\
\hline Tavares LTDA & 081273 & 022 & $16 / 01 / 90$ & 10 \\
\hline
\end{tabular}

Figura 2.5: Relação de Dados

colher uma chave candidata para ser o mecanismo principal de identificação de uma tupla, e a esta chave escolhida denomina-se chave primária.

Das relaçôes apresentadas na tabela da figura 2.5 , nota-se que a partir de um CGC identifica-se um único Nome de Fornecedor, e que com o nome do fornecedor identifica-se unicamente um CGC. Isto mostra que existe dependência entre os dados numa tupla. Quando existem determinadas dependências entre os dados de uma tupla diz-se que os dados não estão normalizados. Isto ocorre quando exitem atributos cujo valor pode ser obtido diretamente de outros atributos. Regras para normalização de dados são apresentadas, por exemplo, em [Gane83].

$\mathrm{O}$ processo de normalização geralmente leva à criação de novas relaçōes. Por exemplo, se os dados da tabela da figura 2.5 forem normalizados obtém-se as relações apresentadas na tabela da figura 2.6 .

É importante notar que a normalização dos dados levou a uma redução na duplicação da informação. Isso faz com que num sistema normalizado o sistema de gerenciamento da base de dados possa aumentar sua eficiência na eliminação de inconsistências causada pela réplica de dados. Por outro lado, a eliminação das dependências funcionais pode causar perda de significado na representação [Codd70].

Inúmeras dependências e formas normais foram introduzidas na década de 70 , tendo Codd apresentado inicialmente as dependências funcionais que constituem a primeira, segunda e terceira formas normais, todas elas tratam de dependências funcionais. As dependências funcionais em bancos de dados são importantes por permitirem a normalização dos dados, podendo ser vistas, também, como uma generalização do conceito de "chave", pois pode-se determinar as chaves candidatas analisando-se propriedades das dependências funcionais.

$\mathrm{Na} a$ ágebra relacional existem algumas operações elementares, que são: seleção, projeção, produto cartesiano, união e diferença de conjuntos. A aplicação de cada uma dessas operaçôes elementares resulta numa nova relação. A partir destas operaçôes elementares da álgebra relacional, define-se uma linguagem de consulta à 
Relação de Fornecedores

\begin{tabular}{|c|c|}
\hline NF & CGC \\
\hline Lord S.A. & 002312 \\
\hline Tavares Ltda & 081273 \\
\hline Minimax S.A. & 199981 \\
\hline
\end{tabular}

Relação de Produtos Recebidos

\begin{tabular}{|c|c|c|c|}
\hline CGC & NP & DE & Q \\
\hline 002312 & 152 & $21 / 05 / 89$ & 88 \\
\hline 081273 & 022 & $31 / 01 / 90$ & 30 \\
\hline 199981 & 003 & $15 / 02 / 90$ & 90 \\
\hline 002312 & 131 & $11 / 12 / 89$ & 16 \\
\hline 081273 & 022 & $16 / 01 / 90$ & 10 \\
\hline
\end{tabular}

Figura 2.6: Relação de Dados Normalizados

base que implementa operações similares para acesso às informaçōes da base, permitindo que usuários criem diferentes visões da base.

\section{Modelo Entidade Relacionamento}

O Modelo Entidade Relacionamento (ME-R) foi proposto como uma ferramenta com capacidade de permitir representação semântica e estruturas de dados manipuladas pela base [Chen76].

Com o propósito de embutir tal capacidade no sistema, o modelo parte do princípio de que o mundo real é composto por objetos (representados por seus atributos) e associações entre esses objetos. Na terminologia do modelo, os objetos são chamados "entidades" e as associações entre objetos são ditos "relacionamentos". Diz-se que é uma entidade qualquer elemento que possa ser identificado, unicamente, através de um determinado conjunto de atributos. Para cada atributo há um conjunto de valores que o mesmo pode assumir, que é denominado "Domínio do atributo". Tomando-se um conjunto de atributos com diferentes valores para cada atributo estar-se-á representando entidades diferentes, ou seja, um "Conjunto de Entidades". Desta forma, o modelo representa, num mesmo conjunto, objetos do mundo real estruturalmente semelhantes . Por exemplo, cada empresa tem uma razão social e um CGC. Assim, do exemplo acima, (Lord S.A., 002312) é uma enti- 
dade e (Tavares LTDA, 681273) é outra entidade. Neste caso diz-se que o conjunto de entidades "EMPRESA" é identificado por uma "razão social" e um "CGC". Com isto, pode-se estender $o$ conceito de entidade para que se possa representar qualquer ente desejado, inclusive elementos abstratos tais como "conceitos" e "definiçōes".

Diz-se que há um relacionamento entre entidades quando existe algum tipo de associação entre as mesmas. Por exemplo: a empresa Lord S.A. "fornece" 152. Ou que uma determinada entidade "fornece" produto (ou produtos) a outra entidade. Diz-se que um conjunto de relacionamentos é um grupo de relacionamentos que têm a mesma estrutura. Com isto nota-se que uma entidade pode estar relacionada com diversas outras em um mesmo conjunto, o que define a chamada "restrição de cardinalidade" de um relacionamento, que pode ser 1:1, 1:N, N:1 ou N:M.

A descrição de uma base de dados que utiliza o Modelo Entidade-Relacionamento é normalmente feita através de notação gráfica. O chamado Diagrama Entidade-Relacionamento, baseia-se em figuras geométricas (retângulos, losangos e elipses para simbolizar entidades, relacionamentos e atributos, respectivamente) para representar o modelo da base.

Por exemplo, um modelo para representar a tabela da figura 2.6 pode ser da forma mostrada na figura 2.7.

Devido à grande capacidade de representação semântica do modelo, é comum que se utilize o ME-R para projetos de bases de dados independentemente de sua implementação. Além disso, foram introduzidos conceitos de hierarquias de abstração, segundo as quais é imposta uma disciplina de estruturação que permite o projeto de uma base de dados onde os objetos não estão necessariamente na terceira forma normal, conseguindo mesmo assim, garantir a integridade e consistência da base [Smith77a].

Caso se quisesse acrescentar a informação de que M "EMPRESAS" fornecem $\mathrm{N}$ "PRODUTOS", ter-se-ia o diagrama representado na figura 2.8 . 


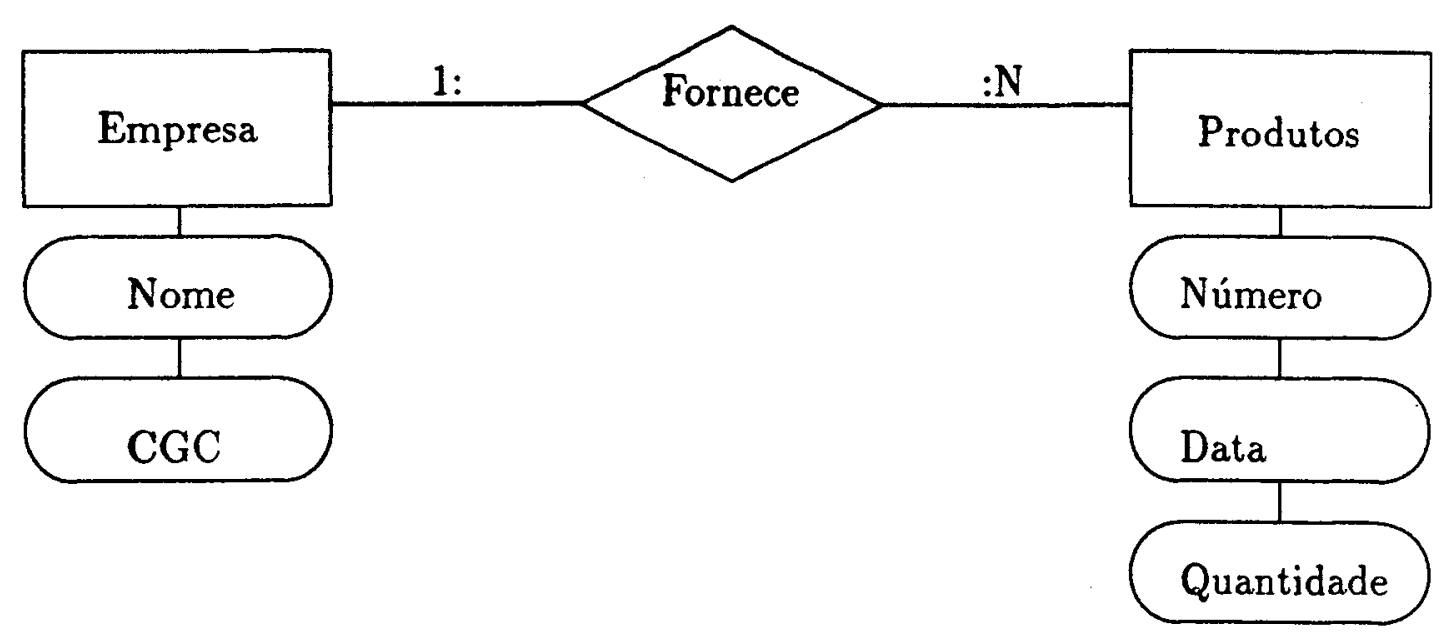

Figura 2.7: Representação no ME-R da figura 2.6

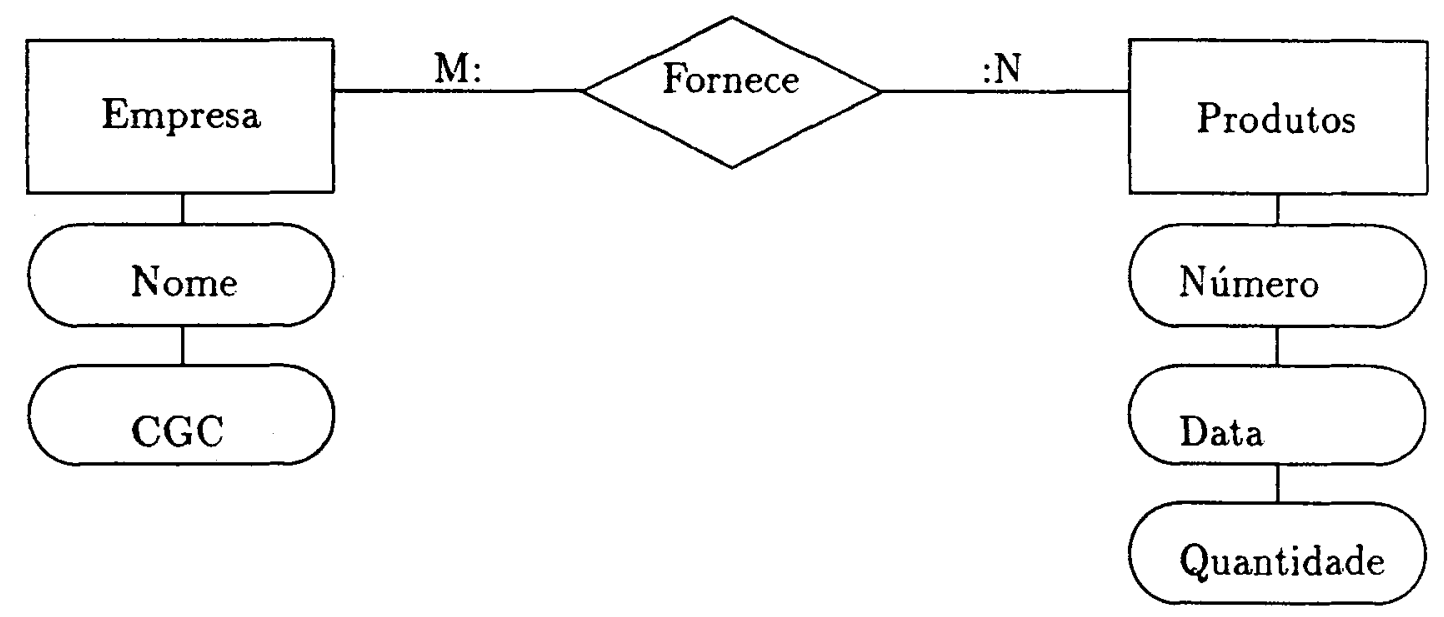

Figura 2.8: Representação no ME-R 


\begin{tabular}{|c|c|c|}
\hline \multicolumn{2}{|c|}{ Empresa } & \multicolumn{1}{c|}{ Produtos } \\
\hline CGC & $1: \mathrm{N}$ & Quantidade \\
\hline Nome & & Data \\
\hline & & Número \\
\hline
\end{tabular}

Figura 2.9: Representação no Modelo de Rede da Figura 2.6

\section{Modelo de Rede}

O modelo de rede surgiu após estudos do DBTG (Data Base Task Group), dentro do CODASYL, na década de 60, e utiliza-se de um diagrama de estrutura de dados, semelhante ao proposto por Bachman em 1969, para representar os registros. No diagrama é representado um conjunto de registros e suas ligaçóes. Neste modelo existe uma restriçã̃o de cardinalidade, uma vez que apenas relacionamentos de cardinalidade 1:M são diretamente representados. Nos relacionamentos de cardinalidade 1:N o registro que aparece apenas uma vez é dito "Owner" e o registro que pode aparecer múltiplas vezes é dito "Member" [CODASYL71].

A figura 2.9 mostra a modelagem do mesmo exemplo. Note-se que neste tipo de modelagem os registros se interligam de forma arbitrária, desde que satisfaçam a condição de cada registro "Member" estar associado a um único "Owner". Assim, estendendo-se a representação para informar que um determinado produto pode ser fornecido por $\mathrm{M}$ empresas, tem-se a figura 2.10 .

\section{Modelo Hierárquico}

O Modelo Hierárquico é similar ao Modelo de Rede, no sentido de que os dados e as relações entre eles também são representados por registros e ligações. Porém há a restrição de que o Registro Pai, que origina a associação, ocorra uma única vez, enquanto o Registro Filho pode ocorrer múltiplas vezes. Assim, o Modelo Hierárquico difere do Modelo de Rede por organizar os registros em coleçôes de estruturas em árvores ao invés de grafos arbitrários. 


\begin{tabular}{|c|c|c|}
\hline \multicolumn{1}{|c|}{ Empresa } & \multicolumn{1}{|c|}{ Produtos } \\
\hline CGC & $1: \mathrm{N}$ & Quantidade \\
\cline { 3 - 3 } & & Data \\
\hline & $1: \mathrm{M}$ & \\
\hline & & Número \\
\hline
\end{tabular}

Figura 2.10: Representação no Modelo de Rede de um Relacionamento de Cardinalidade $M: N$

\begin{tabular}{|c|c|c|}
\multicolumn{1}{c|}{ Empresa } & \multicolumn{1}{c|}{ Produtos } \\
\hline CGC & $1: \mathrm{N}$ & Quantidade \\
\hline Nome & & Data \\
\hline & \\
\hline
\end{tabular}

Figura 2.11: Representação no Modelo Hierárquico de um Relacionamento de Cardinalidade $1: \mathrm{N}$ 

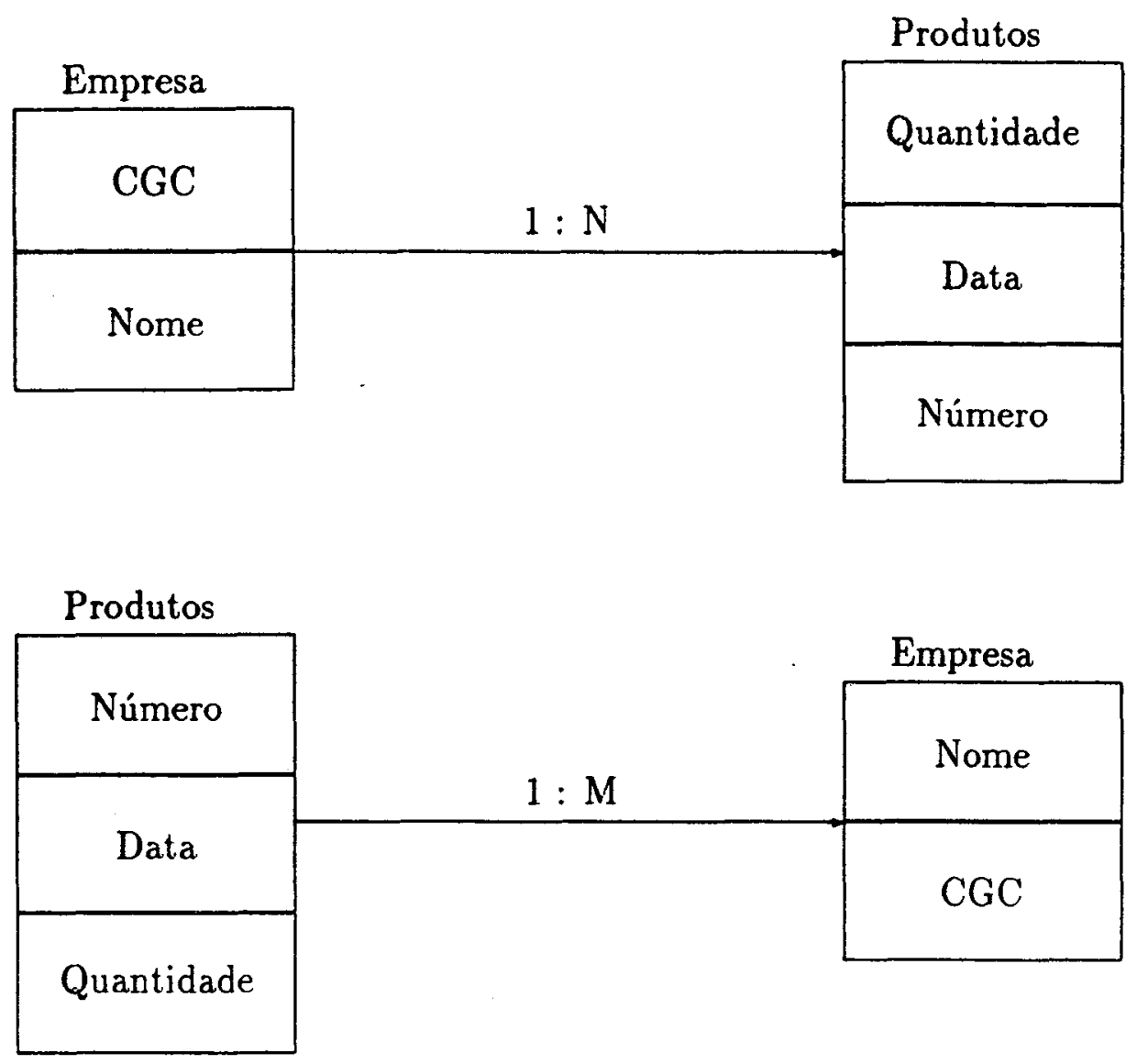

Figura 2.12: Representação no Modelo Hierárquico de um Relacionamento de Cardinalidade M:N 
$\mathrm{Na}$ figura 2.12 é apresentado o relacionamento de cardinalidade N:M no Modelo Hierárquico. Ou seja, $\mathrm{M}$ empresas fornecem $\mathrm{N}$ produtos.

O exemplo apresentado na figura 2.11, mostra a representação no Modelo Hierárquico do problema proposto para a representação no Modelo Relacional.

\section{Modelo de Representação de Objeto}

Os modelos de dados apresentados anteriormente surgiram em ambientes onde o objetivo eram aplicaçóes comerciais, ou seja, o volume de dados a ser manipulado é grande e os dados muito semelhantes em estrutura.

O Modelo de Representação de Objetos, é baseado na teoria dos grafos. O objetivo de seu desenvolvimento reside em dar suporte a aplicações de projetos em engenharia, permitindo um alto grau de representação semântica [Traina Jr.86].

Devido a necessidade de detalhamento do modelo, para que se possa explorar suas capacidades na implementação deste trabalho, mais detalhes serão apresentados no capítulo 5.

\subsubsection{Consistência em Bases de Dados}

Os programas de aplicação têm acesso a informações em uma base de dados através de operações de leitura, num dispositivo de armazenamento de massa, trazendo as informações necessárias para a memória principal e posteriormente reescrevendo-as no mesmo dispositivo. A manipulação desses dados pelos programas de aplicação pode fazer com que as cópias dos dados que estão na memória principal não contenham valores idênticos aos valores armazenados. Neste caso, o estado em que se encontra a base de dados após a ocorrência de um destes eventos é dito inconsistente.

Num ambiente multi-programado, cópias de dados na memória podem ser manipuladas paralelamente pelos programas de aplicação. Desta forma, para se garantir a consistência da base de dados, deve-se supor que os programas de aplicação sejam compostos por conjuntos de ações (primitivas de leitura e escrita na base) que sempre levam a base de um estado consistente (antes da execução) para um estado consistente (após a execução).

\subsubsection{Integridade em Bases de Dados}

Existem determinadas regras em uma base de dados, impostas pelo Administrador da Base de Dados, que devem permanecer imutáveis. Por exemplo, pode-se 
impor que num sistema bancário o saldo do cliente nunca pode ser negativo. Assim como esta assertiva, inúmeras outras devem ser satisfeitas para que a base não se degenere. Então, diz-se que uma base de dados está integra se, ao ser confrontada com o conjunto de regras do sistema, todas as regras são satisfeitas.

Os conjuntos de ações que levem a BD de um estado consistente para um estado consistente garantem, além da consistência, a integridade da BD. No entanto, ainda podem ocorrer danos à máquina que provoquem perda de integridade.

\subsubsection{Versões}

Em ambientes onde há desenvolvimento de projetos, pode-se encontrar situações onde equipes estejam trabalhando simultaneamente em partes de um mesmo projeto. Assim, o desenvolvimento de um projeto se dá acompanhado de versões e alternativas do mesmo.

Muitas versões de um mesmo projeto podem existir num determinado instante, e esta característica exige que os Sistemas de Gerenciamento de Base de Dados possuam a capacidade de armazenar e gerenciar múltiplas versões. Este sistema é denominado "Gerenciador de Versões" ("Version Server") [Traina Jr.91] [Katz84].

Foram propostos diversos Sistemas de Gerenciamento de Versões [Stonebraker81] [Katz84]. Contudo, estes sistemas assumem que o Sistema de Gerenciamento da Base de Dado tem orientação a registro.

Katz em 1986 apresentou um modelo de dados semântico orientado a objetos no qual é mostrada a complexidade de representar um projeto que evolui em função do tempo numa base de dados [Katz86].

\subsection{Conclusão}

$\mathrm{Na}$ abordagem apresentada acima, o SGBD surge como uma máquina virtual que interage com o Sistema Operacional e com aplicativos. São mostradas algumas características que devem ser suportadas por estes sistemas, tais como: consistência, integridade, controle de versões, características dos modelos de representação de dados e os níveis de abstração que compõe o SGBD. Utilizando-se o conceito de máquina vírtual apresentado, pode-se conceber-se um SGBD composto por três niveis lógicos, que seriam: comunicação com os aplicativos, manipulação de informações (trata de todo o acesso lógico e filtra as informações do aplicativo para que possa haver acesso a dados da base) e o nivel mais baixo, que estabelece o protocolo de acesso aos dados. Os protocolos de acesso, bem como as formas de concorrência, serão apresentadas nos capítulos 3 e 4 . 


\section{Capítulo 3}

\section{Transações}

Um modelo de base de dados é um conjunto de estruturas de dados que abstraem objetos relevantes para o usuário. Os dados da base podem ser manipulados por programas de aplicação que se comunicam com o usuário. A execução de um programa de aplicação pode corromper a integridade da base, bastando para isto que ao término da execução alguma regra de integridade seja violada. Para evitar que esses efeitos colaterais possam ocorrer criou-se o conceito de transação.

Neste capítulo apresenta-se o conceito de transação e suas extensões: atomicidade de transações, transações seriais e entrelaçadas, dominio de consistência e estados de uma transação; e, estabelecem-se algumas considerações sobre granularidade em SGBD orientados a transações.

\subsection{Definição de Transação}

Define-se transação a: qualquer sequência de ações que manipulam a base de dados e que preservam a sua consistência [Gray78].

Noçôes de consistência foram introduzidas por Eswaran [Eswaran76] [Gray 78] e outros. Pressupondo-se que cada transação, quando executada separadamente, leva a base de um estado consistente para um estado consistente, é argumentado que o bloqueio dinâmico sobre os objetos ("Entidades") é um esquema bastante flexível, além de facilitar a recuperação em caso de falhas do sistema, quando a base mantém arquivos diferenciais [Severance76].

Para exemplificar o conceito, imagine-se um sistema bancário onde a transação $\mathrm{T}$, mostrada no Exemplo 3.1, deve transferir fundos da conta do cliente A para a conta do cliente B. 


\section{$T: \operatorname{LEIA}(A)$}

$A<-A-50$

$\operatorname{ESCREVA}(\mathrm{A})$

$\operatorname{LEIA}(\mathrm{B})$

$B<-B+50$

$\operatorname{ESCREVA}(\mathrm{B}$ )

\section{Exemplo 3.1}

Note que se por alguma eventualidade o sistema falha antes que a transação tenha sido executada completamente, a base ficará inconsistente. Isto porque a quantidade total de fundos do banco deveria permanecer inalterada, caso a transação tivesse sido completada. Com este exemplo pode-se notar que apenas a execução completa de uma transação é que garante a integridade da base da dados. Isto nos leva ao conceito de atomicidade de uma transação.

\subsection{Atomicidade de Transação}

Diz-se que uma transação é atômica se todas as suas ações são executadas ou então nenhuma ação é executada [Korth86].

Quando algum evento não permite a execução completa de uma transação, o subsistema de gerenciamento de transaçóes da base de dados deve identificar o estado da transação e permitir alguma forma de recuperação do estado em que a base se encontrava antes do inicio da execução desta transação, dando a impressão de que nenhuma ação foi efetuada.

Um ponto a ser destacado é que, para a transação do exemplo 3.1, o sistema deverá manter constante a quantidade de fundos do banco. Este conceito é importante pois exemplifica noções de regras de consistência, as quais devem ser observadas pelas transações.

No exemplo de transação dado acima supôs-se que apenas esta transação estaria sendo executada, ou seja, apenas o cliente A estaria transferindo fundos para a conta do cliente B. Mas, é possível a existência de outros clientes manipulando os fundos das contas A e B. Por uma questão de eficiência, pode-se imaginar, num 
sistema multiprogramado, a sobreposição temporal das transações. Este conceito é melhor explicado a seguir.

\subsection{Transações Seriais e Entrelaçadas}

Não havendo sobreposição de execução de transações no tempo, ou seja, somente é iniciada a execução de uma nova transação quando a anterior foi levada a cabo, então, diz-se que as transações são executadas de forma serial (ou não entrelaçada). Neste caso a base de dados sempre é levada de um estado consistente para outro estado consistente; por definição de transação. Para isso, assume-se que a base de dados esteja inicialmente num estado consistente. Disto resulta um novo problema, que consiste em maximizar o número de transaçóes executadas num dado intervalo de tempo.

Dado um conjunto de transações, é possivel que se identifique subconjuntos de transações que podem ser executadas paralelamente no tempo. Este processo é conhecido por entrelaçamento de transações, pois ações de várias transações são sobrepostas no tempo.

Quando a execução de transações é sobreposta no tempo, surgem dois problemas críticos a serem considerados:

- O primeiro é que a concorrência pelos recursos (dados da base) pode provocar impasses ("dead lock") na base. Este problema, em sistemas orientados a transações, depende do algoritmo utilizado para controle de concorrência e será tratado no capítulo 4 (referente a controle de concorrência).

- O segundo diz respeito a consistência da base, ou seja, é importante que a base pareça estar consistente para cada transação. Isto leva a conceituar domínio de consistência de uma transação.

\subsection{Domínio de Consistência de Transações}

Para garantir a consistência de transaçōes, é necessário a existência de um gerenciador de configuraçóes que estabeleça um protocolo de acesso à base, a fim de manter a sua integridade e consistência. Esse protocolo de acesso à base de dados, ao qual todas as transações estão obrigadas, é um conjunto explícito de assertivas sobre a base, e estabelece o que se chama de domínio de consistência. Por exemplo, [Farrag87] considere duas transaçóes T1 e T2 como mostradas abaixo:

$$
\text { T1 : } X<--X+1 \text {, }
$$




$$
\begin{array}{r}
Y<-Y+1, \\
T 2: Y<-2 * Y, \\
X<-2 * X,
\end{array}
$$

Suponha-se que uma assertiva de consistência sobre a base seja que $\mathrm{X}=\mathrm{Y}$.

Se for considerada a seguinte sequência de execução das ações destas transações:

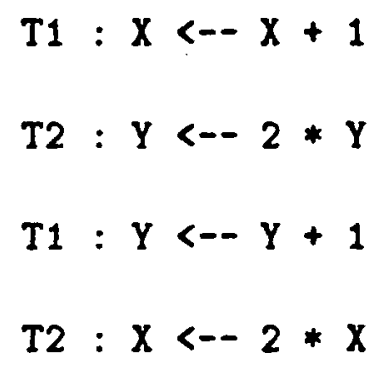

ter-se-à a base em um estado inconsistente.

O exemplo acima introduz dois novos conceitos:

- a necessidade de um escalonador de transações, que elege a transação a ser executada num dado instante,

- consistência em presença de transações entrelaçadas: é importante notar que não é condição necessária que a base de dados esteja sempre num estado consistente, mas sim, que a visão da transação seja sempre de uma base consistente. Ou seja, se cada transação de um conjunto de transaçôes satisfizer os critérios de consistência da base, independentemente da ordem de execução, a base sempre será levada de um estado consistente para um estado consistente. Assim, transaçōes operam sobre subconjuntos consistentes de dados, e cada transação garante consistência dos dados que manipula, não importando se a base toda é consistente.

\subsection{Estados de uma Transação.}

$\mathrm{Na}$ ocorrência de uma falha, o sistema passa a não refletir mais um estado real de consistência da base de dados. Contudo, uma transação deve sempre garantir 
esta consistência. Assim, quando algum tipo de falha ocorre numa transação pode-se imaginar uma mudança de estado do processo (transação).

Uma transação que acaba de ser submetida ao SGBD assume um estado que será chamado de "Ativo".

Quando uma transação está no estado ativo, exitem apenas duas possibilidades de mudança de estado, ou seja:

- caso ocorra uma falha do sistema, ou qualquer evento que não permita a continuidade de execução do processo, então a transação passa para um estado "falho";

- ou ao término da execução da última ação, quando entâo, a transação passa para um estado de "Compromisso Parcial";

caso nenhum desses estados seja atingido, é porque a transação continua ativa.

O estado "Compromisso Parcial" indica que todas as operaçôes da transação foram bem sucedidas. Contudo, ainda não foram feitas as devidas atualizações físicas na base. Caso estas operaçôes sejam bem sucedidas, diz-se que a transação está no estado de compromisso ("Committed").

O estado "Compromisso Parcial" pode ser eliminado, dependendo do sistema de recuperação de falhas implementado. Neste caso, a transação pode passar diretamente do estado ativo para o estado de compromisso. Para controle de versão da base, o estado de compromisso parcial é utilizado para se retardar as operações de escrita. Por esse motivo, existe ainda a possibilidade de falha em tempo de escrita, podendo então a transação passar do estado de compromisso parcial para o estado "Falho" [Korth86].

Uma vez que uma transação tenha atingido o estado "Compromissado", as operações sobre a base que a transação efetuou não podem ser desfeitas, mesmo que ocorra falha no sistema.

Transações que atinjam o estado falho passam para o estado "Abortado"; e neste ponto o sistema deve garantir a atomicidade da transação, desfazendo todas as operações executadas, verificando se a transação deve ser repetida (ou se realmente não há condições de prosseguir com sua execução) e, possivelmente, refazendo as transações que foram executadas paralelamente.

A figura 3.1 mostra os possiveis estados de uma transação num sistema orientado a transações. 


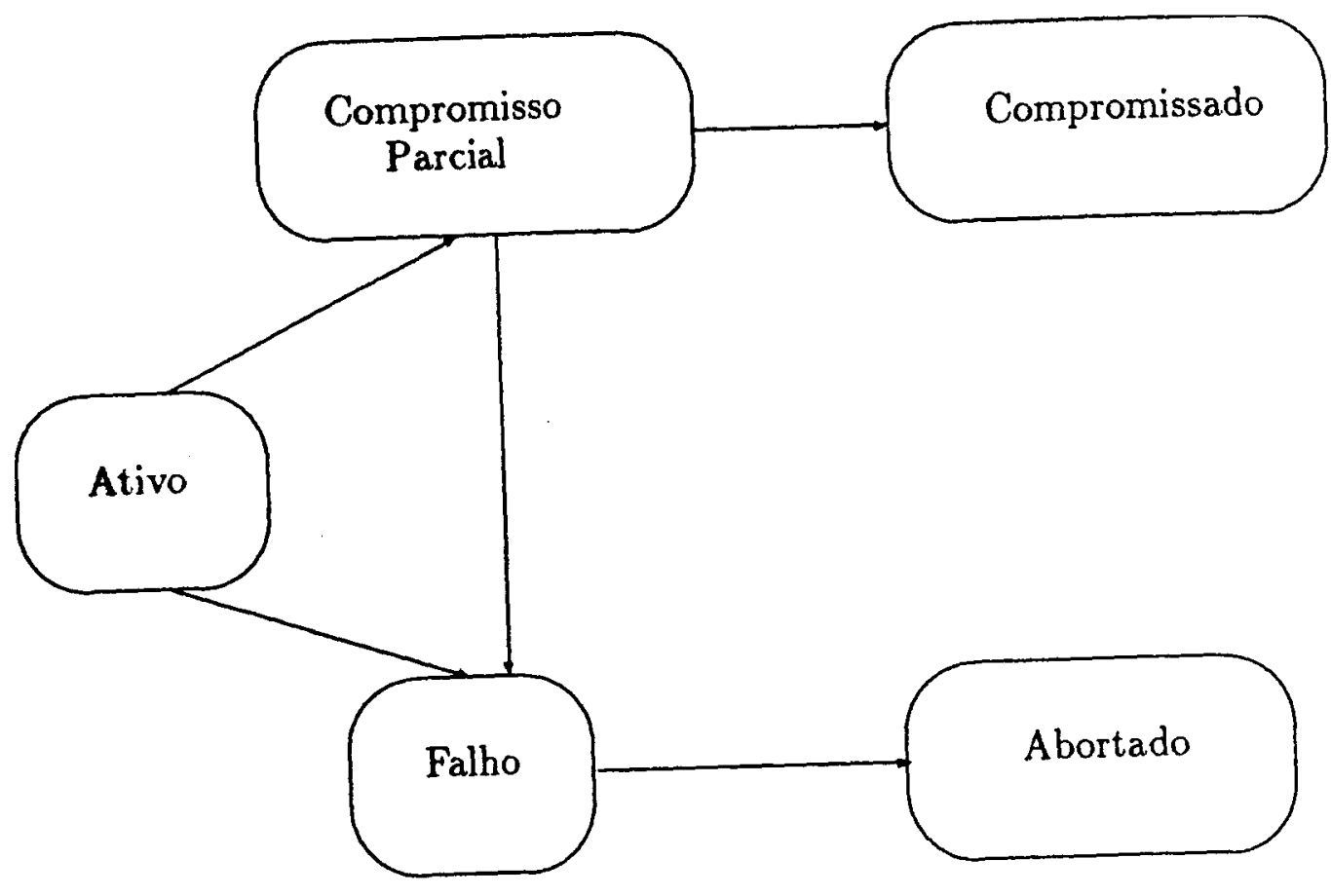

Figura 3.1: Estados de uma transação 


\subsection{Considerações sobre Granularidade em Sis- temas Orientados a Transações}

Aceita-se que uma transação seja uma unidade de consistência, e que algum mecanismo de proteção sobre itens de dados seja oferecido pelo sistema. Neste ponto, duas questões devem ser levantadas:

- qual deve ser o tamanho do grânulo em um sistema de base de dados orientado a transaçóes?

- Qual deve ser o número máximo de transações ativas num determinado instante?

Intuitivamente, a primeira questão deve ser analisada balanceando-se o seguinte par de metas conflitantes: maximização do grau de concorrência e minjmização da sobrecarga do sistema para proteção de itens de dados. Para a segunda questão, os objetivos que se deve balancear são: maximização de utilização dos recursos e minimização de conflito entre transações.

Existem três fatores que influenciam diretamente as respostas para estas questões, que são:

1. Tamanho da transação: o sistema é ajustado para atingir maior eficiência quando as transações são curtas ou longas?

2. Política de proteção sobre itens de dados:

2.1 Política de aquisição de dados:

2.1.1. Pré-requisição: todos os itens de dados sobre os quais a transação opera devem ser obtidos no inicio da transação.

2.1.2. Requerido quando necessário: nesta caso, itens de dados são requeridos por uma transaçâo, um por um, de acordo com sua necessidade.

2.1.3 Requerido em ordem: este tipo de política é semelhante a requerido_quando_necessário, porém existe uma ordenação linear entre os grânulos e cada transação tem que requisitar os grânulos naquela ordem.

2.2 Política de liberação de itens de dados: que especifica quando e como um item de dado deve ser liberado. Para evitar complicaçôes na recuperação, caso ocorra falha, todas as ações sobre itens de dados devem ser guardadas até que a transação atinja o estado de compromisso.

3. Protocolo de acesso: este é o padrão que as transações seguem para acessar a base de dados. $\mathrm{O}$ acesso pode ser em seqüência, localizado ou aleatório. 
Em [Pun87] é feita uma análise de eficiência que aborda aspectos de granularidade sobre um sistema centralizado de base de dados orientado a transações.

\subsection{Considerações}

Num ambiente que admite multi-programação, processos distintos podem possuir cópias locais de dados da base. Isto permite que tais processos possam estar munipulando informações que não refletem o estado real da base, ou seja, pode existir inconsistência de dados. Para resolver este problema, foi proposto neste capítulo que as operações sobre dados da base devem ser efetuadas através de transaçôes. Contudo, esta solução pode provocar efeitos colaterais que dependem do protocolo de controle de concorrência sobre os dados. Tais protocolos são apresentados e analisados no capítulo 4 . 


\section{Capítulo 4}

\section{Controle de Concorrência em Sistemas Orientados a Transações}

Os sistemas de computação modernos podem ser classificados em dois grandes grupos: os sistemas monoprogramados e os sistemas multiprogramados. Nos sistemas monoprogramados apenas um programa pode ser executado de cada vez; ao passo que nos sistemas multiprogramados, programas podem ser executados de forma entrelaçada. Por exemplo, enquanto um programa executa alguma operação de Entrada/Saída de dados, o sistema pode alocar o processador para um outro programa.

Quando transações são executadas concorrentemente, a execução entrelaçada das ações de transaçôes submetidas ao protocolo de acesso à base podem produzir resultados indesejáveis, conforme apresentado no capítulo 3 . Controle de concorrência é a atividade de eliminação desses resultados indesejáveis e é executado pelo o que se convencionou chamar "Escalonador de Transações".

O objetivo do controle de concorrência é produzir uma execução que tenha o mesmo efeito de uma execução serial (não entrelaçada). Em 1983 Berstein introduziu o conceito de "Serializability Transactions", que são transações que podem ser executadas paralelamente, cujo resultado final é o mesmo que uma execução serial [Berstein83].

\subsection{Algoritmos de Controle de Concorrência}

Diversos algoritmos de controle de concorrência têm sido propostos e os mais comuns são: Bloqueio em Duas Fases ("Two Phase Locking"), Ordenação por Tempo de Chegada ("Timestamp Ordering") e o Otimista ("Optimistic"). Embora existam 
vários algoritmos para controle de concorrência, não há um algoritmo de propósito geral para protocolos de acesso a base de dados livre de impasses ("dead-locks"), sendo esses algoritmos desenvolvidos para casos especiais [Kung81]. Apresenta-se uma proposta de algoritmo de propósito geral, segundo o qual os algoritmos de "Bloqueio em Duas Fases" e "Ordenaçâo por Tempo de Chegada" aparecem como pontos extremos de uma sequência de algoritmos para casos especiais de controle de concorrência [Farrag87].

\subsubsection{Algoritmo Baseado em Ordenação por Tempo de Chegada}

Uma forma de se conseguir o efeito de serialização é controlar a ordem na qual ações são executadas. Quando uma ação é submetida ao protocolo de acesso à base, ela pode ser executada imediatamente, atrasando a ação de outro processo, ou rejeitando a ação. Se a ação é rejeitada, então a transação que solicitou a ação é abortada, todas as transaçôes que solicitam escritas são desfeitas e transações que levam quaisquer dos valores produzidos por aquelas escritas também são abortadas.

No caso da ordenação por tempo de chegada ao sistema, a cada transação Ti no sistema é associado um instante ("timestamp") fixo e único denotado por TS(Ti). O TS de uma transação é fornecido pelo sistema antes que a transação entre em execução. Se uma nova transação Tj é submetida ao sistema, então $\mathrm{TS}(\mathrm{Ti})<$ $\mathrm{TS}(\mathrm{Tj})$. Neste processo pode-se usar tanto um contador de transaçôes centralizado quanto o relógio do sistema para implementar o método.

Note-se que é importante assegurar a seqüência de execução das transações, pois se $\mathrm{TS}(\mathrm{Ti})<\mathrm{TS}(\mathrm{Tj})$ então a execução de Ti juntamente com $\mathrm{Tj}$ deve ser equivalente à execução de Ti seguida por $\mathrm{T} j$, segundo a lista ordenada por "timestamp".

Para implementar este algoritmo, deve-se associar a cada objeto $\mathrm{X}$, dois valores de tempo de chegada:

$\mathrm{WT}(\mathrm{X})$ : que indica o maior tempo de chegada ao sistema de qualquer transação que tenha efetuado corretamente uma operação de escrita ( write(X)).

$\mathrm{RT}(\mathrm{X})$ : que indica o maior tempo de chegada ao sistema de qualquer transação que tenha efetuado corretamente uma operação de leitura $(\operatorname{read}(\mathrm{X}))$.

Os valores de WT e RT devem ser atualizados a cada nova operação read(X) ou write $(\mathrm{X})$.

O modo de operação do algoritmo é o seguinte: 
- Suponha que $\mathrm{Ti}$ execute um read(X), assim existem duas possibilidades para $\mathrm{WT}(\mathrm{X})$ :

1. se o $\mathrm{TS}(\mathrm{Ti})<\mathrm{WT}(\mathrm{X})$ isto significa que alguma outra transação, que entrou em execução após Ti, já modificou o objeto X. Assim, a operação Ti deve entrar num estado falho, podendo ir para os estados "Abortado" ou "Ativo", o que significa dizer que no último caso a transação é repetida.

2. se o $T S(T i) \geq W T(X)$ então a operação de leitura é efetuada e o $R T(X)$ deve ser atualizado para o maior $\mathrm{TS}(\mathrm{Tj})$ que executou uma leitura.

- Suponha que Ti execute "write(X)". Neste caso:

1. se $\mathrm{TS}(\mathrm{Ti})<\mathrm{RT}(\mathrm{X})$, alguma transação que chegou após $\mathrm{T}(\mathrm{i})$ possui uma cópia do valor de X, assim a operação "write(X)" deve ser rejeitada e repetida.

2. se $\mathrm{TS}(\mathrm{Ti})<\mathrm{WT}(\mathrm{X})$, isto significa que a transação está tentando gravar um valor não significativo do objeto. Ou seja, alguma outra transação já modificou $\mathrm{X}$ e a transação deve ser reescalonada.

3. caso contrário, a operação de escrita é efetuada e WT(X) deve ser atualizado para o maior $\mathrm{TS}(\mathrm{Tj})$ que efetuou uma escrita.

A figura 4.1 [Korth82] ilustra a compatibilidade entre os modos de operação "Read" (R) e "Write" (W), gerados através da função de compatibilização " $\mathrm{F}$ " entre o conjunto dos modos de operação $M$. Esta função é definida por:

$\mathrm{F}: \mathrm{M} \times \mathrm{M} \longmapsto\{\mathrm{V}, \mathrm{F}\}$, onde

"V" e "F" são valores lógicos "Verdade" e "Falso", respectivamente. Neste caso, diz-se que " $\mathrm{x}$ " é compatível com " $y$ " se $F(x, y)=v$.

Neste protocolo é assegurado que as operações conflitantes sejam executadas na ordem de chegada ao sistema.

A principal razão para se rejeitar uma ação é que ela chegou "tarde demais". Por exemplo, uma leitura é normalmente rejeitada porque o valor que supostamente deveria ser lido está sendo reescrito (modificado ou atualizado).

\subsubsection{Algoritmo Otimista}

Os sistemas de controle de concorrência onde se utilizam métodos de acesso baseados em bloqueio, possuem uma série de desvantagens [Kung81] em relação aos 


\begin{tabular}{l|l|l|} 
& $\mathrm{R}$ & $\mathrm{W}$ \\
\hline $\mathrm{R}$ & $\mathrm{V}$ & $\mathrm{F}$ \\
\hline $\mathrm{W}$ & $\mathrm{F}$ & $\mathrm{F}$ \\
\cline { 2 - 3 }
\end{tabular}

Figura 4.1: Função de Compatibilidade de Operações

protocolos não bloqueantes [Gray78]. Por exemplo, provoca sobrecarga do sistema maior que o processamento seqũencial quando são executados acessos apenas para leitura, ou na ocorrência de falha de alguma transação, esta somente liberará os recursos no seu término.

Para eliminar estes problemas, foi proposto um método "Otimista", assim chamado por acreditar que não ocorram conflitos entre transações [Kung81]. Neste método não se bloqueiam itens de dado, eliminando-se, portanto, problemas de impasse. Para isto, uma transação possui três fases: "Leitura", "Validação" e "Escrita". Assim, uma operação de leitura é sempre bem sucedida (desde que não seja resposta a uma consulta, pois consultas devem ter como resposta dados atualizados e desta maneira exigem que os dados sejam validados). As operações de escrita devem ser restritas, e são constituídas das fases de leitura, validação e possivelmente de escrita. Isto é, durante a fase de leitura são criadas cópias locais para serem modificadas, desta forma, a fase de validação detecta se a escrita não provocará perda de integridade, e neste caso as cópias são tornadas globais.

A figura 4.2 mostra as três fases de uma transação em função do tempo. Notese que este método é eficiente em sistemas onde não ocorram muitas atualizações sobre um mesmo item de dado.

\subsubsection{Algoritmo Baseado em Bloqueio}

Para que se garanta a seqüência das transações, pode-se estabelecer que o acesso aos dados se dê de forma mutuamente exclusiva. Para isto, alguns ambientes 


\begin{tabular}{|l|l|l} 
Leitura & Validação & Escrita
\end{tabular}

Figura 4.2: Fases de uma Transação em Função do Tempo

utilizam o protocolo de bloqueio ("locking protocol"), assegurando que transações não acessem dados temporariamente inconsistentes. Em 1983 Korth fez um estudo a respeito das primitivas de bloqueio, bem como os modos de bloqueio com seus diferentes graus de exclusão, conceituando-se a compatibilidade das funçōes de acesso à Base de Dados [Korth83].

Um importante aspecto a ser considerado num sistema de gerenciamènto de transações é a escolha das unidades de travamento, isto é, os agrupamentos de dados que devem ser atomicamente travados (bloqueados) para que se garanta a consistência dos dados. Por exemplo, os dados podem ser bloqueados por área, arquivo, registro, campo de registro ou informação lógica [Gray78].

A escolha adequada das unidades de travamento refletir-se-á na carga do sistema quando forem analisados aspectos de eficiência de acesso aos dados e grau de concorrência suportado [Pun87]. Pode-se notar que uma granularidade fina das unidades de travamento permite um grau muito grande de concorrência. Por exemplo, se o travamento for feito ao nível de campo de registro, transações curtas tornam o sistema mais eficiente com relação ao grau de concorrência. Contudo, transaçôes que operam sobre um número muito grande de registros provocam uma sobrecarga do sistema, uma vez que um grande número de operações elementares de travamento e destravamento das unidades será necessárjo.

Para estudo deste algoritmo não serão consideradas questões de granularidade, apresentadas no capitulo 3 . Assim, considerar-se-á apenas que o protocolo de bloqueio resulta em um conjunto de ações chamadas "Bloqueio" ("lock") e "Liberação" ("Unlock").

Dos diversos modos que um dado pode ser bloqueado, este trabalho se ecupará apenas de dois deles, que são: o modo compartilhado e o exclusivo.

Estar no modo compartilhado ("Share") significa que duas ou mais transaçôes têm acesso a um determinado dado (ou objeto). Neste caso, nenhuma das transações associadas, pelo modo compartilhado pode efetuar operação de escrita sobre o mesmo. Denota-se por LS(X) o bloqueio compartilhado sobre o item de dado X.

No modo exclusivo ("Exclusive"), apenas uma transação tem acesso ao dado 
e pode fazé-lo tanto para leitura quanto para escrita e o pedido de acesso exclusivo sobre o item de dado $\mathrm{X}$ é denotado por LX(X).

Um item de dado $X$ pode ser liberado para $o$ acesso simplesmente solicitandose a operação liberação ("Unlock") sobre o item de dado X. A operação é denotada por $\mathrm{UN}(\mathrm{X})$.

\section{Algoritmo de Bloqueio em Duas Fases}

Protocolo de Bloqueio em Duas Fases: é proposto um algoritmo onde requer-se que transaçōes sejam construídas para ter duas fases, uma fase de expansão e uma fase de redução [Eswaran76]. Durante a fase de expansão a transação pode requisitar novos bloqueios ("locks" ou chaves). Entretanto, uma vez que uma transação tenha solicitado o bloqueio sobre um item de dado e não o tenha conseguido, esta transação não poderá solicitar novos bloqueios até que consiga este item ou até que seja repetida.

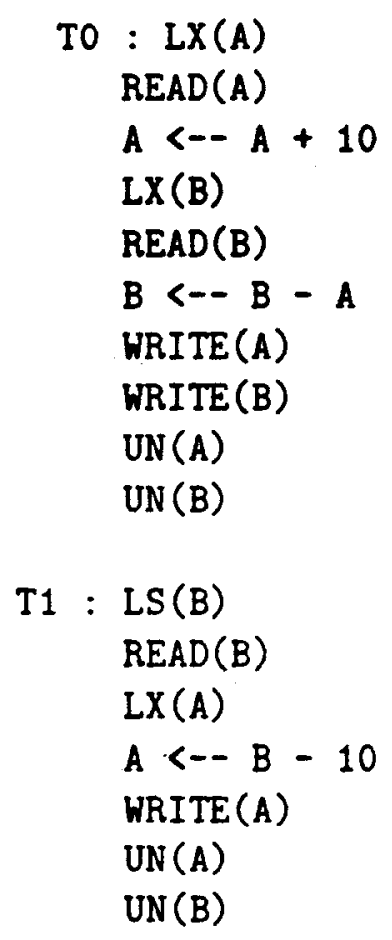

\section{Exemplo 4.1}

No Exemplo 4.1, considerando-se cada uma das transaçôes, não sâo efetuadas operações "LX" ou "LS" após as operações "UN", isto garante as duas fases do protocolo. Contudo, pode ocorrer a execução entrelaçada de T1 e T0, conforme é mostrado no Exemplo 4.2. 


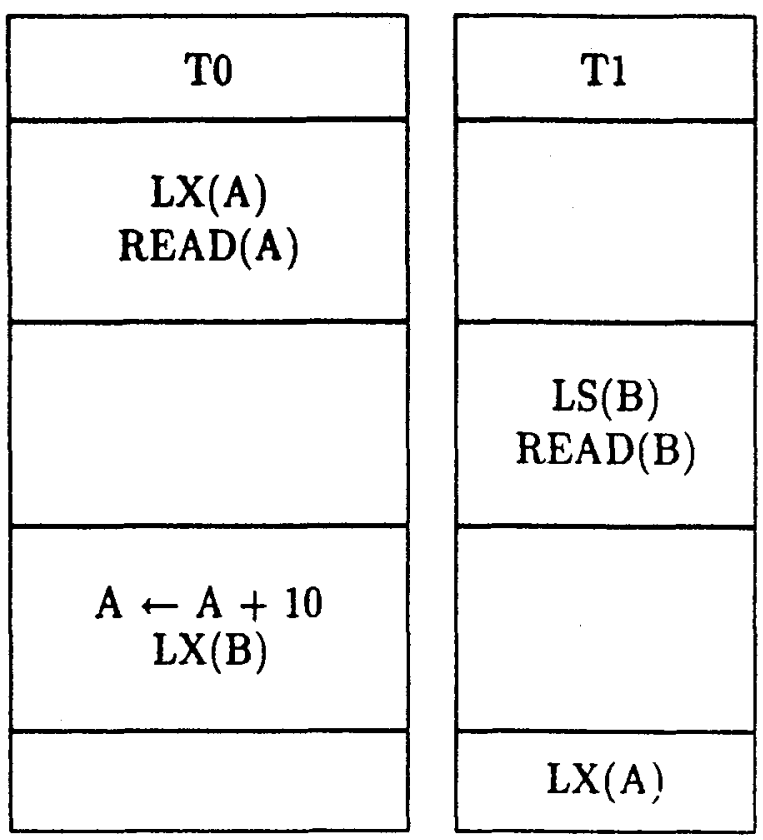

\section{Exemplo 4.2}

Neste ponto o sistema está num impasse ("dead-lock"). Uma vez que a transação T0 não desbloqueia A para que a transação T1 termine com sucesso, e a T1 não libera B para que T0 possa prosseguir.

Se as transações são bem formadas ou seja, existe uma fase de expansão e uma fase de redução, garante-se a consistência do escalonador de transaçôes. Isto é, o efeito da execução entrelaçada dos processos é equivalente ao efeito de alguma execução serial [Eswaran76]. O método de Bloqueio em Duas Fases garante a consistência do escalonador. No entanto, não garante eliminaçâa de impasses, conforme apresentado no exemplo acima.

\subsection{Detecção e Eliminação de Impasses em Bases de Dados}

Os impasses ocorrem tipicamente em Sistemas de Gerenciamento de Transações que se utilizam de métodos de bloqueio sobre ítens de dados e, na maioria das vezes, chega-se à seguinte situaçâo: o programa $\mathrm{A}$ espera para acessar o dado $\mathrm{Y}$ o qual foi bloqueado pelo programa B, enquanto o programa B aguarda para acessar o dado $\mathrm{Z}$ que foi bloqueado pelo programa $\mathrm{A}$. Estes casos de impasses podem ser solucionados pelo sistema. Em alguns sistemas, a cada transaçâo é atribuido um 


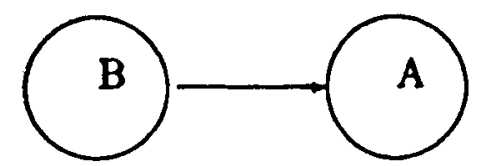

Figura 4.3: Grafo de Espera

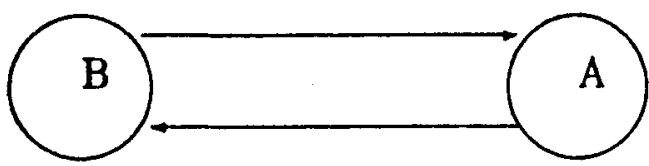

Figura 4.4: Grafo de Espera Apresentando um Impasse

tempo máximo de execução ("timeout"), ao final do qual o processo é abortado.

Para eliminar esta saida forçada, através do sistema operacional, Agrawal e outros, propuseram um algoritmo para solucionar impasses em sistemas que utilizam o protocolo de bloqueio de duas fases, com as seguintes condiçōes: todas as operaçôes de bloqueio são exclusivas e, uma transação somente pode solicitar um bloqueio de cada vez e é suspensa caso não lhe seja permitido o acesso [Agrawal83]. Este método não garante a eliminação de impasses, mas permite que sejam aplicadas técnicas de prevenção e recuperação de impasses [Agrawal83] [Jiang88].

Procura-se detectar os impasses utilizando-se para isto um grafo orientado, onde os nós representam transações e os arcos indicam que uma determinada transação aguarda que outra transação libere um determinado item de dado. Por exemplo, a figura 4.3 apresenta o estado onde a transação " $B$ " aguarda pela liberação de um item de dado bloqueado pela transação " $A$ ". Neste caso, detecta-se um impasse quando se tenta inserir um novo nó no grafo e este gera um ciclo. Por exemplo, caso a transação "A" solicite um item de dado bloqueado pela transação " $\mathrm{B}$ ", conforme mostra a figura 4.4 .

No caso em que o sistema detecta a possibilidade de impasse, o sistema de gerenciamento de transações pode atuar de duas formas:

1. Eliminar impasses. Isto é, eleger tantas transações quantas forem necessárias e passá-las para o estado falho,

2. Detectar com antecedência a ocorrência do impasse, impedindo que a transação que provocaria tal situação continue no estado ativo: passando-se para o estado falho. 


\subsection{Um Sistema de Controle de Concorrência Orientado a Transações}

O sistema ROAM ("Recovery Oriented Access Method") é usado pela maioria dos Sistemas de Gerenciamento de Base de Dados comerciais orientados a transações, podendo também ser utilizado como gerenciador de arquivos, como por exemplo no Sistema Operacional PREMIOS [Stonebraker85]. Para garantir a seqüência, os bloqueios são mantidos até o fim da transação e páginas de disco são usadas como grânulos dos bloqueios. As transações que fazem apenas leitura, não bloqueiam e nunca interferem nas transações de atualização. Seus acessos são feitos utilizandose multiplas versões, de maneira similar ao apresentado por Chan [Chan82]. As mesmas versões são usadas para desfazer, com êxito, as operações efetuadas por transações que tenham falhado (fazer o "Rollback" das transaçōes).

Quando um usuário do ROAM, o qual não tenha declarado o tipo de acesso a base ("exclusivo" para escrita, ou "Compartilhado" para apenas leitura) se submete a uma operação de leitura ("read") ou escrita ("write"), o ROAM adquire, transparentemente, um bloqueio para leitura ou para escrita sobre a página do disco. Se o bloqueio não pode ser garantido, o ROAM enfilera os requerentes, a menos que ele detecte a possibilidade de haver um impasse. Para garantir que o disco fique intacto após alguma falha do sistema ou para que um usuário possa abortar sua transação, o sistema cria para isto uma pré-imagem de cada registro modificado da página de disco, no arquivo de histórico. E mais, cria também uma pós-imagem, que é usada para dar prosseguimento a partir de um ponto de verificaçâo de integridade ("checkpoint") no caso de falha onde dados sejam perdidos. Quando uma transaçâo atinge o estado "compromissado", um "Registro de Compromisso" é escrito no arquivo de histórico e todas as escritas pendentes são completadas, antes que o controle retorne ao usuário.

\subsection{Conclusão}

Neste capítulo foram apresentados algoritmos de acesso a base de dados, onde, são apresentados os protocolos não bloqueantes e os protocolos baseados em bloqueio.

Os protocolos não bloqueantes ganham em eficiência dos protocolos bloqueantes quando o número de conflito de acesso entre transaçóes é pequeno, ou o escalonador é estritamente serial, ou em sistemas onde operaçôes apenas de leitura são efetuadas com freqüencia muito maior que as operações de atualizaçào ou escrita.

Foi mostrado que o impasse nos SGBDs advêm dos algoritmos complexos ba- 
seados em bloqueio e a sincronização de acesso aos dados pode provocar danos ao sistema. No entanto, sistemas comerciais utilizam-se de protocolos de acesso baseados em bloqueio, conforme apresentado na seção 4.4, e possiveis impasses da base podem ser detectados e eliminados [Gray78] [Jiang88]. 


\section{Capítulo 5}

\section{Modelo de Representação de Objetos}

Neste capítulo introduz-se o Modelo de Representação de Objetos (MRO), bem como o atual estado em que se encontra a implementação do Gerenciador de Objetos (GEO) [Traina Jr.91] em desenvolvimento no ICMSC, que é a parte central de um SGBD apoiado no MRO [Traina Jr.86] [Traina Jr.88].

\subsection{Apresentação do modelo}

O MRO foi desenvolvido para dar suporte a aplicações nas quais os modelos tradicionais, apresentados no capítulo 2, tornavam-se deficientes devido ao baixo grau de representação semântica apresentado por tais modelos [Traina Jr.86].

No MRO a representaçâo dos entes do mundo real se faz através da modelagem destes entes, juntamente com suas associaçôes. Para tal, considera-se que quaisquer que sejam os entes que se deseje modelar, esses serão objetos. Assim, utiliza-se um Dígrafo (grafo orientado) Rotulado (cada nó do dígrafo possui um identificador) Ponderado (os arcos têm pesos associados) Categorizado (classificação dos nós em diferentes categorias) para modelar objetos, os quais são identificados univocamente pelo rótulo (ou nome do objeto) e podem ser agrupados em categorias (analogamente ao conceito de entidade no ME-R). Este agrupamento por categorias se dá, no MRO, pela associação de um "TIPO" para cada objeto. Com isto, coloca-se a categorização apenas como mais um atributo do objeto. $\mathrm{O}$ mesmo é feito em relação aos arcos ponderados, agrupando-os num conjunto de relacionamentos através de seus respectivos "TIPOS".

Cabe salientar que neste modelo a chave de acesso a um objeto não é parte 
do conjunto de atributos do objeto, mas sim, um identificador, único para cada objeto (o nome do objeto, ou código do objeto). 0 modelo também permite que objetos sejam identificados através de seus relacionamentos e sempre que há um relacionamento entre dois objetos, há o relacionamento oposto, que é caracterizado pela orientação dada às arestas do digrafo. Para isto o MRO explora a características dos grafos orientados, onde, dada uma aresta, esta associa univocamente dois nós. Desta forma, embute-se no modelo a capacidade semântica de um relacionamento identificar um objeto, o que nâo ocorre nos demais modelos aqui considerados.

Para especificação do esquema de dados foi criado um Diagrama de Representação de Objetos - DRO - onde se utilizam de recursos , circunferências e arcos de circunferências, para representar os tipos de objetos e tipos de relacionamentos. Quando se quer representar instâncias da base, deve-se utilizar um Diagrama de Representação de Instâncias - DRI - . As figuras 5.1 e 5.2 apresentam respectivamente o DRO e o DRI da figura 2.6, exemplificando uma transformação do Modelo Relacional para o MRO.

\subsection{Abrangência dos Identificadores de Objetos}

Para evitar a restrição de que nomes de diferentes objetos tivessem que ser diferentes, estabeleceu-se que os identificadores de objetos fossem válidos dentro de um determinado escopo, ao qual denominou-se contexto. Assim, quando se cria o contexto de uma aplicação, estabelece-se o conjunto de objetos para o qual a aplicação é válida. A este sub-conjunto denomina-se colônia, e diz-se que uma colônia é "habitada" por objetos. E o modelo permite que se criem hierarquias de abstração [Smith77a] [Smith77b]. Ou seja, quando se tem uma visão macroscópica do sistema, este apresenta um pequeno grau de detalhe. Contudo, um objeto pode constringir uma colônia, de forma que ao se colocar este objeto em consideração, este se apresente de forma mais detalhada [Traina Jr.88].

\subsection{Meta-base de Dados}

No GEO, pode-se criar uma separação lógica da base em duas partes, a base onde se armazenam instâncjas de objetos (área de trabalho dos usuários) e a metabase que armazena o esquema. Para isto, é usada uma estrutura de arquivos lógicos que armazenam dados estruturalmente semelhantes ao invés de armazenarem dados relativos a um determinado esquema. Para a modelagem do $\mathrm{MRO}$ asssume-se que o mesmo é composto por "TIPOS" de: ENTIDADES, OBJETOS, RELACIONAMENTOS, ATRIBUTOS COLÔNIAS e outros, que descrevem o Meta-Esquema de 
dados para o modelo e cada arquivo lógico contém um Meta-Tipo de objeto. A figura 5.3 mostra o Meta-Esquema do MRO, onde existem os seguintes meta-tipos:

- Identificadores: correspondem a todos os identificadores de objetos da base de dados.

- Objetos: correspondem a todas as informaçóes de cada objeto da base de dados.

- Colônias: armazenam conjuntos de tipos de objetos que habitam em cada classe.

- Relacionamentos: correspondem a todos os relacionamentos existentes na base.

- Atributos: armazenam o conjunto de cada objeto ou relacionamento da base de dados.

Atributos das várias características: existirá um Tipo de Atributo específico para cada característica de atributo (Propriedade, Regra, Posição, Comentário, e outros).

Neste sistema, a Meta-Base armazena informações léxicas, sintáticas e semânticas que constituem o Esquema de Dados das informações manipuladas pelo SGBD. Ou seja, informações que especificam como os dados se relacionam e qual seu significado para o SGBD.

\subsubsection{Versões}

Normalmente, projetos de engenharia são elaborados de forma que se consegue distiguir determinadas fases de desenvolvimento do projeto. Por exemplo, quando se deseja projetar uma casa, a planta de uma determinada casa especificada por um engenheiro pode permanecer inalterada, e o projetista desta, passa a considere-lá uma versão. Isto significa que esta planta não sofrerá mais alterações, contudo, pode-se acrescentar novas informaçôes sobre a mesma criando-se alternativas para o projeto final. Estas alternativas podem se tornar versões a partir do momento que o(s) projetita(s) determinam. Em SGDEs é necessário que se estabeleça um controle, para que se identifique sobre qual versão um determinada usuário está atuando num dado instante.

Um modelo de representação de objetos é apresentado em [Katz84], no qual é sugerido que a cada abstração de um novo objeto deve-se criar uma versão para aquele novo objeto. Desta forma o usuário deve informar ao sistema qual versâo $\mathrm{e}$ que objeto deseja acessar. 


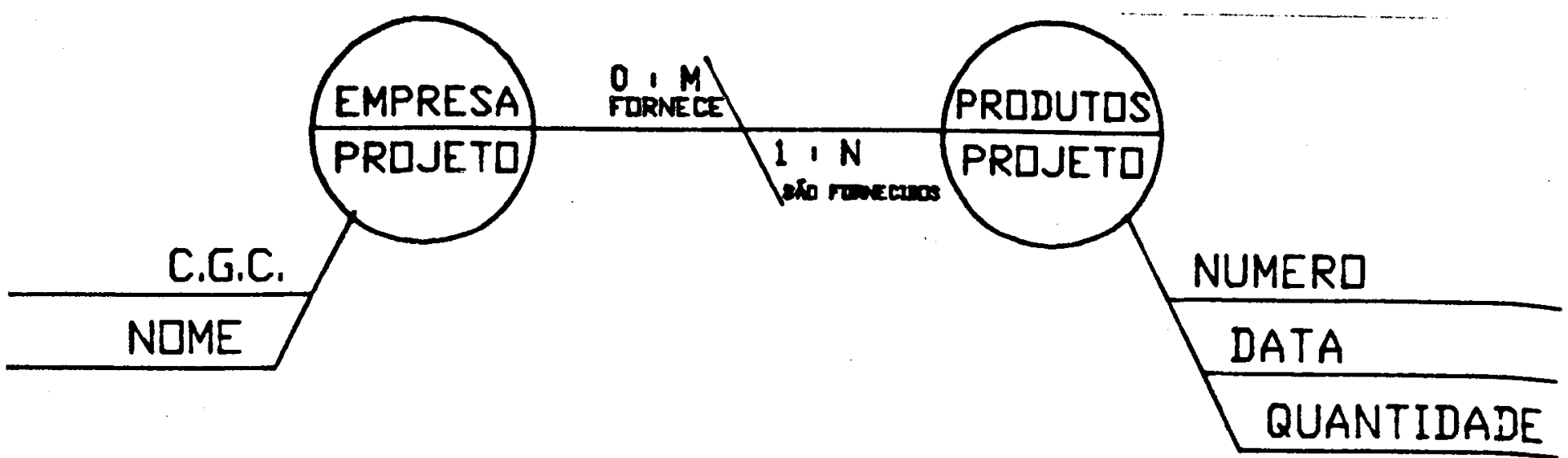

Figura 5.1: DRO da figura 2.6

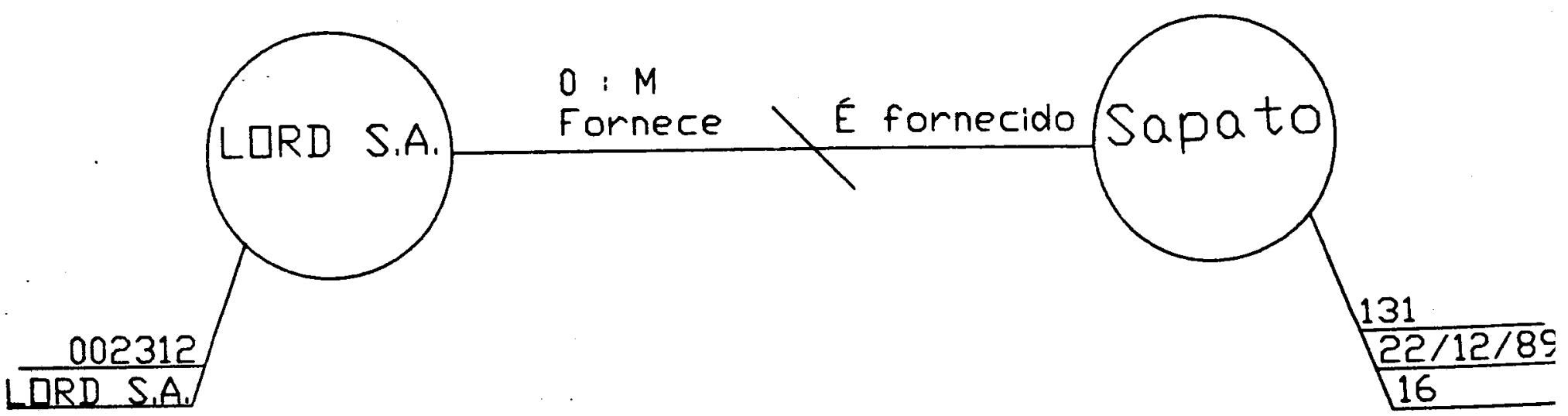

Figura 5.2: DRI da figura 2.6 


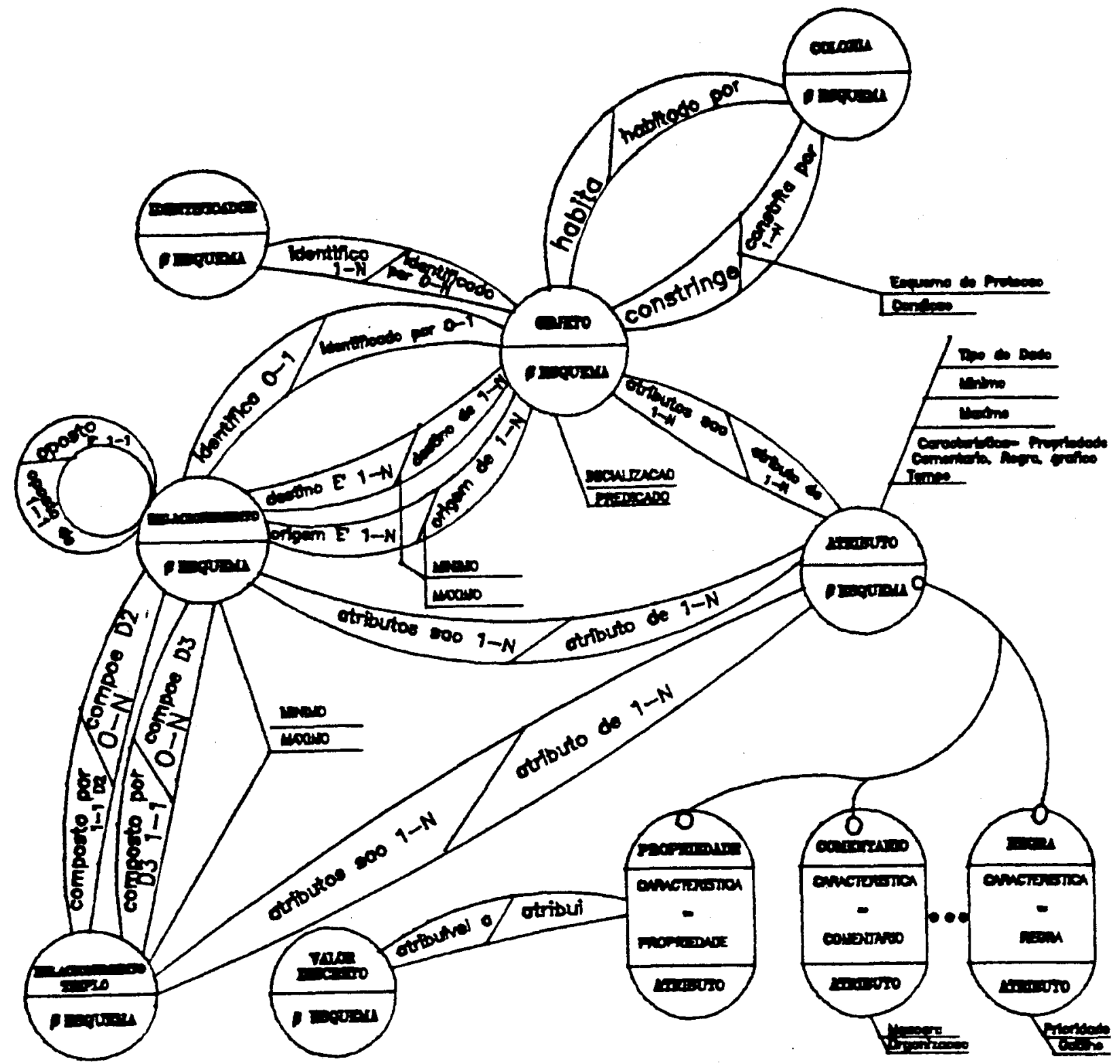

Figura 5.3: Meta-Esquema do MRO 
No GEO a instância de um novo objeto pode criar uma versão de projeto e somente serão chamados de versões aqueles projetos que não devam ser modificados, caso contrário, fica caracterizado uma variação no projeto. Assim, uma variante pode se tornar uma versão de projeto ou um projeto em desenvolvimento. Devido à característica do MRO estar modelado na meta-base do GEO, a criação de versões de projetos se dá no GEO através da módificação da meta-base.

\subsection{Conclusão}

O MRO foi proposto com o objetivo de se criar um modelo de dados para aplicações de projetos em engenharia. Nesses ambientes, espera-se que o modelo permita a representação de tipos de dados complexos. Por exemplo, representaçâo de padrões gráficos, projetos de circuitos elétricos, eletrônicos, hidraulicos, e outros.

O GEO é um sistema de gerenciamento de bases de dados que suporta os objetos básicos do MRO. Através do conceito de meta-base, o GEO pode operar sobre estes objetos em concordância com o seu meta-esquema, o qual é modelado no MRO e está armazenado na meta-base.

A partir das premissas apresentadas nos dois últimos parágrafos, será proposto no capítulo 6 um SGBD que utilize as funções básicas do GEO para manipulação de objetos, acrescentando-se os módulo de controle de concorrência e comunicação com os aplicativos. 


\section{Capítulo 6}

\section{Projeto de uma Versão Multiprogramada do GEO}

O GEO (Gerenciador de Objetos) é um Sistema de Gerenciamento de Base de Dados implementado em microcomputadores compatíveis com a linha IBM-PC/XT. Este sistema suporta o desenvolvimento de aplicações utilizando bases de dados orjentadas a objetos, ou seja, aplicações para as quais os modelos de dados apresentados no capítulo 2 não são adequados. Em ambientes em que modelos de dados orientados a objetos são adequados, pode-se utilizar o Modelo de Representação de Objetos - MRO. Assim, o GEO foi modelado no MRO e desenvolvido para dar suporte a aplicações que o utilizem.

O objetivo deste trabalho é o de apresentar o projeto de uma versão do GEO que suporte acesso multi-usuário concorrente. Para isto, foi proposto que:

1. A versão mono-usuário do GEO, já implementada, fosse estudada e que se efetuassem as devidas modificações para que o sistema pudesse ser migrado para um ambiente multiprogramado.

2. Se reconhecessem as características do sistema operacional, que pudessem ser exploradas para a implementação da versão do GEO multiprogramado.

3. Fossem descritas e implementadas as primitivas que fariam a interface servidor/cliente do GEO.

4. Se implementasse o sistema de gerenciamento de transaçôes.

A implementação do GEO, versão mono-usuário, pode ser apresentada através de três módulos lógicos, conforme ilustra a figura 6.1 .

Entenda-se na figura 6.1 que o módulo: 


\begin{tabular}{|c|c|c|}
\hline $\begin{array}{c}\text { Nível } \\
\text { Semântico }\end{array}$ & $\begin{array}{c}\text { Manipulação de } \\
\text { Objetos Lógicos }\end{array}$ & $\begin{array}{c}\text { Gerenciador de } \\
\text { Objetos Físicos }\end{array}$ \\
\hline
\end{tabular}

Figura 6.1: Módulos Lógicos do GEO

Sistema de Comunicação entre Processos

Sistema de Gerenciamento de Transações

Nivel Semântico

Manipulaçãa Lógica de Objetos

Sistema de Gerenciamento de Memória

Manipulação de Registros Físicos

Figura 6.2: Módulos Lógicos do GEO Multi-usuário 
- Nível Semântico é composto por um conjunto de primitivas, de manipulação da base de dados, que estabelece uma interface com aplicativos e que, portanto, não deve ser modificado.

- Manipulação de Objetos Lógicos suporta as primitivas do Nivel Semântico, e é capaz de localizar os registros lógicos nos quais as ações solicitadas, pelos usuários, serão aplicadas.

- Gerenciador de Objetos Físicos é responsável por estabelecer um eficiente sistema de acesso aos Registros Físicos (Blocos de Dados armazenados em disco). Neste módulo são implementados algoritmos de controle de memória "cache", para acesso a disco, que permitem um melhor desempenho do SGBD, quando o parâmetro de análise é o tempo de acesso ao registro físico gasto pelo sistema operacional.

$\mathrm{Da}$ análise dos módulos anteriormente apresentados, concluju-se que deveriam ser efetuadas algumas modificações no módulo Gerenciador de Objetos Físicos, a fim de permitir concorrência sobre alguns itens de dados e que se acrescentassem dois outros módulos, que são:

1. Comunicação, que tem por finalidade estabelecer a comunicação entre processos através do sistema operacional.

2. Sistema de Gerenciamento de Transações (SGT), que tem por finalidade garantir a atomicidade das transações e estabelecer o protocolo de acesso aos itens de dados armazenados na base.

A figura 6.2 apresenta a forma lógica como os novos módulo são inseridos na versão GEO mono-usuário, para torná-la uma versão multi-programada.

A figura 6.3 ilustra a forma lógica como inúmeros processos deverâo acessar diversos gerenciadores. É importante notar que existe um processo ativo (chamado "gerenciador") que controla o acesso a um determinado arquivo (chamado "base"). Desta forma os aplicativos estarão concorrendo no sistema operacional pelo acesso a um gerenciador. Os usuários têm disponível um conjunto de primitivas de manipulação da base [Traina Jr.91b], as quais passam por um processo de empacotamento (transparente ao usuário), e são enviadas ao GEO através de primitivas de comunicação entre processos que são suportadas pelo sistema operacional.

Note-se que na representação lógica do sistema de troca de mensagens, ilustrado na figura 6.3 , a versão GEO multi-usuário pode ser desenvolvida numa única máquina, desde que este equipamento disponha de um sistema operacional multi-programado. Isto por que, podem-se tornar clientes e servidor processos concorrentes no sistema operacional. 


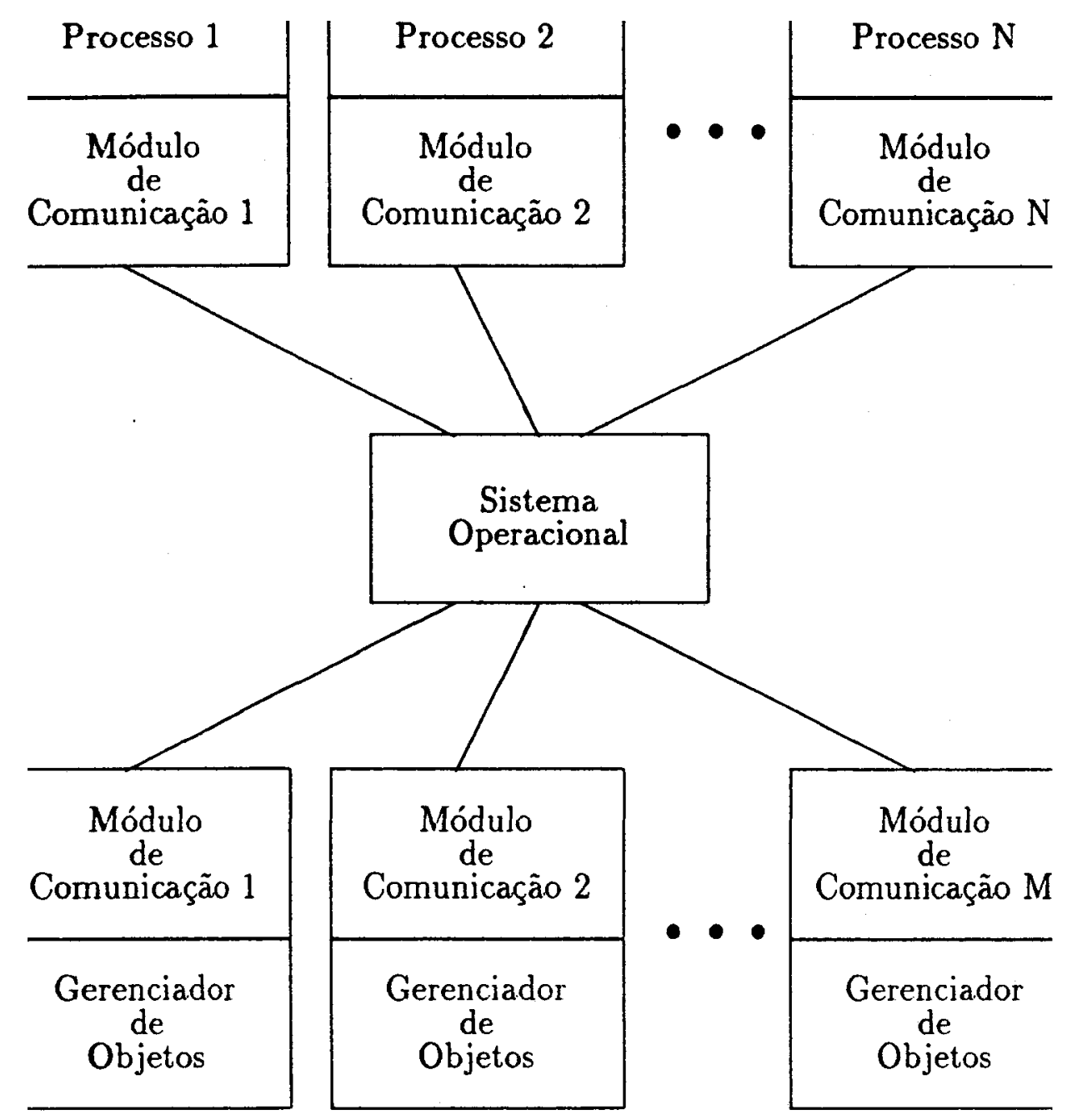

Figura 6.3: Representação do Sistema de Comunicação do GEO 
Com a disponibilidade de equipamentos Sun modelo Sparc I, decidiu-se que a versão do GEO existente fosse migrada para este equipamento. Esta decisão foi tomada levando-se em consideração as características que são oferecidas pelo ambiente de desenvolvimento SunOS. Tais características, necessárias para o desenvolvimento desta dissertação, foram apresentadas no item 2.1 deste capítulo.

A escolha do ambiente de desenvolvimento (sistema operacional multiprogramado) foi tomada levando-se em consideração a disponibilidade de equipamentos. Isto implicou diretamente na necessidade do sistema operacional suportar comunicação entre processos. Note-se que esta versão do GEO, com as devidas modificaçôes na interface de comunicação pode ser utilizada em redes de computadores. Contudo, a finalidade deste trabalho é tornar o GEO um sistema de gerenciamento de base de dados multi-programado. Assim, a possibilidade de o GEO suportar, também, chamadas de processos remotos ("Remote Procedure Calls") foram estudadas, mas, apenas para que o sistema seja suficientemente flexivel e não tenha que sofrer profundas alterações, caso se deseje especificar uma interface de comunicação mais aprimorada. 


\subsection{Estrutura Lógica do Sistema GEO}

No sub-item 2.2.2 do capitulo 2 caracterizou-se quatro grandes grupos de usuários, segundo o mecanismo de interação destes com a base. Para o objetivo desta dissertação esses grupos foram reorganizados, uma vez que é necessário que se destingua apenas o grupo de administradores da base de dados (ADBs) dos demais grupos de usuários (projetistas). A figura 6.4 mostra a estrutura lógica do GEO considerando a diferenciação estabelecida a priori.

O módulo 1 (Interfacear Base) é composto por um conjunto de ferramentas que permitem ao Administrador da Base de Dados (ABD) ter acesso às primitivas de controle do sistema. Cabe notar que o ABD possui acesso mais amplo que o citado acima. Mas, para esta dissertaçâo são consideradas apenas as ferramentas que dizem respeito ao controle das ações do sistema de gerenciamento de transações e ao Sistema de Controle de Concorrência.

O módulo 2 (Processar Ações) é composto por um conjunto de primitivas que estabelecem as açóes que os aplicativos dos projetistas podem solicitar. Note-se que o conjunto de primitivas de acesso à base, disponiveis para os projetistas, não são executadas pelo processo do usuário, mas sim pelo Sistema de Gerenciamento da Base de Dados. Isto significa que todas as ações são codificadas e transmitidas para o processo que estabelece o protocolo de acesso à base.

O módulo 3 (Gerenciar Açôes) é composto pelas primitivas que compõe o sistema de gerenciamento da base de dados. Este aglutina as funçóes dos Sistemas de Gerenciamento de Transações, Sistema de Controle de Concorrência, Interface com Aplicativos, Manipulação de Objetos Lógicos e o Sistema de Gerenciamento de Memória.

O módulo Gerenciar Ações, da figura 6.4, corresponde a um gerenciador de uma base de dados ("Base MRO"). Nessa figura os componentes "Fila de Entrada" e "Fila de Saída" são os elos de comunicação Aplicativos/Gerenciadores (Clientes/Servidores, respectivamente). O componente "Memória Estável" é um arquivo intermediário, utilizado para que se consiga garantir a atomicidade das transações, e será melhor explicado no item 6.3 deste capítulo.

As tabelas 6.1 e 6.2 contêm as descriçōes dos dados que aparecem nos fluxos apresentados nos diagramas de fluxo de dados das figuras 6.4 e 6.5 , respectivamente.

As ferramentas do módulo 1 podem ser melhor especificadas pela "explosão" do mesmo módulo conforme é apresentado na figura 6.5 .

O módulo 1.1 (Selecionar Operaçâo) estabelece a interface entre as ferramentas e o $\mathrm{ABD}$. Através de sub-comandos o $\mathrm{ABD}$ pode agir sobre o sistema. 


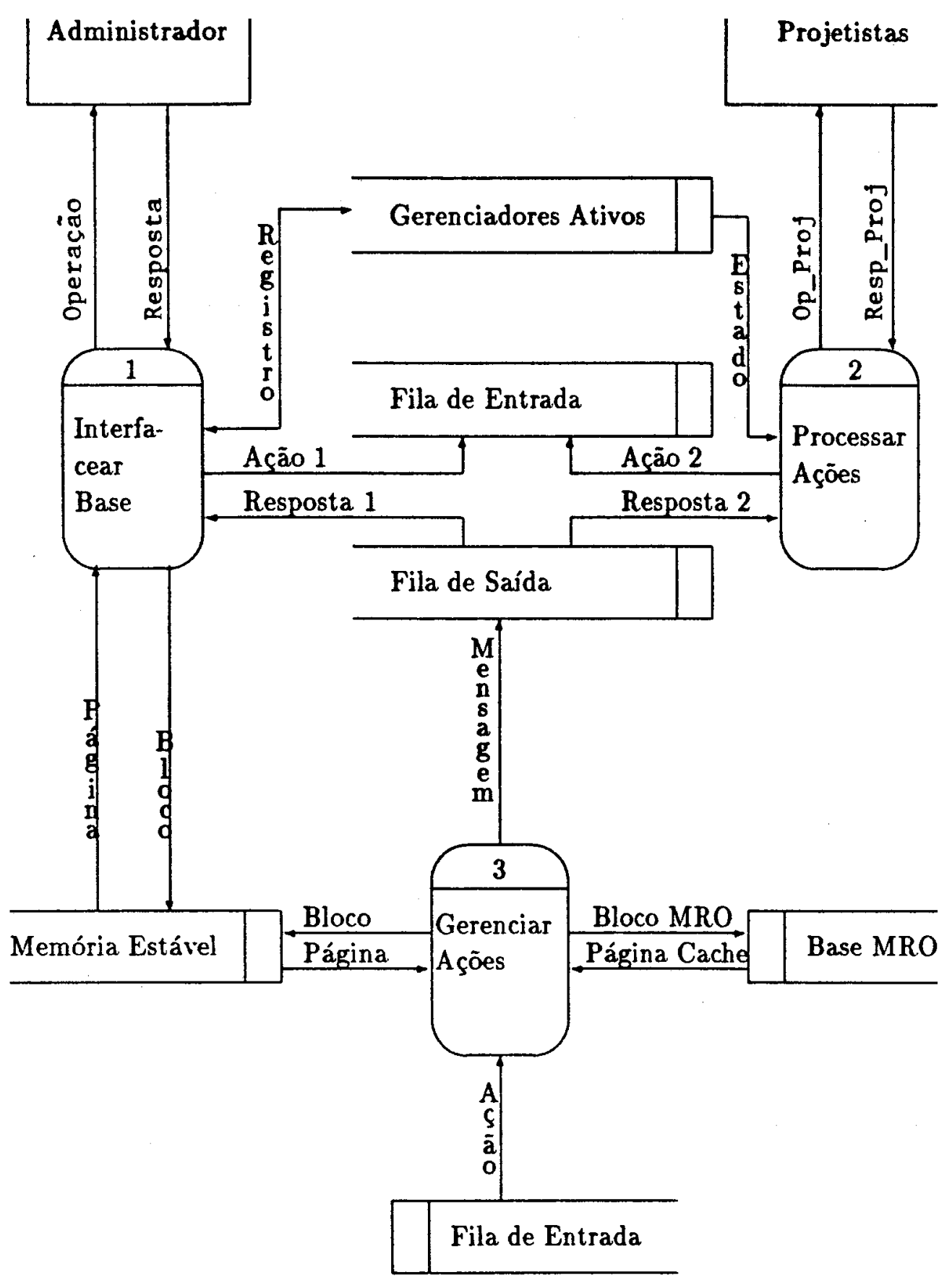

Figura 6.4: Diagrama de Fluxo de Dados do Sistema 
Tabela 6.1: DESCRIÇÃO DOS DADOS DA FIGURA 6.4

\begin{tabular}{|c|c|c|}
\hline Dado & Significado & Tipo \\
\hline Operação & $\begin{array}{l}\text { Solicita que seja executada uma ferramenta do } \\
\text { ABD }\end{array}$ & Inteiro \\
\hline Resposta & Resposta a uma solicitação feita pelo $\mathrm{ABD}$ & Cadeia \\
\hline Opr_Proj & Operação solicitada por um projetista & Inteiro \\
\hline Resp_Proj & $\begin{array}{l}\text { Resposta a operação solicitada por um proje- } \\
\text { tista. Pode ser o código de erro da função ou os } \\
\text { parâmetros de retorno da mensagem }\end{array}$ & Cadeia \\
\hline Ação 1 & Açấo solicitada do gerenciador pelo ABD & Cadeia \\
\hline Ação 2 & $\begin{array}{l}\text { Ação solicitada ao Gerenciador pelo projetista. } \\
\text { Esta ação é colocada na fita de mensagem do ge- } \\
\text { renciador }\end{array}$ & Cadeia \\
\hline Respostal & $\begin{array}{l}\text { Mensagem Retornada do Gerenciador para a in- } \\
\text { terface }\end{array}$ & Cadeia \\
\hline Resposta 2 & $\begin{array}{l}\text { Mensagem Retornada do Gerenciador para o pro- } \\
\text { jetista }\end{array}$ & Cadeia \\
\hline Mensagem & Resposta do gerenciador à uma ação & Cadeia \\
\hline Bloco & $\begin{array}{l}\text { Corresponde a uma página do cache mais os iden- } \\
\text { tificadores de bloco na base MRO e Transação } \\
\text { do SGT. Deve ser gravado quando finaliza uma } \\
\text { transaçâo ou falta espaço no "cache" }\end{array}$ & MRORegovf \\
\hline Página & $\begin{array}{l}\text { Corresponde a um bloco da memória estável e é } \\
\text { lido quando a informação deve retornar ao cache } \\
\text { ou quando a base for atualizada. }\end{array}$ & MRORegovf \\
\hline Bloco MRO & $\begin{array}{l}\text { Corresponde a um bloco físico de uma base MRO. } \\
\text { Somente é escrito quando a transação está "com- } \\
\text { promissada". }\end{array}$ & Cadeia \\
\hline Página Cache & $\begin{array}{l}\text { Um bloco do arquivo MRO que foi solicitado e não } \\
\text { está no cache. }\end{array}$ & Cadeia \\
\hline
\end{tabular}




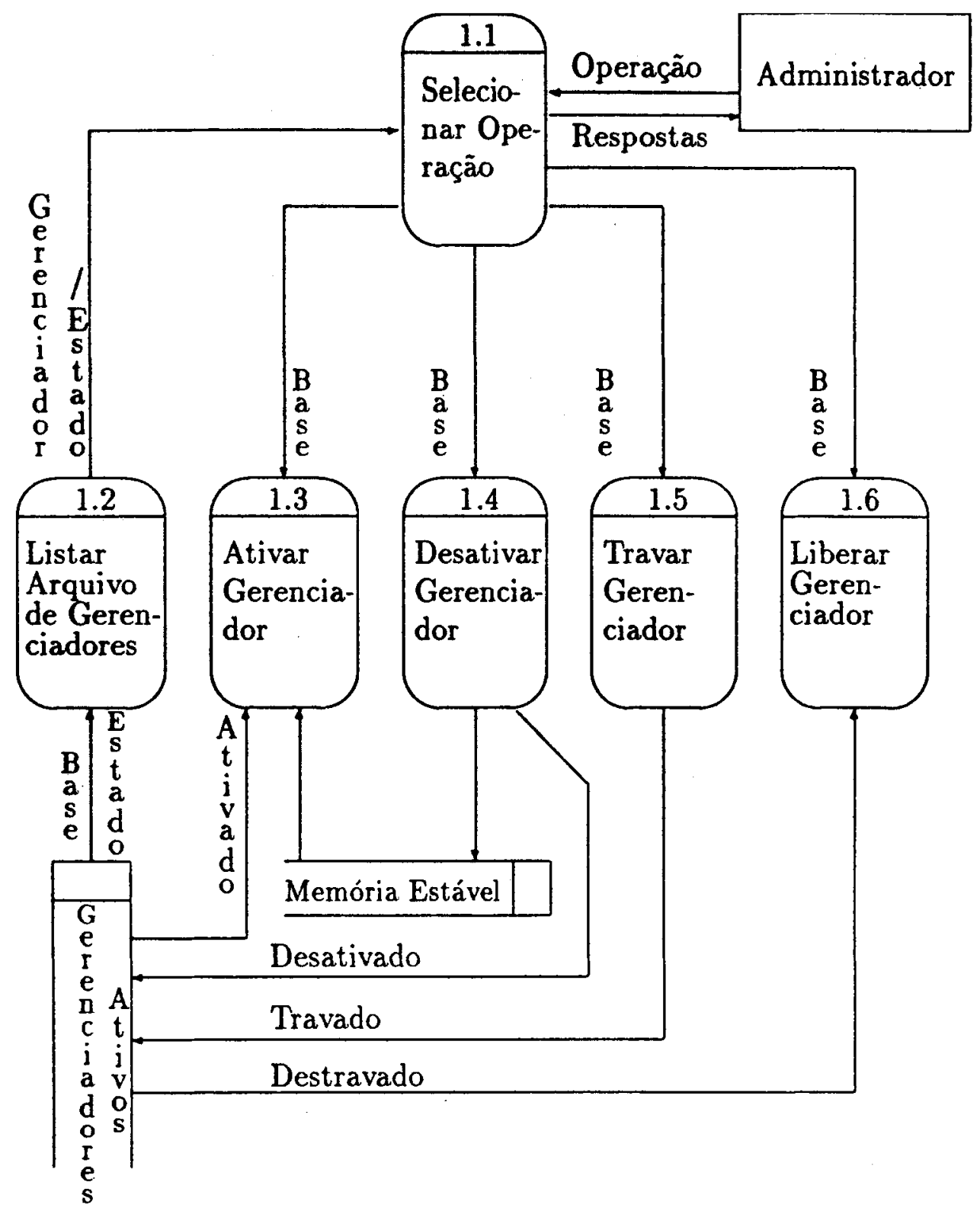

Figura 6.5: Diagrama de Fluxo de Dados das Ferramentas do ABD 
Tabela 6.2: DESCRIÇÃO DE DADOS DA FIGURA 6.5

\begin{tabular}{|l|l|l|}
\hline \hline Dado & Significado & Tipo \\
\hline \hline Gerenciador & Código do gerenciador contido no arquivo & Inteiro \\
\hline Estado & Estado em que se encontra o gerenciador & Inteiro \\
\hline Base1 & Nome do arquivo que corresponde à base a ser ativada & Cadeia \\
\hline Base2 & Nome do arquivo que corresponde à base a ser desativada & Cadeia \\
\hline Base3 & $\begin{array}{l}\text { Nome do arquivo que corresponde ao gerenciador a ser tra- } \\
\text { ado }\end{array}$ & Cadeia \\
\hline Base4 & $\begin{array}{l}\text { Nome do arquivo que corresponde ao gerenciador a ser li- } \\
\text { berado }\end{array}$ & Cadeia \\
\hline Registro & $\begin{array}{l}\text { Ao ser eliminada uma base, seu registro associado no ar- } \\
\text { quivo de gerenciadores, deve ser eliminado }\end{array}$ & REGGEO \\
\hline Ativado & $\begin{array}{l}\text { Atualiza ou cria um novo registro que informa a existência } \\
\text { de um gerenciador ativo }\end{array}$ & REGGEO \\
\hline Desativado & $\begin{array}{l}\text { Modifica o registro correspondente ao gerenciador infor- } \\
\text { mando ao sistema que o gerenciador foi desativado }\end{array}$ & REGGEO \\
\hline
\end{tabular}

de controle de transações.

O módulo 1.2 (listar Gerenciadores Ativos) informa ao ABD todos os gerenciadores do sistema e seu estado de atividade.

O módulo 1.3 (Ativar Gerenciador) este módulo abre uma base GEO e permanece ativo até que a base seja finalizada (desativada).

O módulo 1.4 (Desativar Gerenciador) opera sobre o arquivo de gerenciadores ativos e informa aos processos que se comunicam com o gerenciador que $o$ mesmo será desativado. $\mathrm{O}$ anexo 3 apresenta a primitiva de desativação que permite ao ABD determinar se a desativação é normal ou forçada e se é forçada se há ou não perda das transações pendentes.

O módulo 1.5 (Travar Gerenciador) envia uma mensagem ao SGT para que apenas as transaçóes do ABD sejam efetuadas.

O módulo 1.6 (liberar Gerenciador) envia uma mensagem ao SGT para que efetue ações de todas as transaçôes ativas no sistema. 


\subsection{Modificações Efetuadas Sobre a Versão Mo- no-usuário}

Para que se entendam as modificações, efetuadas na versão mono-usuário do GEO, é necessário que se compreenda os mecanismos de acesso aos registros físicos da base. Note-se que o "Nível Semântico", apresentado na figura 6.2, garante aos usuários acesso exclusivo às colônias. No GEO, isto não significa, necessariamente, que os objetos são acessados de forma exclusiva, uma vez que, por exemplo, a eliminação de um relacionamento afeta o relacionamento oposto e, possivelmente, os objetos envolvidos, nos casos onde o relacionamento entre ambos é do tipo fraco.

Quando um usuário solicita alguma operação sobre a base, o SGT pode verificar se a ação solicitada faz parte de alguma transação ativa no GEO; contudo, não pode detectar a semântica da ação. Note-se que as operações de atualização, criação ou consulta a objetos da base têm embutidas operações de leitura e escrita. Isto levou à criação de dois niveis de controle de acesso, sendo o primeiro nível formado pelos módulos SGT e Nível Semântico e o segundo foi embutido no Sistema de Gerenciamento de Memória (SGM). Assim, mesmo que as ações façam parte de transações, o SGM pode detectar se as operações (de leitura ou escrita sobre o bloco) podem ser efetuadas pela transação.

As sub-seç̧ões a seguir apresentam as modificações efetuadas sobre o Sistema de Gerenciamento de Memória, e apresentam o projeto lógico dos sistemas de Gerenciamento de Transações e Comunicação do GEO, respectivamente.

\subsubsection{O Sistema de Gerenciamento de Memória do GEO}

O objetivo do SGM é fazer com que o acesso aos registros da base seja efetuado de forma eficiente, a fim de minimizar o tempo de acesso aos elementos solicitados pelo usuário (ou aplicativo). Para isto, foi criado um sistema de memória "cache" para acesso a disco, onde cada registro desta memória tem tamanho, em bytes, exatamente igual ao tamanho de um bloco de dados manipulado pelo sistema de gerenciamento de arquivos do sistema operacional. Para controle da memória "cache" o SGM utiliza uma técnica que permite detectar, entre os registros residentes no "cache", quais os menos utilizados e, dentre os menos utilizados, qual está a mais tempo sem ser acessado. Através deste critério, o SGM elege qual registro deve sair da memória "cache" quando é necessário que um registro seja trazido do disco para a memória principal.

Além das estruturas de dados implementadas para construir um mecanismo eficiente de acesso aos registros lógicos do arquivo, a memória "cache" tem associada duas outras estruturas de dados que permitem detectar o tipo de operação efetuada 
Páginas do Cache Operação efetuada

\begin{tabular}{|c|c|c|}
\hline & Dado 1 & Leitura \\
\hline 1 & Dado 2 & Leitura \\
\hline \multirow[t]{3}{*}{2} & Dado 3 & Escrita \\
\hline & 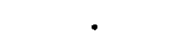 & . \\
\hline & . & . \\
\hline $\mathrm{N}$ & Dado N & Escrita \\
\hline
\end{tabular}

Figura 6.6: Controle do Tijpo de Operação Efetuada sobre a Página

sobre os registros e o endereço lógico do registro no arquivo da base.

A figura 6.6 ilustra a estrutura de dados que controla o tipo de acesso efetuado sobre as páginas do "cache" (Leitura/Escrita). Esta informação aumenta a eficiência do sistema, pois permite que apenas as páginas atualizadas pelos usuários sejam copiadas para o disco quando eleitas para sair do "cache". As informaçôes contidas na figura 6.6 são, por exemplo: leram-se nas páginas $0 \mathrm{e} 1$ do "cache" e escreveram-se páginas 2 e $\mathrm{N}$.

A figura 6.7 apresenta o diagrama hierárquico das funções que integram o SGM da versão mono-usuário do GEO. Verifica-se no sistema a exitência de duas primitivas de acesso à base, uma para leitura e outra para escrita de um registro. Para aumentar a eficiência do SGM, as operações de esrita no arquivo da base são atrasadas. Isto significa dizer que um registro que tenha sido atualizado por uma ação, somente será transcrito para o arquivo quando for eleito para sair do "cache", isto é, quando estiver a mais tempo sem ser acessado e for o menos utilizado.

Este sistema de gerenciamento de memória, da maneira como foi implementado para a versão GEO que executa em sistemas mono-programados, torna-se inadequado para utilização em ambientes onde se tem multi-programação, pois, como se sabe [Berstein83], nestes ambientes há necessidade de se estabelecer algum controle de concorrência sobre ítens de dados acessados simultaneamente por diferentes 


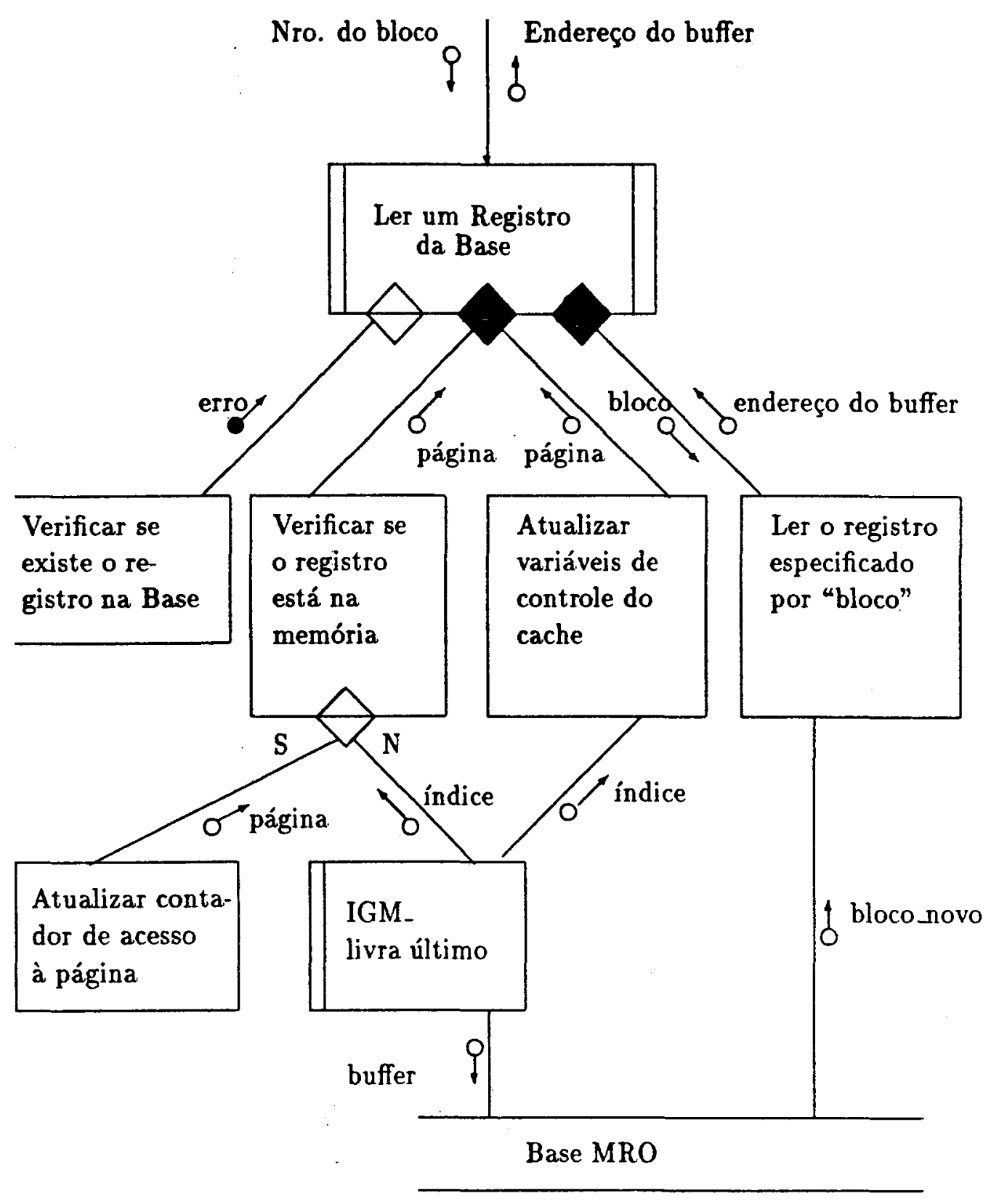

Figura 6.7: Diagrama Hierárquico do SGM versão mono-usuário 


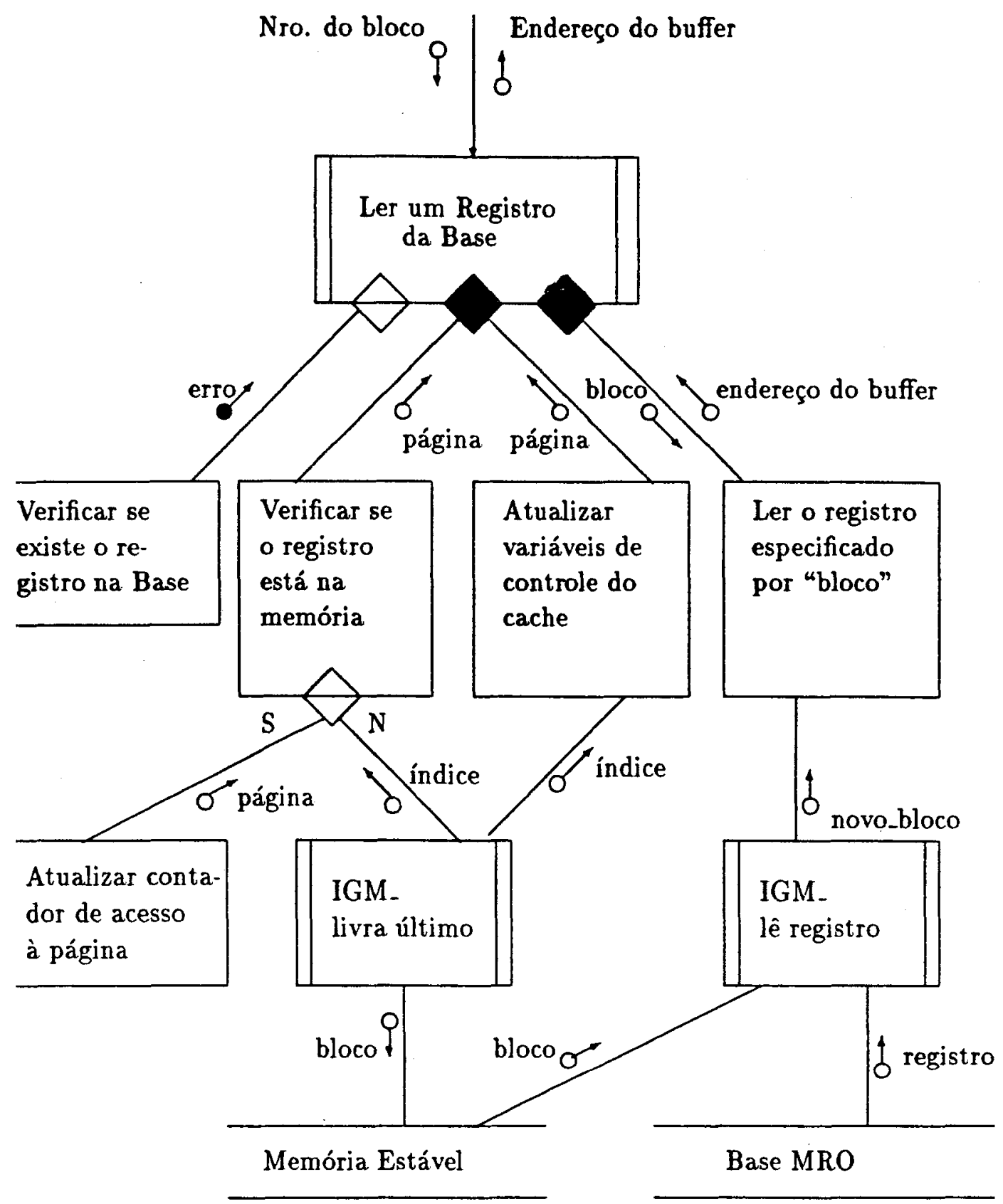

Figura 6.8: Diagrama Hierárquico do SGM versão multi-usuário 


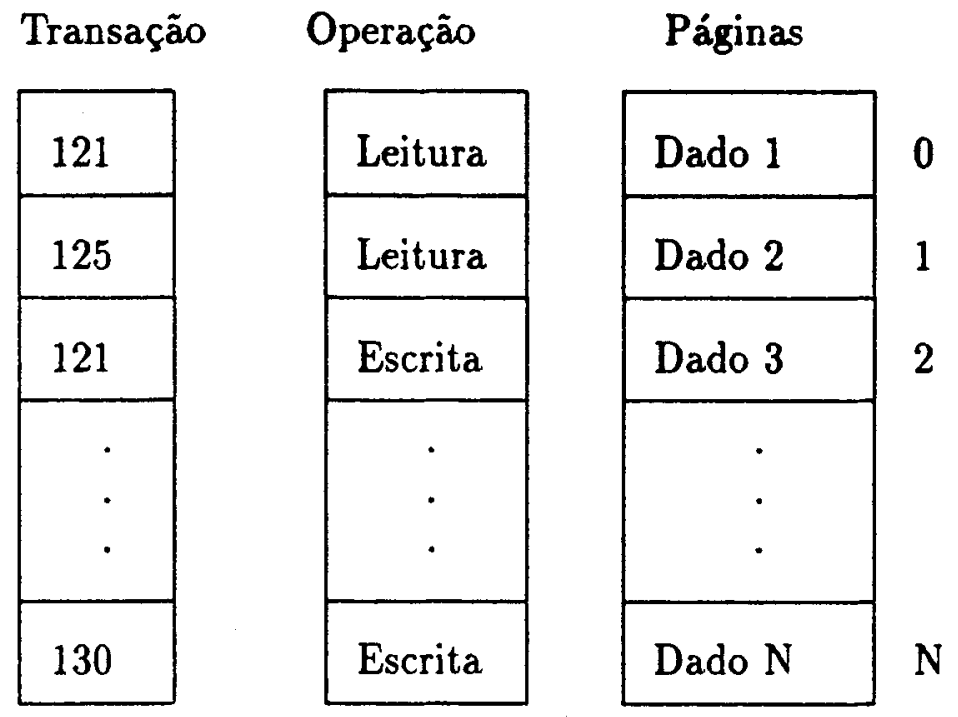

Figura 6.9: Estrutura de Controle de Transação

transações que manipulam a base de dados, e deve- se garantir a atomicidade e a consistência destas transações. Para garantir a atomicidade das transaçôes, o SGM foj modificado, conforme ilustra a figura 6.8, de tal forma que as informações atualizadas por uma determinada transação somente são atualizadas na base quando a transação é finalizada, ou seja, atinge o estado "Compromissado", conforme apresentado no capítulo 3 .

A necessidade de se garantir a atomicidade das transações levou à criação de um arquivo transiente, chamado de "Memória Estável", conforme ilustrado na figura 6.4. Este arquivo é utilizado para garantir a recuperação de registros atualizados, quando ocorre o estouro do "cache" ("overflow"), e armazena registros de transaçôes parcialmente compromissadas. A figura 6.8 apresenta a estrutura lógica do SGM para a versão multi-programada do GEO. Note-se nesta estrutura que as operações de escrita na base são efetuadas apenas no arquivo de estouro do "cache", ou seja, na memória estável. Deve-se salientar que apenas as transações que são finalizadas com êxito é que podem estar corretas, isto porque neste protótipo não estão previstos danos físicos da mídia.

Para que o Sistema de Gerenciamento de Transações (SGT), no nível do SGM, 
identifique quais páginas do "cache" estão associadas a quais transações, foi criada uma estrutura auxiliar que mantém tais informações, conforme ilustra a figura 6.9. Por exemplo, lê-se que a transação 121 tem acesso às páginas 0 e 2 para leitura $e$ escrita, respectivamente. Esse mecanismo de controle de acesso aos dados físicos do SGM, permite ao SGT garantir o controle de concorrência mesmo em ações indiretas (conforme exemplificado no início desta seção). Isto é conseguido confrontando-se o código da transação código da transação corrente associada à página. Com a estrutura de dados apresentada na figura 6.9, o sistema de gerenciamento de memória pode informar ao sistema de gerenciamento de transações para que este invalide a ação (ou passe a transação para o estado "falho").

Note-se que as interfaces entre os níveis físico e lógico são as mesmas, apenas foram modificadas suas funções para que não ocorram operações de atualização da base sem que a transação seja finalizada. 


\subsubsection{O Sistema de Gerenciamento de Transações do GEO}

É importante notar, vide figura 6.2, que quaisquer das sub-camadas podem informar o SGT da ocorrência de alguma falha na execução das ações. Para o SGT, cada ação é composta por três partes lógicas, conforme ilustra a tabela Estrutura Lógica de uma Ação. Os módulos Verificar se a ação pode ser executada e Verificar se a açâo nâa falhou estabelecem o protocolo de acesso à base de dados, isto é, deve verificar a validade de todas as açôes solicitadas. Para isso, o SGT possui uma estrutura de dados, chamada MRO_BCT (Bloco de Controle de Transaçōes para uma base MRO), sobre a qual foram implementadas primitivas de manipulação [Traina Jr.91b]. Esta estrutura é uma lista linear que armazena o estado de cada transação pendente no sistema ("Ativa" ou "Falha").

Para que um usuário consiga efetuar alguma operação na base, é necessário que este solicite primeiramente um registro de controle de transações (isto deve ser feito através da primitiva "G_abre" [Traina Jr.91b]). Este registro mantém informações que estabelecem o estado corrente da base no qual as transaçōes, solicitadas pelo cliente associado ao ambiente, podem ser efetuadas. Ao conseguir um MRO_BCT (registro de controle de transações), o usuário fica associado a um valor lógico, que é a sua identificação na base, só então as transações podem ser inicializadas, através da primitiva "G_transacao". Inicializada uma transação as ações que compõem a transação podem acessar a base. Tendo obtido acesso à base, o usuário passa a interagir com o Nivel Semântico para que consiga acesso às colônias [Traina Jr.88]. Este mecanismo garante o controle de concorrência do sistema, contudo, ajnda pode haver falha durante a execução do corpo da ação. Assim, o módulo Verificar se a transação não falhou verifica a validade de cada ação e pode fazer com que uma transação mude de estado. Ao completar uma transação o usuário deve executar a primitiva "G_fim". Esta primitiva informa ao SGT que a transação deve ser finalizada, ou seja, passada para o estado "Compromissado".

Estrutura Lógica de uma Ação

\begin{tabular}{|l|l|l|}
\hline $\begin{array}{l}\text { Verificar se a ação } \\
\text { pode ser executada }\end{array}$ & Corpo da ação & $\begin{array}{l}\text { Verificar se a } \\
\text { transação não falhou }\end{array}$ \\
\hline
\end{tabular}

A seguir são apresentados alguns exemplos de aninhamento de transações.

Exemplo 1:

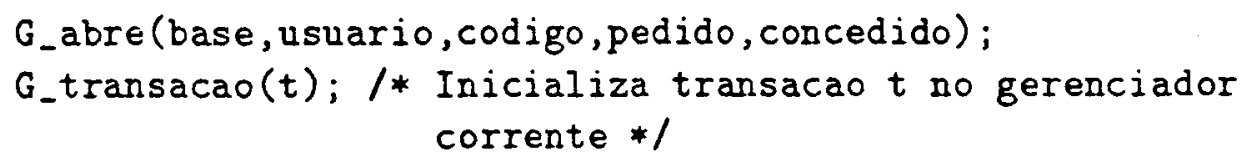




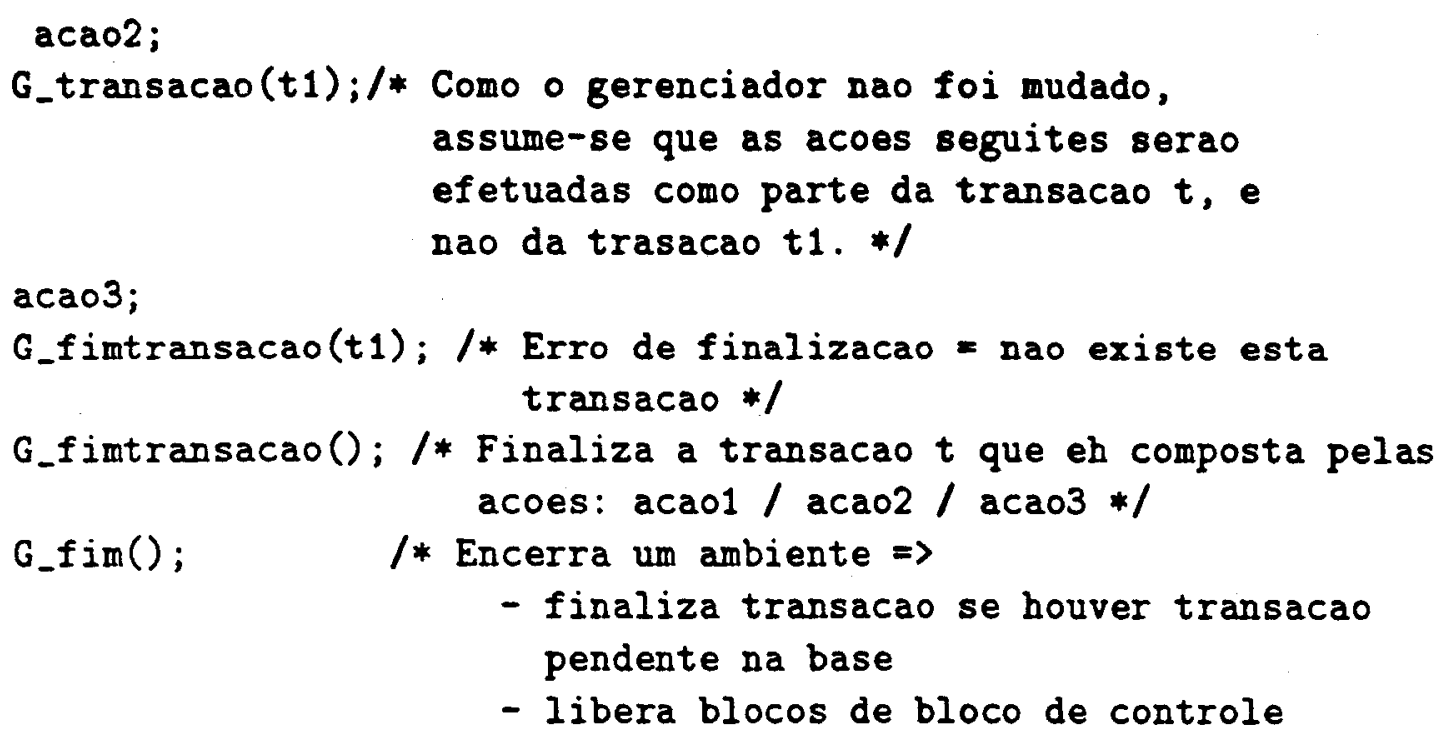

Exemplo 3:

G_abre(Base1, usuario, codigo, pedido, concedido);

G_abre(Base2, usuario, codigo, pedido, concedido);

G_corrente(1); /* Torna corrente o gerenciador cujo codigo eh $1 * 1$ 


\begin{tabular}{|l|}
\hline Aplicativo \\
\hline Sistema de \\
Gerenciamento de \\
Transações \\
\hline
\end{tabular}

Figura 6.10: Estrutura Servidor/Cliente Mono-programado

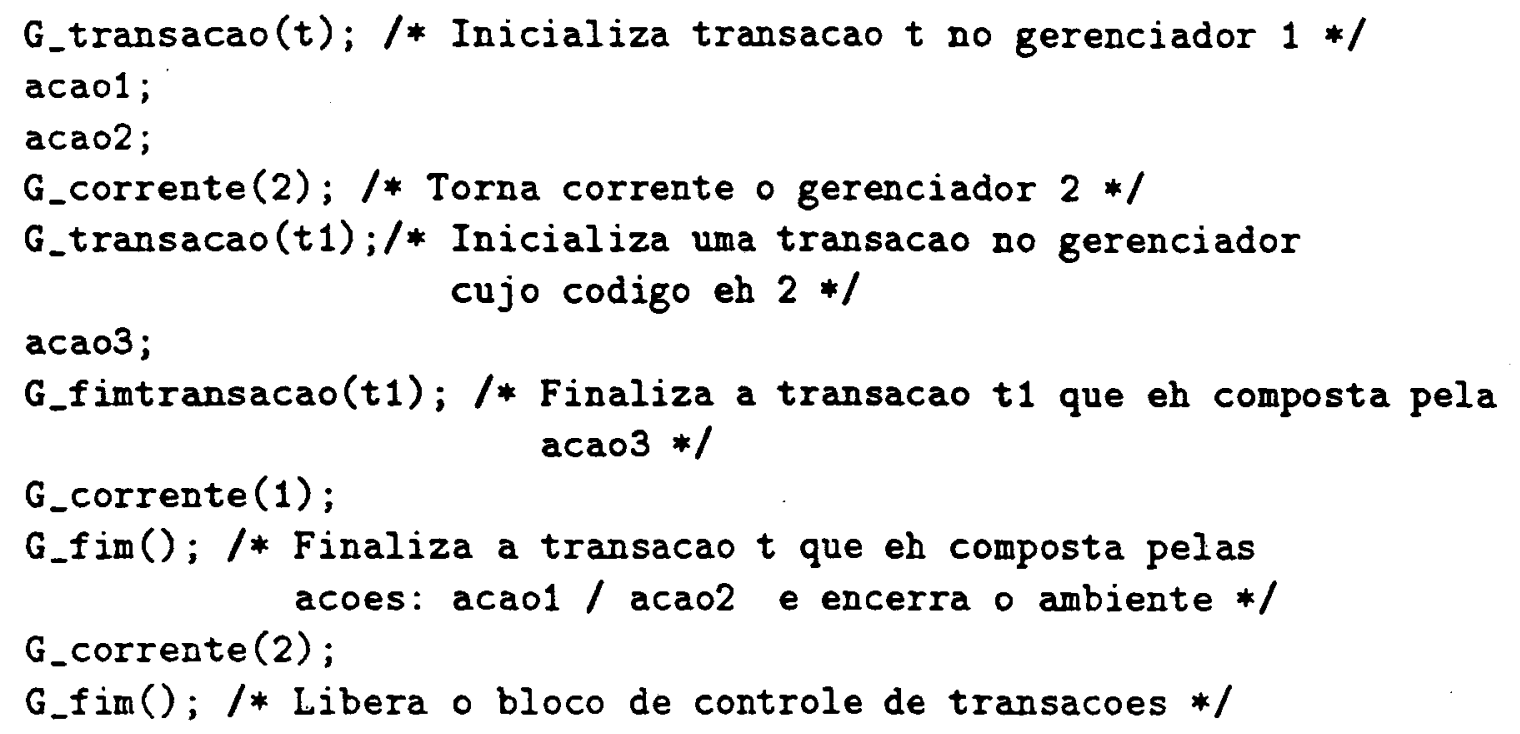

O Conjunto de primitivas que constituem o cliente [Traina Jr.91b], estabelecem um sistema de gerenciamento de transações local que permitem a um dado cliente possuir mais que uma transaçâo aberta, desde que cada transação esteja vinculada a um único servidor.

Para os ambientes que não admitem multi-programação, deve-se modificar uma variável diretiva para o compilador. Desta forma, serão eliminados durante a compilação as primitivas que formam o sistema de comunicação entre processos, fazendo com que os aplicativos do cliente sejam ligados diretamente às primitivas do servidor conforme ilustra a figura 6.10 .

A diferença desta estrutura para a estrutura que se tinha antes deste trabalho é que. as transações são atômicas mesmo em ambientes onde se tem monoprogramaçào,. 
Tabela 6.3: DESCRIÇÃO DOS DADOS DA FIGURA 6.11

\begin{tabular}{|l|l|l|}
\hline \hline Dado & Significado & Tipo \\
\hline \hline Ação & $\begin{array}{l}\text { Operação solicitada pelo Administrador da Base } \\
\text { de Dados }\end{array}$ & Cadeia \\
\hline Mensagem & $\begin{array}{l}\text { Mensagem retornada pelo Gerenciador para a In- } \\
\text { terface do Administrador da Base de Dados }\end{array}$ & Cadeia \\
\hline Objeto & $\begin{array}{l}\text { Elemento da Base solicitado e/ou manipulado por } \\
\text { uma ação }\end{array}$ & Cadeia \\
\hline Erro-acesso & Erro ocorrido na execução de uma ação & Inteiro \\
\hline $\begin{array}{l}\text { Solicita- } \\
\text { objeto }\end{array}$ & $\begin{array}{l}\text { Endereço Lógico do Registro que armazena o Ob- } \\
\text { jeto a ser acessado }\end{array}$ & Inteiro \\
\hline Erro & Erro de Finalização de uma transação & Inteiro \\
\hline Transação & Valor Lógico que identifica um cliente & Inteiro \\
\hline Página-cache & $\begin{array}{l}\text { Um bloco da Base MRO juntamente com a identi- } \\
\text { ficação do registro lógico na Base e a identificação } \\
\text { do cliente que acessou o bloco }\end{array}$ & MRORegovf \\
\hline Bloco-MRO & Corresponde a um bloco físico de uma Base MRO & Cadeia \\
\hline Código-erro & $\begin{array}{l}\text { Corresponde ao código retornado pelo módulo que } \\
\text { efetua a atualização quando ocorre alguma falha }\end{array}$ & Inteiro \\
\hline Transação & Código da transação a ser finalizado & Inteiro \\
\hline $\begin{array}{l}\text { Registro- } \\
\text { atualizado }\end{array}$ & $\begin{array}{l}\text { "Buffer" escrito na memória estável quando ocorre } \\
\text { finalização de uma transação ou estouro da } \\
\text { memória "cache" }\end{array}$ & MRORegovf \\
\hline Bloco-noro & Bloco transcrito da memória estável para a Base & Cadeia \\
\hline
\end{tabular}

A explosão do módulo 3 (Gerenciar Ações) da figura 6.4 resulta na figura $6.11^{1}$, e a descriçâo dos respectivos fluxos são apresentados na tabela 6.3.

O módulo 3.1 (Gerenciar Transações) tem por finalidade gerenciar as atividades globais do Sistema de Controle de Concorrência e do Sistema de Gerenciamento de Transaçōes (SGT). O SGT interage com os módulos:

- Gerenciar Memória e pode solicitar um objeto bem como informar o modo de acesso a tal objeto ("Exclusivo" ou "Compartilhado"), e obtém como resposta o objeto solicitado ou um código de erro que informa que o objeto não pode ser trazido para a memória.

\footnotetext{
${ }^{1}$ Vide [Traina Jr.91b] para especificação dos tipos citados na tabela
} 


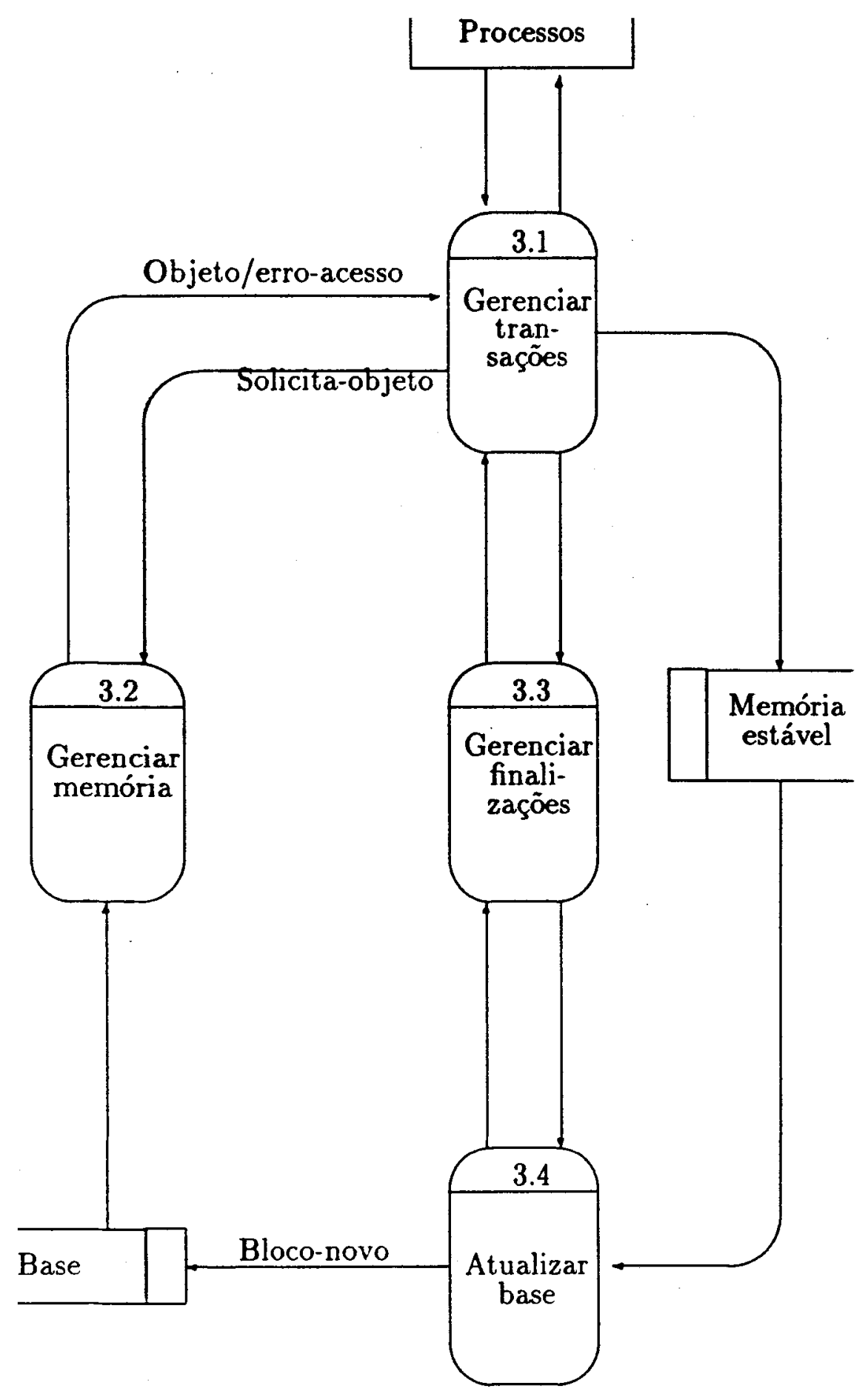

Figura 6.11: Diagrama de Fluxo de Dados do Núcleo GEO 
- Inicializar/Finalizar Transações que informa quando uma determinada transação deve ser finalizada, e obtém como resposta o estado da finalização, ou seja, se a transação foi finalizada com êxito ou não.

É importante notar, vide figura 6.2, que quaisquer das sub-camadas podem informar o SGT da ocorrência de alguma falha na execução da ação. Desta maneira o SGT está habilitado a invalidar a ação ou abortar a transação que solicitou a ação, chamada de "transação corrente".

A estrutura de colônias [Traina 86], intrínseca ao Modelo de Representação de Objetos (MRO), garante que se um usuário possui acesso a uma colônia, então este tem acesso exclusivo a todos os objetos constritos por esta colônia. Esta restrição de acesso, faz com que o controle de concorrência seja efetuado em uma camada superior à camada de manipulação lógica de objetos, chamada "Nivel Semântico", e transfere a responsabilidade de conseguir acesso a objetos da base para o usuário (ou para o aplicativo).

O módulo 3.2 (Gerenciar Memória) tem por finalidade efetuar apenas as operaçōes de leitura e escrita da base, e utiliza basicamente os mesmos algoritmos implementados para a versâo mono-usuário. As modificaçôes efetuadas no sistema de gerenciamento de memória do GEO serão melhor especificadas no item 6.5.

O módulo 3.3 (Gerenciar Finalizações) tem por finalidade fazer a atualização da base e a liberação dos recursos utilizados por uma determinada transação, isto é, neste módulo uma transação pode passar do estado ativo para os estados: "Falho", "Parcialmente Compromissado" ou "Compromissado". O Sistema de Gerenciamento de transaçôes mantém listas de todos os registros que estâo associados às transações e somente libera tais registros para atualização da base.

O módulo 3.4 (Atualizar Base) tem por finalidade efetuar a atualização dos registros modificados pelo usuário na base. Este módulo somente é executado após - Sistema de Gerenciamento de Transações ter passado a transação para o estado de "Compromisso Parcial", isto significa que todos os registros que foram modificados pela transação já foram copiados para a memória estável. Assim, o módulo Atualizar Base deve copiar os registros modificados da memória estável para a base, atualizar - registro de estado da base e informar ao SGT da ocorrência de erro. Ao ser executado este módulo a transação é dita "Compromissada".

A figura $6.12^{2}$ apresenta o módulo Gerenciar Transaçôes do Sistema de Gerenciamento de Transações com mais detalhes. O significado dos respectivos fluxos são apresentados na tabela 6.4.

Neste nivel de detalhe, o módulo:

\footnotetext{
${ }^{2}$ Vide [Traina Jr.91b] para especificação dos tipos citados na tabela
} 


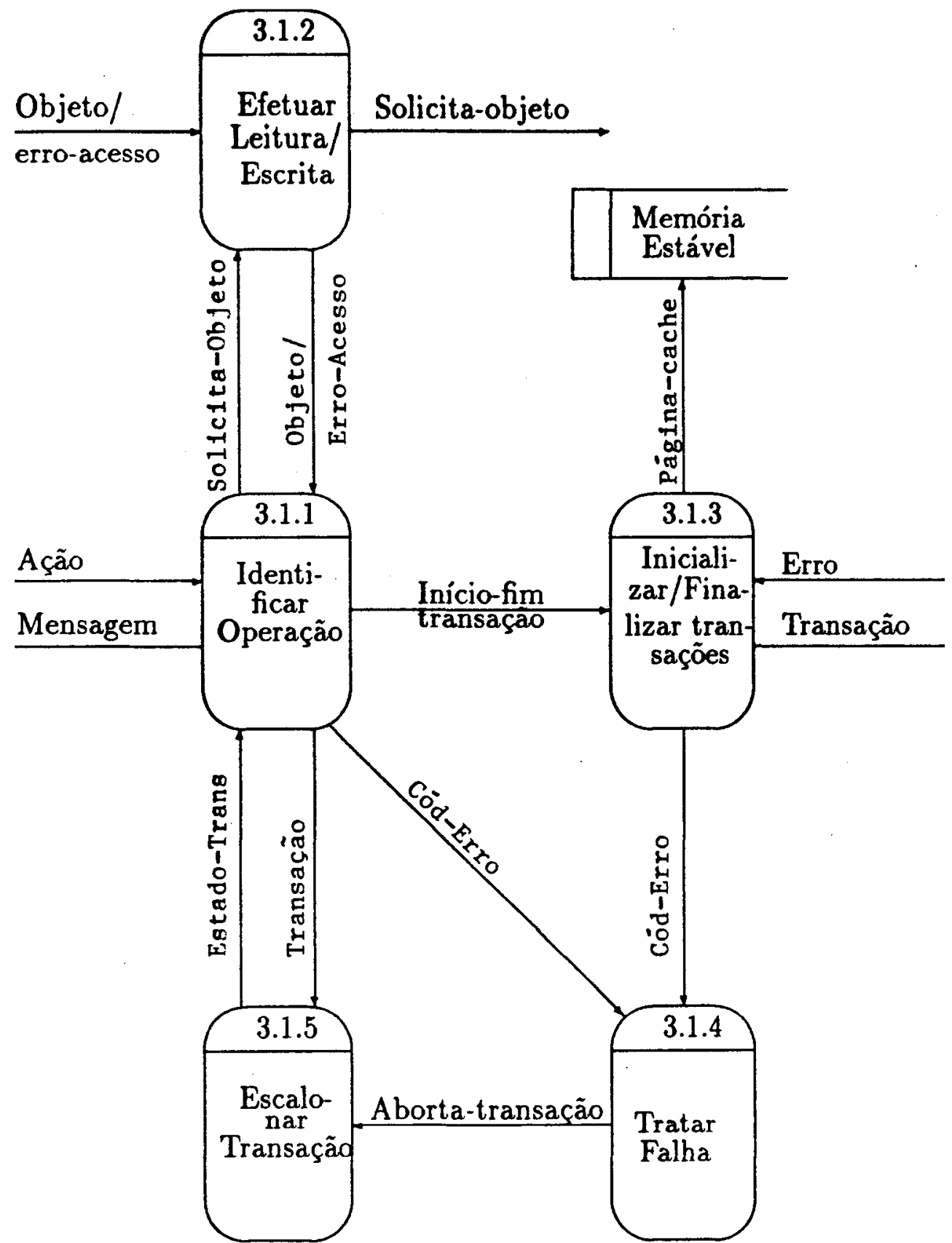

Figura 6.12: Explosão do Módulo "Gerenciar Transações" 
Tabela 6.4: DESCRIÇÃO DOS DADOS DA FIGURA 6.12

\begin{tabular}{|l|l|l|}
\hline \hline Dado & Significado & Tipo \\
\hline \hline Ação & $\begin{array}{l}\text { Operação solicitada pelo Administrador da Base } \\
\text { de Dados }\end{array}$ & Cadeia \\
\hline Mensagem & $\begin{array}{l}\text { Mensagem retornada pelo Gerenciador para a In- } \\
\text { terface do Administrador da Base de Dados }\end{array}$ & Cadeia \\
\hline Objeto & $\begin{array}{l}\text { Elemento da Base solicitado e/ou manipulado por } \\
\text { uma ação }\end{array}$ & Cadeia \\
\hline Erro-acesso & Erro ocorrido na execução de uma ação & Inteiro \\
\hline $\begin{array}{l}\text { Solicita- } \\
\text { objeto }\end{array}$ & $\begin{array}{l}\text { Endereço Lógico do Registro que armazena o Ob- } \\
\text { jeto a ser acessado }\end{array}$ & Inteiro \\
\hline Erro & Erro de Finalização de uma transação & Inteiro \\
\hline Transação & Valor Lógico que identifica um cliente & Inteiro \\
\hline $\begin{array}{l}\text { Início-fim } \\
\text { transação }\end{array}$ & $\begin{array}{l}\text { Efetua a inicialização ou a finalização de uma } \\
\text { transação }\end{array}$ & Inteiro \\
\hline $\begin{array}{l}\text { Estado- } \\
\text { Trans. }\end{array}$ & $\begin{array}{l}\text { Estado em que se encontra a transação: Falho, } \\
\text { Compromissado ou Parcialmente Compromissado }\end{array}$ & Inteiro \\
\hline Cód-trans. & Identificador Lógico da Transação na Base & Inteiro \\
\hline Cód-Erro & $\begin{array}{l}\text { Identificação do erro ocorrido na execução de al- } \\
\text { guma ação }\end{array}$ & Inteiro \\
\hline $\begin{array}{l}\text { Aborta- } \\
\text { transação }\end{array}$ & $\begin{array}{l}\text { Código de erro que informa ao módulo de trata- } \\
\text { mento de falhas que a transação deve ser abortada }\end{array}$ & Inteiro \\
\hline
\end{tabular}


- Identificar Operação (3.1.1) tem por finalidade estabelecer a comunicação entre os processos e GEO. Este módulo será melhor especificado no item 6.21.

- Efetuar Leitura/Escrita (3.1.2) estabelece a comunicação entre o módulo Identificar Operações e o módulo Gerenciar Memória. Quando é solicitada uma operação de leitura/escrita, este módulo deve utilizar as primitivas de entrada/saída de dados para solicitar o objeto ao módulo "Gerenciar Memória", caso não seja possível o acesso, este devolve um código de erro para o módulo "Identificar Operação", para que a transação seja passada para o estado "Falho".

- Inicializar/Finalizar Transação (3.1.3) inicializa uma transação no gerenciador corrente. Cada cliente pode possuir no máximo uma transação aberta neste gerenciador que, ao ser finalizada, copia os registros atualizados para a memória estável e da mesma para a base, sem que se desfaça o ambiente.

- Tratar Falha (3.1.4) é responsável por determinar qual a causa da falha da transação e abortar a transação. Supóe-se que pode haver quatro tipos de falha:

1. o módulo inicializador pode falhar ao armazenar dados na memória estável,

2. pode haver falha na atualização da base, o que é indicado pelo módulo "Atualizar Base",

3. pode haver falta de memória para o gerenciador de memória ("overflow" da memória "cache"),

4. o usuário aborta a transação ou mata o processo.

Nos sub-itens 1 e 2 pode haver dano físico do dispositivo de armazenamento de massa ou falha de comunicação. Neste caso, o GEO envia uma mensagem ao gerente do sistema.

- Escalonar Transą̧ão (3.1.5) garante a serialização e a atomicidade das transações. Como o "Nível Semântico" garante acesso exclusivo sobre colônias, esta condição é suficiente para que se garanta a serialização. A atomicidade é conseguida através da implementação do arquivo transiente ("Memória Estável"). Este módulo será melhor especificado no item 6.4 deste capítulo.

Na figura 6.11 é ilustrado, de forma lógica, como diversos processos interagem com um determinado gerenciador. Mas, deseja-se que processos possam ter acesso vários gerenciadores, conforme ilustra a figura 6.3. Para resolver esse problema foi criado um conjunto de primitivas que estabelecem um sistema de gerenciamento de transaçôes local, ou seja, para cada processo. 
0

\begin{tabular}{|l|}
\hline $\begin{array}{l}\text { Nome } \\
\text { da } \\
\text { Base }\end{array}$ \\
\hline $\begin{array}{c}\text { Código } \\
\text { do } \\
\text { Gerenciador }\end{array}$ \\
\hline $\begin{array}{c}\text { Código da } \\
\text { transação } \\
\text { no Servidor }\end{array}$ \\
\hline $\begin{array}{c}\text { Fila } \\
\text { de } \\
\text { Saída }\end{array}$ \\
\hline $\begin{array}{c}\text { Código } \\
\text { da } \\
\text { Transação } \\
\text { no Cliente }\end{array}$ \\
\hline
\end{tabular}

1

\begin{tabular}{|l|}
\hline $\begin{array}{l}\text { Nome } \\
\text { da } \\
\text { Base }\end{array}$ \\
\hline $\begin{array}{c}\text { Código } \\
\text { do } \\
\text { Gerenciador }\end{array}$ \\
\hline $\begin{array}{c}\text { Código da } \\
\text { transação } \\
\text { no Servidor }\end{array}$ \\
\hline $\begin{array}{c}\text { Fila } \\
\text { de } \\
\text { Saída }\end{array}$ \\
\hline $\begin{array}{l}\text { Código } \\
\text { da } \\
\text { Transação } \\
\text { no Cliente }\end{array}$ \\
\hline \\
\hline
\end{tabular}

2

\begin{tabular}{|c|}
\hline $\begin{array}{c}\text { Nome } \\
\text { da } \\
\text { Base }\end{array}$ \\
\hline $\begin{array}{c}\text { Código } \\
\text { do } \\
\text { Gerenciador }\end{array}$ \\
\hline $\begin{array}{c}\text { Código da } \\
\text { transação } \\
\text { no Servido }\end{array}$ \\
\hline $\begin{array}{c}\text { Fila } \\
\text { de } \\
\text { Saída }\end{array}$ \\
\hline $\begin{array}{c}\text { Código } \\
\text { da } \\
\text { Transação } \\
\text { no Cliente }\end{array}$ \\
\hline
\end{tabular}

$\mathrm{N}$

\begin{tabular}{|c|}
\hline $\begin{array}{l}\text { Nome } \\
\text { da } \\
\text { Base }\end{array}$ \\
\hline $\begin{array}{c}\text { Código } \\
\text { do } \\
\text { Gerenciador }\end{array}$ \\
\hline $\begin{array}{c}\text { Código da } \\
\text { transação } \\
\text { no Servidor }\end{array}$ \\
\hline $\begin{array}{c}\text { Fila } \\
\text { de } \\
\text { Saída }\end{array}$ \\
\hline \begin{tabular}{c} 
Código \\
da \\
Transação \\
no Cliente \\
\hline
\end{tabular}
\end{tabular}

G_GerCorrente

Figura 6.13: Estrutura de Controle de Transaçōes Local 
Neste sistema o usuário pode informar com qual gerenciador deseja se associar, num dado instante. $\mathbf{O}$ sistema local um gerenciador corrente, caso não seja especificado. A figura 6.13 ilustra a estrutura de dados que estabelece o gerenciador local.

"G_GerCorrente" é uma variável do sistema de gerenciamento de transaçôes local, que informa qual gerenciador deve ser utilizado para a ação solicitada. 


\subsubsection{Sistema de Comunicação Servidor/Cliente}

O módulo de comunicação Servidor/Cliente é um conjunto composto por todas as primitivas de acesso à base de dados, incluindo-se as primitivas do SGT. A impressão causada no cliente (aplicativo que acessa a base) é de que as ações solicitas são executadas pelo seu processo, entretanto, isto não ocorre. Na verdade, quando algum cliente tenta efetuar algum acesso à base, as primitivas disponiveis para o cliente apenas informam o gerenciador (através do sistema de comunicação entre processos do sistema operacional) qual ação deve ser executada, quais são os parâmetros de entrada da função e qual deve ser a fila de resposta.

No ambiente SunOS, as primitivas de acesso à base de dados foram imple mentadas de maneira tal que permitem formar duas bibliotecas distintas, ou seja, uma biblioteca que contém as primitas que, efetivamente, modificam a base (biblioteca do Servidor) e uma outra biblioteca que contém primitivas que informam ao Gerenciador qual ação desejam executar (biblioteca de "stubs" do Cliente). Para gerar as bibliotecas, acima citadas, deve-se modificar a constante diretiva ("Servidor_DOS ${ }^{n}$ ) de compilação e compilar os mesmos arquivos fontes duas vezes. Se a constante "Servidor_DOS" não estiver definida, será gerada a biblioteca do cliente, caso contrário será gerada a biblioteca do servidor.

A estrutura de cada primitiva de acesso à base é a seguinte:

NOME_DA_FUNÇÃO ( Lista de parâmetros formais) \#ifdef Servidor DOS

$S E$ a ação pode ser executada $E N T \tilde{A} O$

corpo da ação

$S E$ a ação falhou $E N T A \tilde{O}$

aborte a transação

\#else

codifique a lista de parâmetros formais

transmita(mensagem)

receba(resultado da execuçâo da ação)

decodifique o resultado obtido

\#endif

retorne o resultado e um código de erro

A definição das estruturas de dados, bem como uma listagem dos arquivos fontes que constituem o sistema de comunicação, podem ser encontradas em [Traina Jr.91b].

A figura 6.14 apresenta a estrutura lógica do sistema de troca de mensagens Servidor/Cliente. O conjunto das primitivas do cliente é mapeado univocamente 
Primitivas do Cliente

\begin{tabular}{|c|c|c|c|c|c|c|}
\hline \multirow{6}{*}{$\begin{array}{l}\mathbf{A} \\
\mathbf{p} \\
\mathbf{1} \\
\mathbf{i} \\
\mathbf{c} \\
\mathbf{a} \\
\mathbf{t} \\
\mathbf{j} \\
\mathbf{v} \\
\mathbf{o}\end{array}$} & Função 1 & \multirow{3}{*}{ 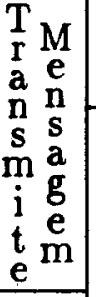 } & \multirow{2}{*}{$\begin{array}{l}\text { Fila de } \\
\text { Entrada }\end{array}$} & \multirow{3}{*}{$\begin{array}{r}\mathrm{M} \\
\mathrm{e} \\
\mathrm{e} \\
\mathrm{R} \\
\mathrm{e} \\
\mathrm{c} \\
\mathrm{c} \\
\mathrm{e} \\
\mathrm{b} \\
\mathrm{b} \\
\mathrm{e} \\
\mathrm{e} \\
\mathrm{m}\end{array}$} & Função 1 & \multirow{6}{*}{ 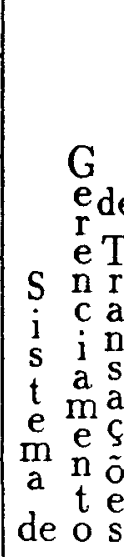 } \\
\hline & Função 2 & & & & Função 2 & \\
\hline & Função 3 & & \multirow{4}{*}{$\begin{array}{l}\text { Fila de } \\
\text { Saída }\end{array}$} & & Função 3 & \\
\hline & & \multirow{3}{*}{$\begin{array}{lll} & & \\
\mathrm{R} & \mathrm{M} \\
\mathrm{R} & \mathrm{e} \\
\mathrm{c} & \mathrm{n} \\
\mathrm{e} & \mathrm{a} \\
\mathrm{b} & \mathrm{g} \\
\mathrm{e} & \mathrm{e} \\
\mathrm{m}\end{array}$} & & \multirow{3}{*}{$\begin{array}{cc}1 & \\
\mathrm{r} & \mathrm{M} \\
\mathrm{a} & \mathrm{e} \\
\mathrm{n} & \mathrm{n} \\
\mathrm{s} & \mathrm{s} \\
\mathrm{m} & \mathrm{a} \\
\mathrm{i} & \mathrm{g} \\
\mathrm{t} & \mathrm{e} \\
\mathrm{e} & \mathrm{m}\end{array}$} & & \\
\hline & & & & & & \\
\hline & Função $\mathrm{N}$ & & & & Função N & \\
\hline
\end{tabular}

Figura 6.14: Estrutura Lógica do Sistema de Comunicaşão 
Tabela 6.5: Estrutura Lógica de uma Mensagem

\begin{tabular}{|l|}
\hline Fila de Comunicação do Cliente \\
\hline Fila de Comunicação do Servidor \\
\hline Código da Transação no Servidor \\
\hline Tamanho da Mensagem do Cliente \\
\hline Código da Função a ser Executada \\
\hline Parâmetros de Entrada da Função \\
\hline
\end{tabular}

no conjunto de primitivas do servidor. Assim, através de mensagens formatadas, é possível que o servidor identifique a ação que deve ser efetuada. Contudo, ao término da execução de cada ação, o gerenciador deve devolver para o cliente os resultados obtidos pela execuçâo.

Para resolver este problema, adotou-se uma fila de entrada para cada cliente e criou-se um campo no protocolo da mensagem enviada do cliente para o servidor que informa, ao servidor, em que fila do sistema deve ser devolvida a resposta da ação. Isto permite que um determinado gerenciador identifique quais clientes estâo conectados, conforme ilustra a figura 6.15. Note-se que para iniciar uma troca de mensagens, é necessário que o cliente possua um ambiente aberto no gerenciador. Para conseguir um ambiente é necessário que este execute a função "G_abre(lista de parâmetros formais)" (conforme explicado anteriormente).

O protocolo de comunicação, desenvolvido para a nova versão do GEO, utiliza as primitivas "msgsnd", "msgrcv" e "msgctl" para a troca de mensagens. Estas primitivas, do sistema operacional ("System Calls"), correspondem ao nivel mais baixo do sistema de comunicação entre processos do GEO. Utilizando-se destas funçôes básicas do SO, foram implementadas as primitivas: 
Tabela 6.6: Estrutura Lógica de uma Mensagem do Receptor do Cliente

\begin{tabular}{|l|}
\hline \hline Fila de Comunicação do Cliente \\
\hline Fila Comunicação do Servidor \\
\hline Código da Transação no Servidor \\
\hline Tamanho da Mensagem Retornada para o Cliente \\
\hline Valor de Retorna da Função \\
\hline Parâmetros de Saída da Função \\
\hline
\end{tabular}




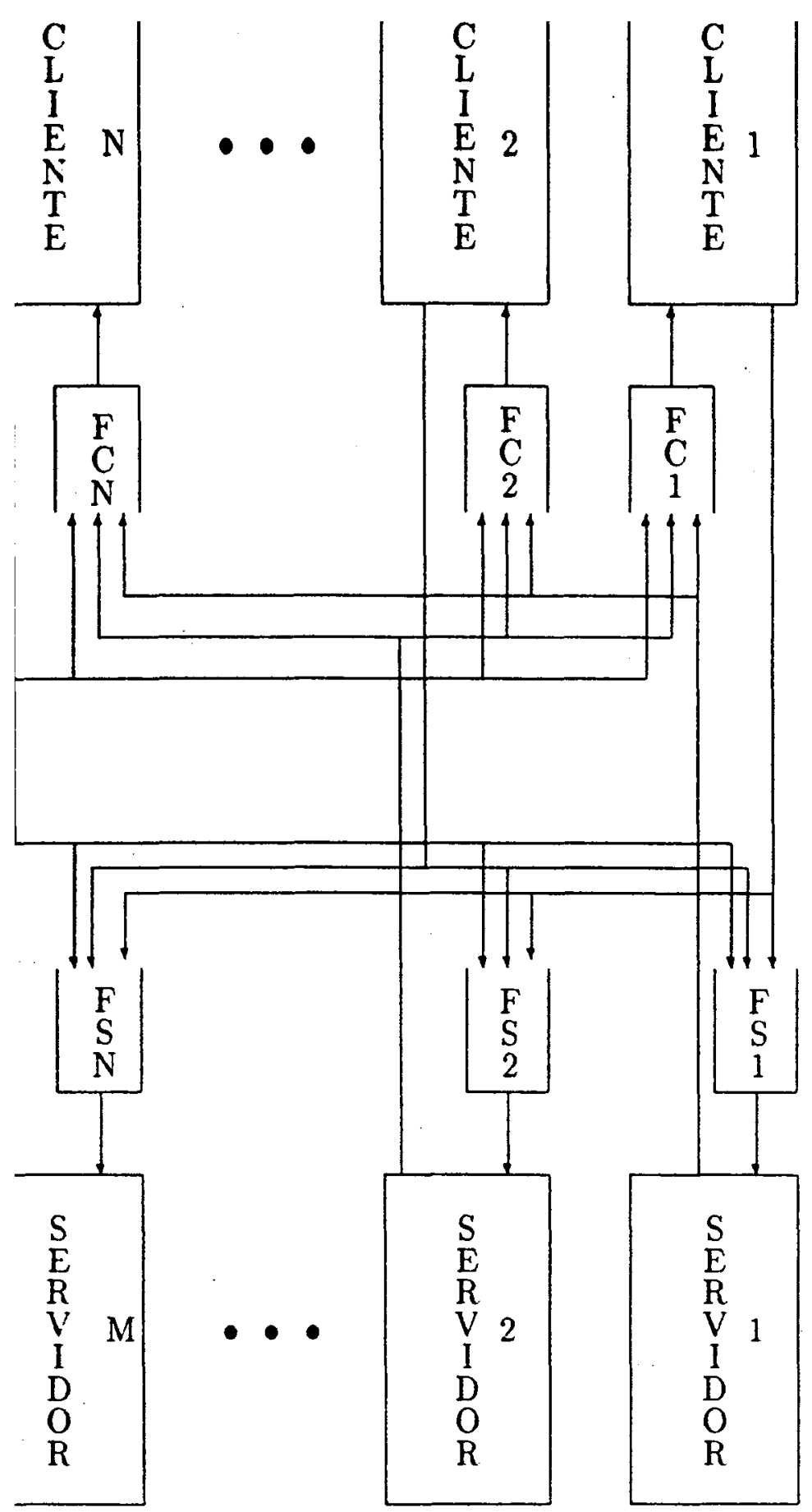

FCi: Fila do i-ésimo cliente

FSi: Fila do i-ésimu servidor

Figura 6.15: Mecanismo de Comunicação entre Clientes/Servidores 
- "G_transmite", que tem por finalidade efetuar a transmição de uma mensagem do cliete para o servidor. $O$ formato da mensagem transmitida é ilustrado pela figura 6.5.

- "G_recebe", que tem por finalidade efetuar a leitura de uma mensagem da fila de saída do servidor. 0 formato da mensagem é ilustrado pela figura 6.6. Nesta primitiva, o processo transmissor fica suspenso à espera de uma resposta do gerenciador.

- "SGT_transmite", que tem por finalidade efetuar a transmissão de uma mensagem, correspondente à resposta de uma ação solicitada, para um cliente.

- "SGT recebe"que tem por finalidade efetuar a leitura de uma mensagem da fila de saida do cliente. $O$ formato da mensagem é ilustrado pela figura 6.5. Uma vez que, a base pode efetuar tarefas intrínsecas do gerenciador, esta primitiva não bloqueia o gerenciador.

Note-se que na implementação do sistema de comunicação, as primitivas acima itemizadas, apenas acrescentam o Código da Transação ou Código do Receptor na cadeia formatada, que lhe é passada pela ação que é executada pelo servidor ou solicitada pelo cliente, respectivamente.

Para iniciar a comunicação com um determinado gerenciador, o aplicativo necessita conhecer os códigos das filas de comunicação do gerenciador e, também, se o gerenciador está apto a atender solicitações. Para solucionar este problema, foi criado um arquivo em memória externa que mantém uma lista dos gerenciadores existentes onde, para cada gerenciador, é armazenado o nome da base ("arquivo que contém os dados da base"), o código do gerenciador, o estado de atividade ("Ativo", "Travado" ou "Desativado") e os códigos das filas de entrada e saída dos respectivos gerenciadores. Ao solicitar o inicio de uma secção de trabalho, o aplicativo informa qual é o nome da base. Assim, o sistema de comunicaçâo é capaz de verificar se é possivel esta solicitação, e mantem estas informaçôes, transparentemente ào usuário. 


\subsection{O Sistema de Escalonamento de Transações do GEO}

Conforme apresentado no capítulo 4 desta dissertação, o "Escalonador de Transaçōes" é formado pelo conjunto de módulos do SGBD responsável por efetuar - controle de acesso a itens de dados e eliminar os possíveis resultados colaterais (apresentados no capitulo 3).

Segundo [Berstein83], o objetivo do escalonador de transações é garantir que a execução de ações de forma entrelaçada (efetuado por um escalonador não serial), seja equivalente à execução das mesmas ações quando sujeitas à um escalonador serial.

No GEO, cada ação corresponde a uma primitiva especificada no nivel da "Interface com Aplicativo", veja [Traina Jr.91b]. Assim, no máximo uma ação pode estar manipulando a base num dado instante. Uma transação na base é composta por um conjunto de ações. Desta forma, aplicativos podem ter acesso a base, concorrentemente, desde que estejam associados à alguma transação ativa.

Analogamente aos sistemas operacionais multiprogramados, os SGBDs multiusuários devem provocar, nos usuários, a sensação de que existe um gerenciador ativo para cada aplicativo. Isto requer que o SGBD permita a criação de um ambiente de trabalho, ou seja, o sistema estabelece um "estado de acesso" do aplicativo, análogo ao estado de um processo no sistema operacional. No GEO, as primitivas "G_abre()" e "G_fim()" criam e finalizam sessões, respectivamente; onde, cada sessão, pode ser composta por diversas transaçôes, conforme exemplificado no item 6.3 .2 deste capitulo.

Para o GEO, a abertura de uma sessão (criação de um ambiente de trabalho) corresponde a:

- Verificar se o usuário tem permissão de acesso à base.

- Aquisição de um Bloco de Controle do Ambiente do usuário.

- Inicialização do ambiente de trabalho do usuário.

A criação do Bloco de Controle do Ambiente, para o usuário, faz com que o ambiente do aplicativo transceda as transações, o que causa a impressão do gerenciador estar disponível apenas para a sua aplicação, desconsiderando-se o tempo gasto para o atendimento. Para o objetivo desta dissertação, são considerados apenas transaçôes curtas. Assim, pode-se supor que o tempo de execução de uma açào é muito pequeno. 
Cabe lembrar que os "nomes" dos objetos na base somente têm significado quando inseridos num contexto. Assim, quando se estabelece $o$ ambiente de trabalho, especifica-se as instâncias, de objetos da base, as quais o aplicativo tem acesso. Como - GEO foi projetado para ambientes de desenvolvimento de projetos, a restrição de acesso dos usuários à determinados contextos, reduz consideravelmente o número de conflitos de acesso. Contudo, esta abordagem não resolve o problema pois, embora minimizados, continua havendo possibilidade de conflito no acesso.

Nesta implementação do GEO, podem ocorrer conflitos em dois níveis, que são:

- Usuários podem ter acesso a uma mesma colônia. Este problema pode ser resolvido no nível semấntico $\mathrm{e}$, portanto, não será discutido neste trabalho.

- Pode haver relacionamento entre objetos de diferentes colônias, acessíveis por diferentes usuários. Este problema é resolvido pelo sistema de gerenciamento de memória, que avisa ao SGT do conflito, colocando o código da ocorrência na estrutura de controle do ambiente. Assim, o SGT pode abortar a transação.

Cabe lembrar, também, que todos os registros atualizados ficam associados a alguma transação, e são liberados apenas quando esta é finalizada. Esta técnica é similar ao "protocolo de bloqueio em duas fases" proposta em [Eswaran76], onde foram eliminadas as primitivas de "pedido de acesso para escrita" e "liberação" do bloco. Isto porque, a liberação do bloco ocorre apenas quando a transação é passada para um dos estados: "Compromissado" ou "Falho". A permissão de escrita nos blocos está associada ao usuário e, portanto, no nível do gerenciador, todos têm permissão.

A figura 6.16 apresenta o diagrama hierárquico de funçôes do módulo gerenciador da base.

Note-se que, neste sistema, as ações são executadas na ordem em que são colocadas na fila de entrada do gerenciador. O módulo "SGT_Executa()" é responsável por restaurar o ambiente do usuário e executar a ação solicitada. A figura 6.17 apresenta o detalhamento do módulo "SGT_Executa()".

A estrutura de um Bloco de Controle é apresentada a seguir, onde observa-se que existem campos de:

1. Controle de ambiente, que informa

1.1 - Transação: que existe uma transação ativa na base, caso este valor seja diferente de zero.

1.2 - pidb: identificador do processo que criou a transaçào. 


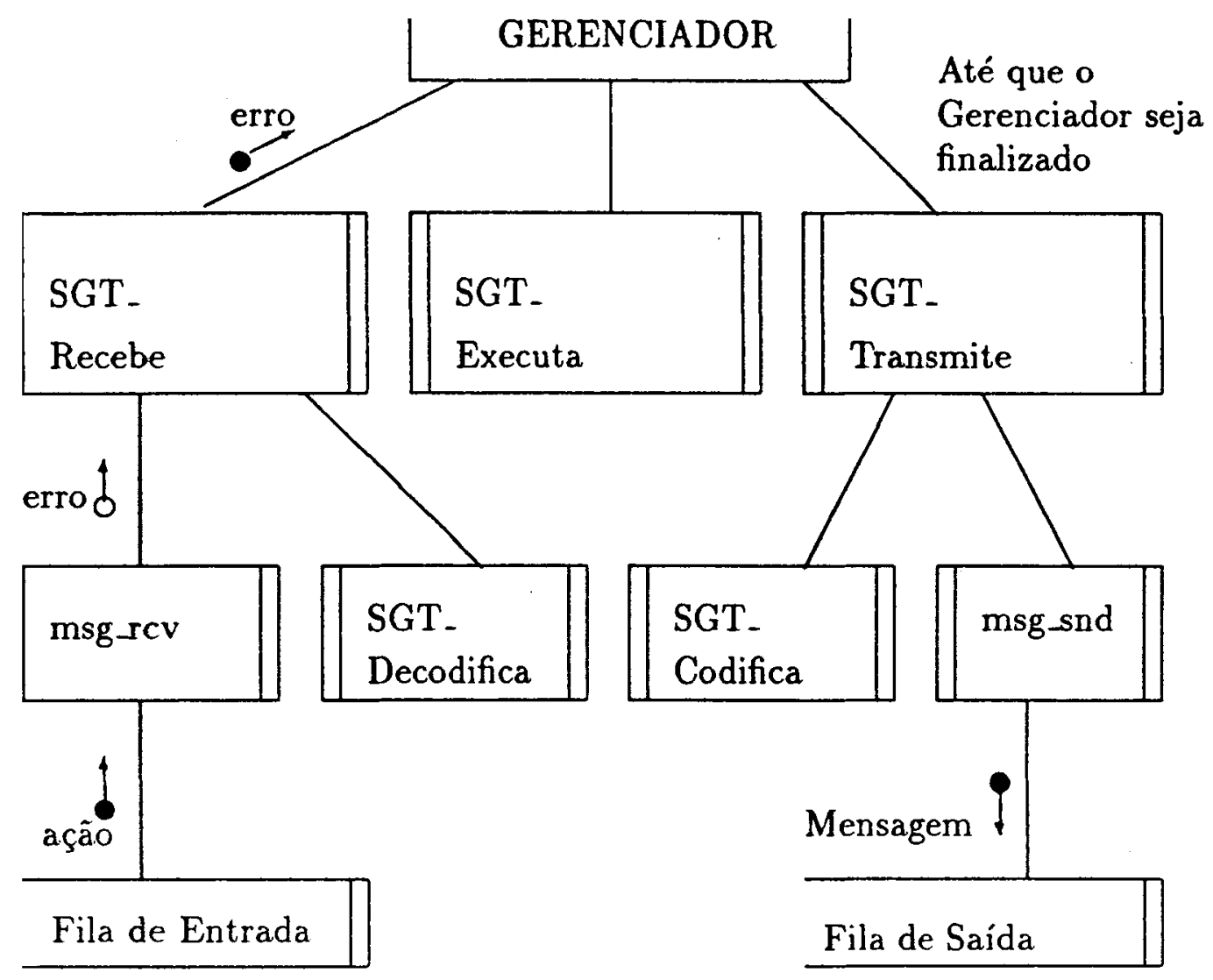

Figura 6.16: Diagrama Hierárquico do Módulo Gerenciador 


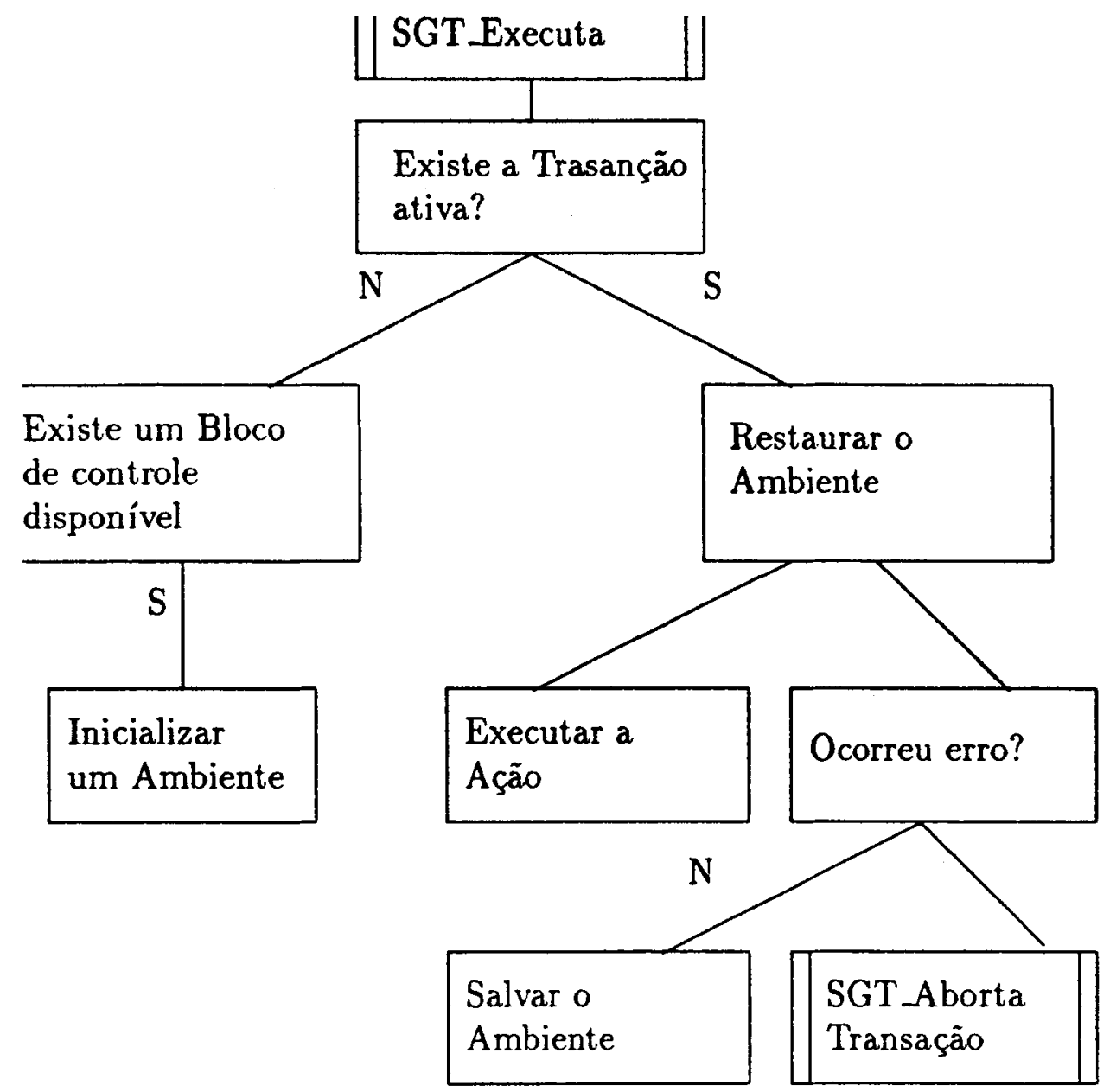

Figura 6.17: Diagrama Hierárquico do Módulo SGT_Executa 
1.3 - acesso: erro ocorrido no acesso à base. Caso o valor do segundo bit seja 1 a transação deve ser abortada, e se o terceiro bit for igual a 1 significa que existe o ambiente mesmo que o código da transação seja 0 (zero), ou seja, este bit indica que o ambiente da aplicação transcende a transação.

2. Controle de estado do sistema para um usuário, que informa

2.1 - Código do Objeto Esquema Corrente

2.2 - Código do Objeto Usuário Corrente

2.3 - Código do Objeto que define a seleção corrente

2.4 - Código do Objeto que define a máscara corrente

2.5 - Colônias Correntes: para cada tipo de colônia informa-se o seu estado:

- Que objeto constringe a Colônia

- Raiz da Colônia

- Tipo de acesso permitido para esse tipo (colônia fechada, aberta para leitura, aberta para escrita ou acesso compartilhado)

2.6 - Colônias acessíveis

- Quem constringe

- Raiz da Colônia

- Tipo de acesso permitido à Colônia

- Tipo de Colônia

2.7 - Registro de Estado Corrente da Base de Dados MRO.

- estado: define quais dos campos do registro de estado são válidos.

- RotErro: Código da rotina que reportou o erro

- CodErro: Código do erro reportado pela rotina

- indicadores: informa a situação de operação das rotinas da base

- objeto corrente: Código do objeto corrente

- identificador: Código do identificador corrente

- colônia: Código da colônia corrente

- relacionamento: Código do relacionamento corrente

- tripla: Código da tripla corrente

- atributo: Código do atributo corrente

- propriedade: Código da propriedade corrente

- comentário: Código do comentário corrente

- regra: Código da regra corrente 
- gráfico: Código do gráfico corrente

- dados: Informações definidas pelo usuário

2.8 - Ambiente corrente da transação

- estado: registro que determina os estados "OFF" (zero) ou "ON" (um) de cada campo dos demais campos da estrutura.

- colativa: registro que determina o código do objeto da colônia ativa.

- nivseman: registro que informa se o nivel semântico do gerenciador está ativo ou não, e se estiver, qual é ele.

- ordem: indica qual é a ordem em que as informações multivaloradas devem ser inseridas na base

- tripla: indica se o relacionamento binário, sendo manipulado, faz parte de uma tripla e se fizer, qual é o relacionamento triplo.

- esqu_ativo: código do objeto que determina qual é o esquema ativo para a transação.

- gerente: indica se o usuário corrente é o gerente (administrador da base). 


\section{Capítulo 7}

\section{Conclusões e Propostas}

Durante o desenvolvimento deste trabalho foram tomadas decisōes de projeto, baseadas na versão monoprogramado do GEO, com objetivo de se conseguir uma versão multiprogramado modular, que servisse de base para a experimentação de técnicas concorrente de manipulação de dados. Assim, diretrizes de implementação foram estabelecidas no sentido de se obter uma implementação modular onde os módulos dedicados ao gerenciamento do acesso multiprogramado pudessem ser explorados, com o mínimo de interdependência entre si e entre os demais módulos do GEO. Devido a idéia de se dispor de um gerenciador que pudesse servir para a implementação de métodos e algoritmos de gerenciamento de acesso multiprogramado, não foram efetuados estudos exaustivos no sentido de se obter uma implementação eficiente, rápida ou poderosa, mas buscou-se um compromisso entre as várias características, priorizando-se assim, a modularidade e a facilidade de alteraçôes ou substituiçâo dos métodos e algoritmos. Assim, implementou-se uma versão multjprogramado, modular, do GEO e deixou-se alguns tópicos pendentes para que sejam objetos para trabalhos futuros.

O item "Conclusões", deste capítulo, apresenta algumas conclusões obtidas a partir do projeto e da implementaçâa. E o item "Propostas" apresenta algumas das sugestões deixadas para trabalhos futuros.

\subsection{Conclusões}

Para a realização deste trabalho, foram efetuados estudos envolvendo Algoritmos, Métodos e Estruturas de Dados que permitissem a construção de um gerenciador de objetos multiprogramado. Assim, foram estudados conceitos de comunicação entre processos, gerenciamento de transações, gerenciamento de 
acesso e escalonadores de processos. Como resultado, construiu-se uma versão multiusuário do GEO, modular e expansível, que teve como principal diretriz de projeto ser passivel de servir como bancada de experimentação dos concejtos envolvidos. Essa versão tem como principais características o projeto e a implementação do:

- Algoritmo de controle de concorrência análogo ao Protocolo de Bloqueio em Duas Fases [Eswaran76], apresentado no capítulo 4 desta dissertação, que garante a atomicidade e a serialização das transações.

- Sistema de comunicação entre processos, que permite ao GEO funcionar de forma análoga a um servidor de arquivos numa rede de computadores digitais.

- Sistema de gerenciamento de transações, o qual permite que falhas ocorridas, na execução das ações, sejam tratadas no nível do escalonador de transações. Explorando-se a capacidade do modelo, foi introduzjdo e implementado o conceito de "Ambiente da Aplicação". O conceito de Ambiente da Aplicação permite, ao escalonador de transações, tratar cada usuário de forma análoga a um processo ativo no sistema operacional, ou seja, cada usuário associado ao gerenciador possui um estado corrente de execução.

- Controle de transaçóes como parte do aplicativo, que possibilata um usuário estar associado a diversos servidores.

O conceito de colônia, implementado no GEO, leva para o nivel semântico o problema de controle de concorrencia de acesso, uma vez que os objetos da base são constritos por colônias. Contudo, podem existir objetos constritos por diferentes colônias com relacionamentos entre si. Isto significa que exitem primitivas da base que poderiam manipular objetos em diferentes colônias, sem que o usuário tivesse feito a solicitação explicita de acesso a priori. A solução adotada poderia provocar impasse na base, mas, na implementação pode-se resolver este problema implementando-se um algoritmo de detecção e eliminação de impasse ou reportando-se o erro para o usuário. Esta abordagem é válida pois, implementado o controle de concorrência sobre colônias, os usuários devem solicitar acesso a todas as colônias que ele utilizará.

Existem casos onde a perda de sincronismo entre o aplicativo e o gerenciador pode fazer com que os processos dos usuários fiquem permanentemente suspensos. O mecanismo de comunicação entre gerenciador e aplicativo foi implementado de forma que a cada solicitação de leitura, de uma mensagem da fila, suspende-se o processo. Assim, caso o servidor seja finalizado, antes de atender a todos os clientes que possuem solicitações pendentes na fila do gerenciador, estes permacem suspensos. Uma situação análoga ocorre quando 
um cliente finaliza suas transações, mas não encerra o ambiente. Neste caso $o$ bloco de controle de ambiente jamais será re-inicializado. Mas, como a solução para esses problemas foge do propósito deste trabalho, documentou-se os casos de tais ocorrências [Traina Jr.91b] e propõe-se soluçôes a serem estudadas e implementadas.

A atomicidade das transações é garantida através da utilização da memória estável. Contudo, é necessário que se incorpore à base estruturas robustas. Isso porque, $o$ arquivo que armazena os dados da base pode sofrer danos devido a operações errôneas das estruturas de acesso do própio GEO, ou devido a falhas do disco ou da memória principal, que o gerenciador de acesso multjprogramado não pode evitar.

\subsection{Propostas}

O mecanismo de comunicação Servidor/Cliente pode provocar situaçôes de impasse para o aplicativo ou a degradação do sistema, conforme apresentado no item anterior. A análise do problema sugere que sejam efetuados estudos sobre validação de protocolo de comunicação, a fim de garantir que os aplicativos não fiquem suspensos por tempo indefinido. Deseja-se também que este novo sistema de comunicação suporte mecanismos de chamada remota de procedimentos ("Remote Procedure Calls"), permitindo a comunicação entre máquinas diferentes, e permitindo um melhor aproveitamento do sistema de controle de transaçôes local do aplicativo, a fim de possibilitar o acesso simultâneo em diferentes gerenciadores, num determinado intervalo de tempo.

Deve ser objeto de estudo o problema causado ao SGBD pelo dano do meio físico de armazenamento. A literatura sugere que a base seja replicada em dispositivos físicos diferentes e que se implementem mecanismos para manter a consistência e a integridade dos dados replicados.

A técnica adotada para solucionar o problema do controle de concorrência deve ser também melhor estudada. Isto porque, o escalonador pode ser estabelecido levando-se em conta o tipo de aplicação e o ambiente de utilização da base. 


\section{Bibliografia}

[Agrawal83] AGRAWAL R; CAREY, M. J.; DEWITT D. J. Deadlock Detection is Cheap. ACM SIGMOD RECORD: 13, (2), 19-34, 1983.

[Agrawal87] AGRAWAL, R.; CAREY, J. M. LINVY, M. Concurrency Control Performance Modeling: Alternatives and Implications. ACM Trans. on Database Systems, 1987, 12(4): 609$654,1987$.

[Berstein83] BERSTEIN, P. A.; GOODMAN, N. - Multiversion Concorrency Control - Theory and Algorithms, ACM Trans. on Database Systems, 8,(4), 465-483, 1983.

[Chan82] CHAN, A. et. al. The Implementation of an Integrated Concurrency Control and Recovery Scheme. ACM SIGMOD RECORD, $\underline{12}$, (2), 1982.

[CODASYL71] CODASYL Data Base Task Group. April 71 Report, ACM, New York, 1971.

[Chen76] CHEN P.P. - The Entity-Relationship Model: Toward a Unified View of Data. ACM Trans. on Database Systems, 1, (1), 9-36, 1976.

[Codd70] CODD E.F. A Relational Model of Data for Large Shared Data Banks, Commun. ACM, 13, (6),377-387, 1970.

[Date86] DATE, C.J. - Introdução a Sistemas de Bancos de Dados 4 ed. Rio de Janeiro, Campus, 513p., 1986.

[Eswaran76] ESWARAN, K.E.; GRAY, J.N.; LORIE,R.A.; TRAIGER, I.L. - The Notions of consistece and predicate locks in a Database System, Commun. ACM, 19, (11), 624-634, 1976.

[Farrag87] FARRAG, A. A. OZSU, M. T. Towards a General Concurrency Control Algorithm for Database Systems. IEEE 
Trans. on Software Engeneering, $\underline{S E-13},(10)$ : 1073-1079, 1987.

[Hull87] HULL, R. \& KING, R. Semantic Database Modeling: Survey, Applications, and Research Issues. ACM Computing Surveys, 19, (3): 201-260, 1987.

[Gane83] GANE, C. \& SARSON, T. Análise Estruturada de Sistemas, LTC - Livros Técnicos e Científicos, R.J., 257 p., 1983.

[Gray78] GRAY, J. N. - Notes on Database Operanting Systems. In: Bayer, R.; Graham, R.M.; Sug. Müller, eds. - Operating Systems: An Advanced Course. New York, SpringerVerlay. 393-481, 1970. (Lecture Notes in Computer Science, 60).

[Gray76] GRAY, J. N. et al. - Granularity of Locks and Degrees of Consistency in a Shared Data Base. In: Nijssen, G.M., ed. - Modeling In Database Management Systems. Amsterdan, North - Holland, 365-394, 1976.

[Jiang88] JIANG, BIN DeadLock detection is really cheap. ACM SIGMOD RECORD, 17, (2):2-13, 1988.

[Katz84] KATZ, R. H. LEHMAN, T. J. Database support for versions and alternatives of large design files. IEEE Trans. on Software Engineering, $\underline{S E-10}$, (2): 191-200, 1984.

[Katz86] KATZ, R. H.; CHANG, E. BHATEJA, R. Version Modeling Concepts for Computer-Aided Design Databases. ACM SIGMOD, 28, (30), 379-386, 1986.

[Korth82] KORTH, H.F. Deadlock Freedom using edge locks. ACM Trans. on Database System, I, (2): 632-652, 1982.

[Korth83] KORTH, HENRY F. Locking Primitives in a Database System. Journal ACM, 30, (1): 55-79, 1983.

[Korth86] KORTH, H.F.; SILBERSCHATZ, A. - Sistemas de Bancos de Dados, São Paulo, McGraw-Hill Ltda, 582 p., 1986.

[Kung81] KUNG, H.T.; ROBINSON, J. T. - On Optimistc Methods for Concurrency Control. ACM Trans. on Database Systems, 6, (2): 213:226, 1981.

[Papadimitriou79] PAPADIMITRIOU, C.H. The Serializability of Concurrent Updates. Journal ACM, 26, (4): 631-653, 1979.

[PunS7] PUN, K. H.; BELFORD, G. G. Performance Study of Two Phase Locking in Single-Site Database Systems. IEEE 
Trans. on Software Engeneering, $\underline{S E-13},(12): 1311-1327$, 1987.

[Severance76] SEVERANCE, S.G.; LOHMAM, G.M. Differencial Files: their Application to the Maintenence of Large Databases. ACM Trans. Database System, 1, (3): 256-267, 1976.

[Smith77a] SMITH, J. M.; SMITH, D. C. P. Data Base Abstractions: Aggregation. Commun. ACM, 20, (6): 405-413, 1977.

[Smith77b] SMITH, J. M.; SMITH, D. C. P. Data Base Abstractions: Aggregation and Generalization. ACM Trans. on Database Systems, 2, (2): 105-133, 1977.

[Stonebraker81] STONEBRAKER, M. - Operating System Suport for Database Management. Commun. ACM, 24, (7): 412- 418, 1981.

[Stonebraker85] STONEBRAKER, M; et. al. Problems in Supporting Data Base Transactions in an Operating System Transaction Manager. Operating Syst. Rev., 19, (1): 06-14, 1985.

[Tanenbaum87] TANENBAUM, S. ANDREW Operating Systems: Design and Implementation. Englewood-Cliffs, Prentice-Hall, 0190, 1987.

[Traina Jr.86] TRAINA, CAETANO Máquina e Modelo de Dados Dedicados para Aplicações de Engenharia. Tese de doutoramento apresentada ao IFQSC-USP, 1986.

[Traina Jr.88] TRAINA, CAETANO ; SLAETS, J.F.W. Um Modelo de Representação de Objetos. In: Simpósio Brasileiro de Bases de Dados, 3, Anais. Recife, Pe, 1988.

[Traina Jr.91] TRAINA, CAETANO. GEO - Um Sistema de Gerenciamento de Bases de Dados Orientado a Objetos - Estado Atual de Desenvolvimento e Implementação. In: Simpósio Brasileiro de Bases de Dados, 6, Anais. Manaus, Am, 1991.

[Traina Jr.91b] TRAINA, CAETANO; CALÔNEGO Jr., NIVALDI. GEO - Manual de Referência do Sistema de Gerenciamento de Transações do GEO. (Em preparação).

[SunOS] SUN MICROSYSTEMS, INC. - SunOS Reference Manual II, release 4.1, California, 1990 